\title{
MARTIAL CITIZENSHIP: FIREARMS, IDENTITY, AND MASCULINITY IN A PUBLIC MILITIA GROUP
}

\author{
A Dissertation \\ presented to \\ the Faculty of the Graduate School \\ at the University of Missouri-Columbia \\ In Partial Fulfillment \\ of the Requirements for the Degree \\ Doctor of Philosophy \\ by \\ DANIEL THOMAS PETRIN \\ Dr. Wayne Brekhus, Dissertation Supervisor \\ JULY 2018
}


(C) Copyright by Daniel Thomas Petrin 2018

All Rights Reserved 
The undersigned, appointed by the dean of the Graduate School, have examined the dissertation entitled

MARTIAL CITIZENSHIP: FIREARMS, IDENTITY, AND MASCULINITY IN A PUBLIC MILITIA GROUP

presented by Daniel Thomas Petrin, a candidate for the degree of doctor of philosophy,

and hereby certify that, in their opinion, it is worthy of acceptance.

Professor Wayne Brekhus

Associate Professor Victoria Johnson

Associate Professor Rebecca Scott

Assistant Professor Larry Brown 


\section{Dedication}

This dissertation and all the work it represents could not have been accomplished without a great deal of support, patience and help from a number of people to whom it is here dedicated. First, Ronald and Elizabeth Petrin, my parents. Their personal experiences with the process of earning their own doctoral degrees were resources that few in my position had access to and for which I am grateful. More to the point of this dedication are the other forms of support they provided, as only parents can-equal parts love, patience and pushing me to finish the task before me. My brothers, Michael and Christopher always had time to chat with me about our hobbies and troubles when I needed to step away from this work and my other obligations. Without my family this process would have been far more difficult and stressful.

For decades of my life, Ryan Dickey, John Franzmann, Shane Rickman have been my closest friends. Without their frequent phone calls, visits, trips to our favorite tavern, and gaming sessions none of my educational achievements would have been characterized by the success, companionship, and levity they were. The new friends I made in Missouri spared me loneliness and insecurity and deserve mention. Josh, Julia, Juan, Eva, David, Mike, Ana, Zach, Jenna, Kenny, Curtis, Andrew, Andrew (but a different one), Kara, and Faiza. I either already miss or will unfortunately soon miss seeing all of you.

Finally, Angela. Without her genuinely superhuman patience with my distractibility, stress, and propensity to create nests of books and articles throughout the house I would not have been able to pursue this research, never mind complete this phase of it. Her willingness to join me in sharing our lives is surely one of the best things that will ever happen to me and so I conclude this dedication with her. To our next adventures. 


\section{ACKNOLWEDGEMENTS}

First, I would like to thank the members of the $10^{\text {th }}$ as well as the owner and employees of the gun store I worked with in pursuing this research. Without exception each of them was welcoming and kind to me despite our intellectual and political differences. They allowed me to ask them what often must have seemed ridiculous questions, participate in their activities, and taught me about their lives. The levels of access they permitted were crucial to the success of this project and they have my gratitude. I hope to visit with each of them again.

All of the sociology faculty at University of Missouri whose course I have had the good fortune to take and with whom I engaged with on the rare occasions I attended social events shaped this research to some extent. None have been more influential than my committee members: Dr. Wayne Brekhus, Dr. Victoria Johnson, Dr. Rebecca Scott, and Dr. Larry Brown from the Geography Department. Each of you have supported the good ideas, pushed me to correct or reconsider the less-than-ready ones, and encouraged me in word and deed throughout this project. It and I are both far better for your collective influence. Thank you. 


\section{TABLE OF CONTENTS}

ACKNOWLEDGEMENTS

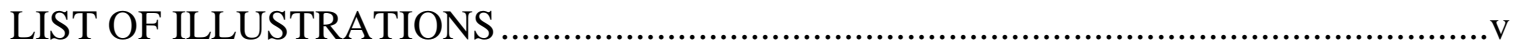

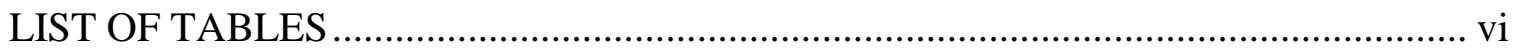

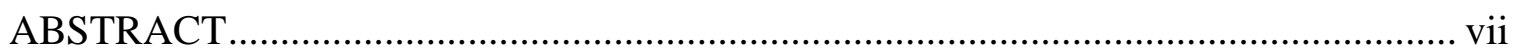

\section{Chapters}

1. Firearms in the Militia and in Everyday Life.......................................................

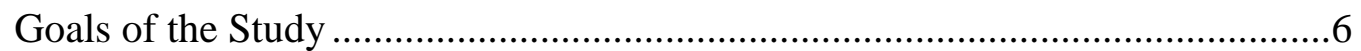

The Everyday Work of Being …………………………..............................

Good Guys with Guns: Theory and Methods in Studying the $10^{\text {th }} \ldots \ldots \ldots \ldots \ldots \ldots \ldots . . .15$

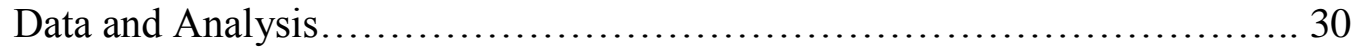

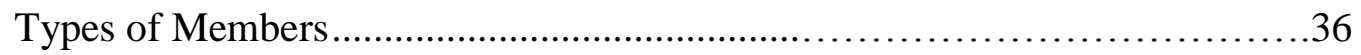

2. "Who wants to have to apologize to their wife or kids that they couldn't protect them?": Ordinary Resources, Narrative, and Messianic Marginality in the Development of Paramilitary Gun Culture ......................................................40

"It's not an assault weapon until you assault someone with it.": Semi-automatic Firearms as a Principal Component of Paramilitary Gun Culture

Gun-Guys and Gals: Increasingly Concentrated and Dedicated Owners............54

Masculinity, Rural and Urban Spaces and the "Conservative Lifestyle" ..........58

The National Rifle Association, Right-Wing Populism, And Militarized Policing: Firearms as a Tool of Masculinity and Security

Messianic Marginality: Storying the Self in a Declining America .74 
3. "In Time of Need": Private Work for the Public Good: Messianic Marginality and

Narrative Work in Public Spaces

Not Keyboard Commandos: How the Militia Introduces Itself in Public Literature

4. "That's Not Really the Point of This.": Negotiating the Boundaries of Messianic

Marginality at Militia Staff Meetings.

"Volunteer Firefighters" with Guns: Militia Staff Meetings as a Space of Negotiating Militia Messianic Marginality .....

The Location .125

Premeeting Socialization

The Meeting Proper. 138

Post-meeting Goodbyes .161

5. "There's a Lot of Loose Talk Going On, Too Much Look Talk for Me": The Outer

Limits of Messianic Marginality at Training Events 164

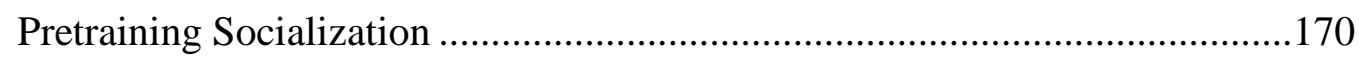

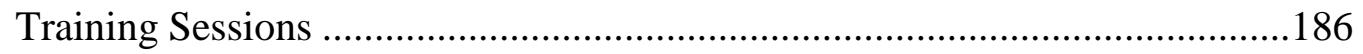

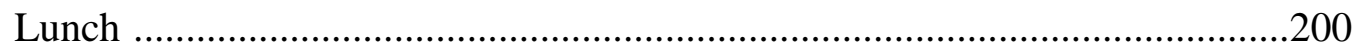

Second Training Sessions, Round Robin, and Day's End ...............................206

6. "Playing Army": The $10^{\text {th }}$ as a Space of Live-Fire Roleplay with Real-World

Consequences.

Shortcomings .219

Future Research. .221

BIBLIOGRAPHY .223

VITA .234 


\section{LIST OF ILLUSTRATIONS}

Figure

1. Firearms Manufactured in the US, 1986 - 2015. Data from Annual Statistical Update of Firearms Commerce in the United States, Department of Alcohol, Tobacco, Firearms and Explosives, 2017

2. Firearms Manufactured in the US, 1986 - 2015. Data from Annual Statistical Update of Firearms Commerce in the United States, Department of Alcohol, Tobacco, Firearms and Explosives 2017

3. Firearms Exported from the US by type, 1986 - 2015. Data from Annual Statistical Update of Firearms Commerce in the United States, Department of Alcohol, Tobacco, Firearms, and Explosives 2017

4. Firearms Imported to the US by type, 1986 - 2015. Data from Annual Statistical Update of Firearms Commerce in the United States, Department of Alcohol, Tobacco, Firearms, and Explosives 2017

5. Firearms Exported from and Imported to the US by type, 1986 - 2015. Data from Annual Statistical Update of Firearms Commerce in the United States, Department of Alcohol, Tobacco, Firearms, and Explosives 2017.

6. Trends in Household Gun Ownership. GSS Data, 2014

7. Trends in Personal Ownership of Guns. GSS DATA, 2014 .55

8. Reproduction of Membership Questionnaire for $10^{\text {th }}$ Recruits 116 


\section{LIST OF TABLES}

Table Page

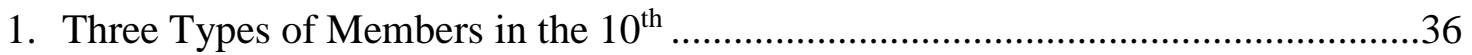

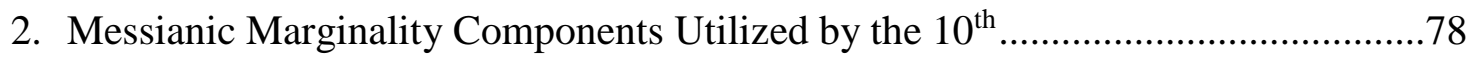

3. Summary Table of Narrative Genres used in Messianic Marginality .....................80

4. Answers to "What is the Biggest Problem that People Face These Days?" ..........137

5. Common Themes and Form of Militia Humor ..............................................162

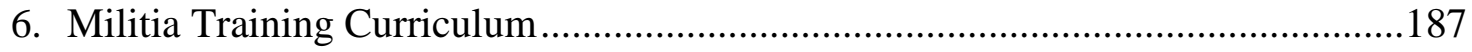




\title{
MARTIAL CITIZENSHIP: FIREARMS, IDENTITY, AND MASCULINITY IN A PUBLIC MILITIA GROUP
}

\section{Daniel Thomas Petrin}

\section{Dr. Wayne Brekhus, Dissertation Supervisor}

\begin{abstract}
This project is a study of the ways in the participants in a public militia group organize and present positive identities in everyday talk and storytelling. This study situates their activities within a larger historical trajectory in which the contentious changes in social hierarchies and political power in the United States over the last several decades has produced a distinctly paramilitary gun culture from which the militia draws its members and the resources they use in their everyday identity work.

Adopting a theoretically informed ethnographic approach to analyzing data gathered over a number of interviews and several hundred hours of field work, this study analysis the ways in which militia members valorize personal characteristics such as firearms ownership, race, sex, religious beliefs, and geographic location in creating valuable social identities. The results, here termed messianic marginality, is a shared identity they express through generic conventions that they use to position themselves as responsible people who through their personal sacrifices and efforts have cultivated skills and moral values that serve not only themselves but the wider society they believe is in decline and does not respect them.
\end{abstract}




\section{Chapter 1}

"This is my Mr. Rogers Gun": Firearms in the Militia and in Everyday Life 
We were driving towards Centerville, a town of about 4000 people located a little less than an hour north of our home, when I turned away from the mid-March landscape of central Missouri and said to my partner "Once upon a time. I think that's what we should use." She looked at me quizzically for a moment before turning her eyes back to the road and responding flatly "Ok." During the trip to this small town we had been trying to decide on a code phrase that I could use to prove that I was not in any danger and that it was safe to pick me up when the meeting I was about to attend ended. It was my first militia meeting. I had suggested earlier in the day that we should have a code word or phrase but we let the topic slide in between our other obligations that day until the trip. The act of finally proceeding to the small building impressed upon me the need to decide on something. Half of the stout, little brick building is office space for a family health clinic, and in the other half the group reserves a monthly space along with the local AA and NA chapters. I picked the phrase "once upon a time" because nobody other than myself would know that it was the name of my wife's favorite television at the moment. I later learned from militia members that this was a form of "operational security" or 'OPSEC' for short. These were not concerns that I had in performing fieldwork at local gun stores and shows. It would later turn out that my concerns were misplaced here as well.

My wife had agreed to drive me there, as she knew both the way to the town and the town itself quite well, having taught in one of their schools for a year prior to the beginning of this project. We also reasoned that were anything to go awry she would be able to respond quickly with the car, whether that meant getting help for me or removing herself from the town. These were not likely outcomes, of course, based on how open the groups and its leaders had been with me. This unit, according to their website, is one of 14 regional units throughout the state that are all under the command of a unit based in one of the state's major cities. It turns out that this militia is no more immune than are many other people to the cultural and political concentrations of power associated with major municipalities. Having investigated the conspicuously open way in which they presented themselves on their website I concluded that the group was relatively safe to approach.

The group was expecting me and the leader at least knew what my purpose was; he had told me that the unit knew too. I met the unit's commander, Charles, several months prior to this and introduced my project and its aim to him over cheese fires and coffee at a local upscale café. He had been easy to get in touch with as his name and phone number were on a pamphlet advertising the group that he had given to me at a gun show. I had not seen them at the gun show since that first encounter and ended up contacting his second-in-command, Wade, to ask about his interest. In what I have come to appreciate as his flippant style, he told me that he would welcome it, but I had called the wrong person to ask about 
such things and he directed me to contact Charles instead. I did so and after a short conversation in which Charles asked me to to clarify that I was indeed just a doctoral student and not part of a watchdog group or agency, he agreed to meet with me.

He scheduled the meeting for December $7^{\text {th }}$, Pearl Harbor Day. When we met at a café in town I asked him if the choice was deliberate and he answered that it was. Early in the conversation he had remained somewhat skeptical as I was not the first person to want to observe them but he grew convivial as we quickly bonded over deer recipes and employment. After about an hour and a half of conversation about my project and his views on the group, he picked up the tab and told me that he would present my project to the group and put it to a vote. It helped my case to point out that there are few studies that engage directly with militia members and this leads to a reliance on assumptions about what they do together and how similar they are to one another. I did not hear back for two months and the last of several attempts at following up, Charles told me that they had voted to allow me to attend a meeting and present my project to them as well as observe their training later in the week. The expectation was that members would tell him or me if they didn't want me around and I would be told to leave and not return.

Our car entered the circle drive outside of the meeting location and there was a man standing outside next to the only other vehicle in the parking lot. I asked my wife to pull around and head off to her own activities rather than park near him. She did so and I exited the car and walked over to meet Wade.

"Are you John?"' he asked

"Nope, Daniel. You're Wade I think? I know you are not Charles, anyway. Good to meet you."

We shook hands before walking towards the door to the building. While we walked he explained that they were expecting someone from the journalism school at the university and he'd figured that was me. He had a key to the door and once he opened it he crammed the doormat into the gap between the door and the frame to keep it open. This was in contradiction to the demands of a sign on the front of door that specified that occupants were not to prop the door open; I said nothing. I became accustomed to doing that throughout the project. Wade explained that they used this building because the meeting room was usually accessible by appointment months in advance and he liked to prepare things that that fashion. We joked that some things-like dealing with what I called "officialdom"-were the same

\footnotetext{
${ }^{1}$ Throughout this document the use of double quotation marks is used to indicate direct quotes transcribed in situ or shortly after they were uttered in field notes. Single quotation marks are used to indicate speech that has either been reconstructed from less complete field notes, recollection, and to denote common terms and phrases.
} 
pretty much everywhere you went. After a few minutes, Charles pulled into the driveway in his red domestic pickup truck, parked, and walked over to us. Wade tried to introduce us but Charles quickly replied that we had already met. While we spoke two other men pulled up in their vehicles and approached. They did not introduce themselves and neither Charles nor Wade introduced me, so we all ended up standing outside the building and chatting while the oldest amongst us, Audrey, 76, smoked a cigarette.

The two new arrivals asked if I was the "Josh guy" and we talked a little about who he might be. Charles asked me directly whether I knew anything about him. I told them that I did not know anybody from that department. They seemed fine with this and briefly talked about a young woman from the journalism school who had come to several of their trainings in the past and written what Charles thought was a 'very welldone piece' about them. There seemed to be only lukewarm agreement about this, though nobody challenged it. Wade and Audrey poked fun at one another. Audrey pretended that he was suddenly unable to recognize Wade. Wade proceeded to suggest was a result of Audrey's age. Wade continued, "I recognize you, but I can't honestly say I like what I see; it's not looking good. Just so we have that out in the open." This amused everybody and then we went inside after a little more chitchat.

The feelings I describe at the beginning of the vignette above are simple in retrospect, and not notably distinct from how other people feel when attending their first militia meetings, or any other social situation populated by strangers. Anxiety, uncertainty, even mild suspicion are common feelings when we enter social situations with standards, participants, and interactional patterns that are unfamiliar to us. To further contextualize my own feelings in the excerpt above, I now would say that was anxious because I did not know how to present myself to militia members or how to talk with them in ways that would not produce a rebuke or other negative sanctioning. Generally speaking, militia members are demographically similar to other populations in the US who feel as though experts, academics, government employees, non-Christians, feminists, city-dwellers, and racial and ethnic minorities are endangering the United States through the changes they precipitate by seeking more equitable social, political, and economic conditions. In short, the members of the militia that allowed me to work with them are anxious about the 
changes facing a country organized in ways that up to this point have largely permitted them to exist in familiar ways, maintain untroubled beliefs about the country and its inhabitants, and only indirectly feel the ways in which their local communities are tied to the rest of the country. As their lifestyles have become more visible to others, their beliefs more clearly challenged, and their connections to the wider society have become more contentious it has produced an uncomfortable mixture of anxiety, indignity, and powerlessness with respect to outsiders as well as hope, goodwill, and empowerment for insiders and those similar to them. The overarching pattern is a familiar one in the United States, as I will elaborate on in the coming pages. The second wave of militia organizing that began after the election of President Obama as well as the rise of white nationalism, the alt-right, and populist backlash against social justice groups, and an increasingly inequitable political economy, are all connected to common threads of institutional and extra institutional racism, sexism, and parochialized nationalism that run throughout the history of the country. Their varied modern expressions are not identical, however, and although they draw on many of the same symbols, stories, and ideas and recruit from some of the same populations these various groups act in distinctive ways with respect to their willingness to engage in politics, commit violence, and interact with the communities in which they live. In other words, the participants in the lethal events of Charlottesville, the different branches of the militia movement, and Tea Party participants all draw upon the sense that they are practicing a particularly authentic type of citizenship, a feeling of ownership over a country they feel is in decline, and draw different connections between to whom they assign blame and the correct ways to respond. In answering how similar sets of cultural resources get put to different uses one must at some point ask how the material 
is used in the mundane interactions between group members and, from there, how it is utilized in social action.

\section{Goals of the Study}

As such, this dissertation asks two sets of questions about the militia unit under study. The first set is broader: what strategies and resources do members of this local militia unit use to maintain their belief in themselves and the group as morally and socially valuable in a highly polarized cultural environment? The second set is narrower: how do members accomplish their identity work in their own social environment, where do they draw those boundaries, and what rules exist for accomplishing this work? In pursuing answers to these questions, the project contributes to three areas of existing sociological knowledge. Beginning with the narrowest of these contributions, this project is adding to the sum of empirical information available on the activities of militias in the United States. An increasing amount information is becoming available regarding the uses of firearms and the direct and indirect impacts they have with respect to the ways they enhance the ability people have to conduct lethal interpersonal violence; less is known about how people go about integrating firearms into their daily lives in ways beyond utilizing them for their basic mechanical purposes and less still about how militia members grapple with the elements above. The bulk of the information pertaining to militias relies upon the militias from the 1990s, the last major wave of activity prior to the current one. My findings indicate that participants in firearms culture draw upon a shared stock of cultural capital in the form of the symbolic and practical importance they find in owning and using firearms as it relates to enacting identities that they feel are morally worthy, socially valuable, and personally satisfying. Despite the generally shared nature of these resources, there remains 
considerable variation in the significance people assign to particular practices or arrangements of identity markers as well as the different strategies they use to understand and present themselves as specific types of people. Compared to the broader culture around firearms the militia highlights not only their value as responsible gun owners who can protect themselves and others, but the need for training and organization in advance of being called upon to do so.

In line with the first contribution, a more significant contribution of this project is the continued exploration of the ways in which the strategies above draw upon hegemonic and marginalized masculine positions, notions of citizenship, and constructions of race, class, and responsibility in response to local interactive needs. Previous scholarship and journalistic efforts have thoroughly established that the primary demographic groupings associated with many of my participants are also a large cross-section of militia membership: non-urban, white, heterosexual, politically conservative ${ }^{2}$, Christian males of middle-age or older who live in rural areas or, at least, strongly identity with their visions of that lifestyle. There is variation in my data that mirrors changes in the number of women becoming engaged with the gun culture, as well as the ways in which firearms manufacturers and culture attempt to appeal to a more diverse group of people. Despite this, the militia relies upon a neoliberal, color-blind ideology of personal responsibility as the root of success, heterosexual, Christian families with traditional gender roles as the foundation of a moral society, and view themselves as required to defend these ideals as

\footnotetext{
${ }^{2}$ I use the term 'conservative' here to reflect the word choice of my key interviewees. Conservative politics, like liberal and progressive politics, are not monolithic and participants each have differing collections of libertarian, conservative, and more progressive view but choose to identify as conservative in comparison to liberals and moderate compared to groups that they feel are extreme such as organized racists.
} 
crucial to an authentic for of United States citizenship they feel is becoming increasingly marginalized by the rest of society.

The final and broadest contribution of this project is its development and application of contemporary theoretical approaches to identity, interaction, and self as active, reflexive processes in which actors consciously and actively engage. In line with these approaches, this project has found that the differences between and within several militia spaces lend themselves to different presentational emphases in interaction and boundary work depending on the broader goings on in the world, who is present, and to what problems they are responding. This dissertation is focused on examining how the different members of the $10^{\text {th }}$ accomplish identity work across three interactive spaces: highly public interaction with the public, semi-public staff meetings, and private training events.

In presenting the answers I have found I will continue this introduction with an overview of the following: an argument for my ethnographic approach to this study, the importance of the link between firearms and masculinity in the militia and the broader contemporary gun cultures, and an overview of the project and its findings.

\section{The Everyday Work of Being}

Although it does not always receive the attention that it could, everyday life and the mundane work that human beings undertake to live it are a vital and vibrant area of sociological inquiry. Sociologists have learned a great deal from dedicated study of the sophisticated strategies, rituals, and meaning-making that goes into activities as varied as the interactive procedures at work in a grocery store checkout line and how people navigate 
the constellations of networks and obligations associated with the competing demands of their families, political orientations, economic obligations, and social lives. The everyday work we each do to 'be' a person of a certain sort in the social contexts we traverse as we go about our lives arguably makes up the bulk of our everyday activity and represents a great deal of personal effort. Much of this effort centers on how we learn to integrate symbols and physical material with the interactive strategies required to accomplish the performance and embodiment of overlapping, yet distinct, social identities. Each of these identities relies on expectations for presentation and interaction that correspond to a given interactional field in which we find ourselves. In these ways, any specific identity, insofar as it is analytically or experientially possible to specify them as distinct from others, necessarily includes emotional components, such as feeling attached to a specific identity as representative of a deeper, authentic 'self'. There are few feelings as disconcerting as believing that peers view us as pretenders to an identity we claim and value, and having little or no power to rectify their view of us. Losing control over our identity work and subsequent limitations placed by others on what sorts of human being we may aspire to be in society has long been a powerful form of punishment for people who violate rules, both formal and informal. It has also been basic fact of social life for people who through institutionalized inequalities are kept in the most marginalized positions in society.

Power at work in everyday interactions is often obscured via several mechanisms dealing with how we are socialized to interpret our experiences in society in ways that align with existing hierarchies and social relations. Our own everyday identity often appears natural to us because we need not give too much consideration to the actions and people with which we are already familiar. The ebb and flow of a life in all of its moments often 
occupy us such that we have little time to reflect on what, if any, significance our activities hold with respect to the influences of a broader social order. As a rule, people can sense moments when larger forces influence their lives but necessity requires them to navigate or mitigate these influences the specific ways in which others wield power over them remain somewhat inchoate and fleeting. A well-heeled professional may feel inconvenienced when stopped by a police officer and ticketed for speeding but is unlikely to need to situate that experience in a broader view of how law and social class interact. A low-income person of color on the other hand is more likely to be constantly aware of both social class and law as a means of protecting themselves from potentially grievous consequences that may follow from the same interaction. Taken together, the naturalized identity work of different settings and their flexible relationships to institutions create conditions under which privileged groups can hide qualities that might challenge their identity presentations, exercise fine control over the identities they do present, and, oftentimes feel invisible against the backdrop of social life. It is easy to believe that nobody would have an interest in one's life and that the work one engages in to construct and enact intelligible, satisfying identities when these quotidian moments are firmly ensconced in institutional support for the relevant styles, equipment, and presentational strategies. Support of this nature enables the habits associated with controlling the presentations of identities that one wants to hide or keep visible. We do not have to work as attentively to manage identities that institutions take for granted as normative and morally acceptable.

When circumstances change, as when an interloper enters our spaces or, still more noticeable to us, we become interlopers in social spaces, the lack of practice, fit, and comfort that interactants experience together foreground this work. Changes the political 
and social weight of everyday actions and identities have historically been more overt and empirically fetching when undertaken by groups whose work has little institutional support. Those facing compound disadvantages, such as racial or ethnic minorities, the economically dispossessed, women, or people with sexual orientations that are unorthodox in their societies are typically visible to others in society. Frequently, this visibility means that they and their styles of life are identified as 'problems' by more powerful people and institutions, and their capacity to control their identity work and audiences is often quite limited. It is easier to spot these labors when their social relevance is increased via social movements advocating for changes in institutional support germane to their needs, identities, and styles of life. The institutions at work also become foregrounded in the responses such challenges engender. Counter movements and agents of social control make clear that the standards being made visible through contestation and those whose identities and daily lives these standards support are to remain either invisible or, at least, under the control of those who have hitherto benefited from them. These are crucial moments to draw upon in furthering our understanding of the ways in which people make use of specific knowledge and materials in organizing their identities. People whose social, political, and economic positions are changing, whether for better or for worse in their own estimations, also navigate changing repertoires of material and strategies for accomplishing 'being' in the world. Whether the shifts are positive or negative in any specific sense the are generally changes in the visibility of those involved as well as their control over by whom their identity work is seen and the rules for by which they wish to be understood. Sociological attention on people, groups, and their strategies for pursuing equality for historically disadvantaged groups others should therefore continue to be complemented by studies 
dealing with the ways in which people whose positions and lives stood in unmarked contrast to the marked, wielded power without direct action, and have generally responded to being marked by selectively drawing upon the repertoires of both the oppressed and the privileged to make sense of their newly visible practices.

To return to this specific project and its questions, in the contestations in American culture and politics since the 1960 s, including the continued civil rights movements, women's rights movements, and economic and social justice movements, the changes that many of the groups above have collectively effected have also exposed more clearly the ways in which whiteness and masculinity, among other characteristics, were taken-forgranted by both institutions and those for whom they were untroubled, controlled parts of their identities. Such a transition is jarring and inspired corresponding contests to control the meaning of whiteness and masculinity and how they relate to one another as well as others. Finding and expressing the significance of everyday identity work takes on an urgent importance when people are newly called upon to account for the styles of life they had taken for granted. Under such conditions people develop strategies to navigate the new gaps between the ways in which their beliefs, practices, and identities have increasingly become visible. Outsiders have marked these characteristics as institutionally supported rather than merely individual preferences and qualities as well as harmful to others and yet, the same characteristics remain deeply valuable to those who rely on them for their daily identity work. Some of these responses are especially visible in their attempts to establish not only the meaning of whiteness, masculinity, Christianity, and patriotic citizenship but to valorize particular strategies for integrating them and then establishing these configurations as the standard to which others are held. 
Of many different organizations that set about this work throughout the latter half of the $20^{\text {th }}$ century and into the present, ranging from resurgent white supremacist groups to far-right populist political movements that eschew overt racism, those that emphasized instruments of violence in their action and identity work are among the most obvious fixtures. During the 1990s, and again after the election of the first African American President of the United States such groups commonly combined their whiteness with patriotism, firearms, religion, and appeals to an idealized past in attempts to reestablish their own identities as the standard for a nation that was increasingly unlike them. Another cultural reference point many of these groups share is that of firearms enthusiasts, another identity that often combines the identity issues above with the changing nature of how many of its participants relate to the state, its capacity to utilize legitimate force in service to its goals, and towards whom that force is directed. During both time periods enumerated above, another loose collection of groups now commonly referred to as militias and the militia movement, drew upon these resources as well, and oftentimes in ways that created a distance between them and more vitriolic racist groups. Aside from a relatively small collection of scholars, journalists, and other interested parties few seek them out and ask them directly what they are doing and who they are but those few cases have proven invaluable in tracing the ways in which members of such groups make sense of themselves, their actions, and demarcate the boundaries they see between themselves and others drawing upon similar resources and reference points.

The members of the $10^{\text {th } 3}$, the militia unit I have participated with for the last 3 years are like many participants in the gun culture in that they share a belief that the United

\footnotetext{
${ }^{3}$ Despite the public nature of the group I elected to identify the unit itself using this pseudonym.
} 
States is in decline, or will be shortly, as well as a belief that people like them have a responsibility to mitigate the damage this decline can inflict on them, on their communities, and upon those who might ask them for help. In large part, then, the members of the $10^{\text {th }}$ are also responding political and social changes outlined above that they see as challenges to the prestige, power, and morality of practices associated with firearms and the forms of citizenship and patriotism with which they most comfortably identify. During their meetings and trainings, members of the $10^{\text {th }}$ highlight elements of their behavioral repertoires which through their participation in the group become a vehicle for not only accomplishing daily life but also reinforcing their personal understandings of their importance and value to their communities and the United States. In responding to these concerns there are impulses outsiders would recognize, such as the desire to care for loved ones and neighbors, concern over the concentrations of wealth and power, as well as concern over the levels of gun violence in the country. At the same time, any such recognitions would have to account for the additional fact that like other people and groups drawing on this cultural material, many members of the $10^{\text {th }}$ also identify progressive politics, social movements, academia, and the government itself as contributors to these problems.

Aside from the specific risks that it can present, the work of the $10^{\text {th }}$ is not especially different from the ordinary work that people who are not members of the gun culture or militia movement engage in; it differs primarily in the emphasis placed on firearms ownership, active citizenship, valuing particular visions of American history, and the rules for organizing this material in ways that do not stretch the ideological boundaries above too far. It is therefore not the case that any special theories of self or interaction are 
necessary to understand them. Instead I sought more nuanced, empirical data about the ways they use available cultural information and repertoires to do identity work in the context of the changes in the value and legitimacy of their positions and practices. As a person transitions from the broader cultural grouping into increasingly private militia spaces the rules become more flexible, but only to the point that an instance of identity work begins to seriously limit or challenge the central rules for self-presentation in the militia. In addressing the dynamics of identity work in the militia I develop two central concepts in this manuscript with respect to their uses in the daily work of my participants, paramilitary gun culture which serves as a source of many ordinary resources for militia identity work and messianic marginality, an identity and set of interactional strategies that I believe most groups associated with the counterreaction to the social changes outlined above draw upon and that the members of the $10^{\text {th }}$ utilize in order to present themselves as morally-upright people whose beliefs and practices are, in their opinion, particularly valuable for managing risks in an increasingly dangerous world but who are also unfairly maligned by outsiders who despise and undermine them.

In service to demonstrating the link between the identity work and resources of the $10^{\text {th }}$ and the broader countermovement of which they are a part I will first elaborate on the role of firearms as an identity resource that allows both groups to link whiteness, masculinity, citizenship, and responsibility together in ways that allow them to valorize their behaviors and beliefs relative to others who endanger or dismiss them.

\section{Good Guys with Guns: Theory and Methods in Studying The 10 ${ }^{\text {th }}$}

Firearms and the practices associated with them are an everyday part of life in the United States in a number of ways that have no equal throughout much of the rest of the 
world. Based on the popularity and availability of firearms within its borders compared to similar nations as well as prevalence of positive meanings associated with firearms and their use it is commonplace for observers to refer to the U.S. as being or having a 'gun culture'. In practice, 'gun culture' is often a shorthand way of encapsulating a constellation of firearms-related identities, practices, and beliefs as well as a generalized animating force behind them. Buried in the term is the uncritical assumption that there is little variation or nuance in the ways that people integrate firearms into everyday life. Academically and publicly the tendency is to focus on their utility in criminal enterprises and the tens of thousands of deaths and injuries they produce each year-including roughly 36,000 gunrelated fatalities in 2015 alone (Murphy et. al 2017: 12). My point is not at all that such concerns are misplaced, they are not and frankly, require a much greater volume of study and attention. Instead, I argue that even a brief examination of statistical information available on firearms ownership and use readily suggests that there is much more to examine in firearms and gun culture than we capture in the often depressing public health and criminological data. This is self-evident even in the data on ownership statistics.

It is difficult to be certain precisely how many firearms are privately owned in the US. This is the case for a couple of reasons. For several of the last decades gun rights advocates, lobbyists, and sympathetic politicians have helped to create a situation wherein the pursuit of even basic findings may quickly become political and professional liabilities (Melzer 2009). This alone suggests the importance that at least one politically effective population places on owning firearms and their hostility to any potentially unsympathetic outsider attention to what firearms they own and what they do with them. In other words, studies represent threats to the abilities of these populations of gun owners or supporters to 
control the visibility and interpretation of their identities and practices. The demographics of firearms ownership may exacerbate this problem as the most enthusiastic owners are reliably members of generally unmarked demographic and social categories. For this population, studying firearms and the people associated with them as potential social problems challenges the normalcy and moral values that they associate with their behaviors and beliefs. Even were these conditions different, there are other basic problems researchers face: the fact that firearms are high-durability goods and it is difficult to know when they exit circulation, the presence of a significant underground market, and the unknown number of legal and illegal private sales characterized by scant record keeping. In 1994 an estimated 40\% of gun owners purchased guns sans a background check (Cook and Ludwig 1997), and an estimated 22\% did so between 2013 and 2015 (Miller, Hepburn, Azrael 2017). Based on these data it is largely unclear how many gun owners acquire their guns in ways that do not require a background check and therefore produce no records

Regardless of these difficulties, researchers do produce estimates of the firearms stock, referring to the number of devices in circulation, from time to time and they consistently and strongly suggest that there are enormous numbers of privately owned firearms in the United States. Several million more are added to the population each year. Chronologically, earlier attempts estimated the numbers to be 90 million in 1968 (Newton and Zimring. 1969), 100 to 140 million in 1978 (Wright, Rossi, Daly. 1986), in excess of 220 million as of 2000 (Vizzard, 2000), and between 206 and 235 million in 2004 (Hepburn, Miller, Azael, and Hemenway 2007). The most recent survey research of which I am aware puts the number at roughly 265 million (Azrael, Hepburn, Hemenway, Miller 2016). According to this most recent data $42 \%$ of these firearms are handguns while the 
rest are long guns such as shotguns and rifles. While the general trend in firearms ownership appears to be moving downwards from a peak of around 50\% of households in the late 1970 s to $31 \% ; 22 \%$ of individuals are estimated to personally own a firearm (Smith and Son 2015) but the most recent ownership figure is in fact an increase from the low point of $20 \%$ of individuals recorded in 2010 (Azrael et al. 2016). The increasing number of firearms and declining ownership statistics mean that the ownership of this stock is concentrating among fewer people. These most recent estimates mean that there are between 50 and 58 million gun owners, $86 \%$ of whom own approximately half of the available stock and $14 \%$ of whom own the remainder (ibid: 42-43). It is empirically unjustified to assume that these few millions of people who own most of the far utilize firearms them in identical ways or assign the same meanings to them or the practices associated with them. Somebody who owns a gun because they inherited it, bought one during a period of personal insecurity, or, like me, simply enjoys target practice are likely to understand the devices in ways that significantly vary from to those who own many of them. There is a general consensus among the literature that much of the recent growth in the national stock of firearms can be attributed to increases in the manufacture and sales of handguns and what are commonly termed 'assault weapons' or 'modern sporting rifles,' depending upon whom you ask. I will substantiate this trend later in this introductory chapter. These types of weapons have relatively limited use for hunting (Vizzard, 2000: 24-27). This is particularly true of popular handguns although the modular nature of modern sporting rifles means that they can be used in hunting more readily than most handguns. Hunting does not explain the continued growth of either category, however, as GSS data suggests that the number of households containing people who hunt has been 
persistently declining and is now at a low of $15 \%$ (Smith and Son 2015). The findings of Azreal et. al. (2016) indicate that nearly $70 \%$ of gun owners they surveyed reported that the primary reason they owned a firearm was for protection against people, and, frankly, harming people is a task for which these weapons above are well-suited given that many of them were designed and manufactured with that purpose in mind. These trends align well will earlier and contemporary literature identifying the trends towards assigning utility and value to firearms primarily in terms of self-defense from other human beings; this is often thought of as stemming from racialized fears of crime and disorder despite a lack of clarity regarding the efficacy of this notion or precisely which motivational factors produce this behavior (see McDowall 2005 for a review of the latter as well as Kleck and Gertz 1995, Smith and Uchida 1988, Bankston, Thompson, Jenkins, and Forsyth 1990, McDowall 1995, Costanza and Kilburn, Jr. 2004, Lemieux 2014).

Although my focus is the daily identity work of militia members they are deeply enmeshed in the gun cultures of the United States and rely on the material and symbolic resources it furnishes for much of their activity. This dissertation addresses this relationship in that I argue that among multiple gun cultures present in the US (see Lizotte and Bordua 1980 for an earlier argument to this end), a particular gun subculture has developed and achieved prominence over the last several decades. I refer to this subculture as a paramilitary gun culture. Any single gun culture can be defined as a set of firearms, accessories, practices, and values associated with a particular set of outcomes associated with them. For instance, a hunting gun culture would be centered on hunting rifles and shotguns, equipment for luring and successfully shooting prey, and whether the animal is prepared as food, a trophy, or both, as well as why. Recreational gun culture would 
similarly revolve around firearms which are engaging to operate, sporting purposes for doing so, and values centered on the entertainment associated with doing so. There is overlap between these cultures at the individual and small group levels at least, meaning it is best to think of the different gun cultures as ideal types. Compared to ideal-type gun cultures associated with hunting or other recreational use paramilitary gun culture specifically refers to a collection of material and narrative practices, identity presentations, experiences, and evaluative standards that assign moral, civic, and practical value to civilian acquisition and training with weapons outside of shooting sports or professional obligations. It is likely the combination of its prominence in the popular imaginationreferring to both its advocates and critics—as well as the lack of obvious countervailing voices among firearms owners that there is the tendency to think this subculture as a 'the' gun culture.

This shift has not been subtle nor have outsiders ignored it and a call has been made to develop a sociology of guns drawing on ethnographic data (Yamane 2017). As with any subcultural group, participants undergo a socialization process through which they learn the meanings associated with firearms and key to socialization into the paramilitary culture is learning how to talk about guns as safe, responsibility and danger, and the uses of weapons in ways that align with the concerns outlined above. Shapira and Simon (2018) have identified this process as 'learning to need a gun.' This is an interactional accomplishment and much as I will later argue regarding masculinity, these authors draw on West and Zimmerman (1987) to argue that increasingly common concealed-carry and gun ownership are "not just connected to political attitudes or cultural narratives, but [literally] constituted by a set of embodied practices that people who carry guns undertake." 
(ibid:4). This requires that a person learn to identify owning a firearm is "a need, that guns are safe, that killing another human being is a moral action," and then how to translate those beliefs into practice (ibid: 4). While there are some basic points that most cultural participants would agree upon such as the basic notion that private citizens have a fundamental right to own firearms and that such devices carry with them a set of responsibilities.

I am at Main Street Guns, a small local gun store that I had been visiting long before the proprietor agreed to allow me access to it as a field site. It is early February and I decided to visit the store for an hour or two. It had somewhat busy because it is a Saturday, although there are few very predictable patterns when it comes to what days will be the busiest. Burton, the owner, was working today as he does most days. He is in his early 50s, around 5'9" and bespectacled. He makes it a habit to greet everybody who comes into the store with great enthusiasm and asks questions like "what fun can we help you get up to today?" Logan is also working. Logan is a part time employee who also does work for local law enforcement as an officer and weapons expert, as well as training other law enforcement officers (LEOs) in tactics around nearby parts of the country. He is also in his 50s, though older than Burton by several years. Logan is a talker and can speak at length on a variety of topics of interest to him and he frequently will as he seems to relish interacting with people while at the store.

Burton had gone back into his office to finish the paperwork he tries and largely succeeds to stay caught up on so Logan and I had an opportunity to speak for several minutes. He told me about people who are too loyal to certain brands or types of firearms. I asked if they were "gun snobs" and he laughed, admitting that he'd not have used those words but yes, they were. He explained, "plenty of people will come in and just want to bash on some type of gun or another and talk up their favorites. "I think this was a veiled jab at Contemporary Rifles, another store with which they seem to have a bit of an ongoing feud based on their history. Apparently, such people can bug Logan and this encourages him to make sure that nobody is put off by people acting that way at this store. At my inquiring further he elaborated, adding that he does not like "when people come into the store and go on political rants, saying things like fuck the government and fuck the ATF and so on. We, You and I, we have our political perspectives and that's good. But you can't sit there and agree with people like that in the store because it will, even if you agree with them personally, it will run other customers of the store. They'll hear that when they come in and then," he rolls his eyes, indicating that people would find this type of 
talk offputting, "and they leave because you look like some kind of extremists." I see an opportunity in this moment. Since both Logan and Burton always have pistols on their hips while at the store I asked him if his carry was a "5.7" and he said yes. He then explained to me that it was his "Mr. Rogers gun". I smiled and replied, "you'll have to explain that one to me."

Logan: "So, you know Mr. Rogers?"

Daniel: "Yeah, yeah, I grew up with him."

Logan: "Ok, so, yeah, you know what he did when he came in? He put on..."

Daniel: [I interrupted] "The sweater..."

Logan: “...yeah... that's right. His sweater.”

Daniel: "Ok, I get it."

Logan: "So this gun stays here in the safe and I put it on when I get here every day."

He told me that he likes it for his store carry for three reasons. For one, it does incredible damage to flesh. This is due to the high velocity of the ammunition that it fires. This ammo was designed to mimic the ballistic behavior of the projectiles used in modern military rifles but reduced in scale such that it could be fired by smaller weapons. Firing a small round at a high speed allow the round to create a much larger wound channel than a larger, slower round. In short, it creates grievous wounds that rapidly incapacitate the person who suffers them. For two, "it'll knock an aggressor down and keep them from leaving the store which simplifies the legal issues surrounding the issue". Last, "it won't leave the store if I miss." I decided that this last point was possibly true as the weapon does fire a small round but it is also very fast-most of its varieties travel 1000 feetper-second faster than the ammunition my handgun fires. I also felt he was neglecting that there are two very large windows in the front of the store as well as a glass entryway. Both sets of windows look out on a nearby busy street. On the one hand, he has vast experience and may very well be able to shoot accurately under stress. At the same time, I found his assumptions regarding how such an event would play out distressing. Based on his lack of description of where the shooter would be, whether they would have the drop' on him, and so forth I wondered if his vision of this scenario was based primarily on highly favorable conditions. Such a scenario would mean that the bad guy enters the store, proceeds to the back where no stray rounds can fly into traffic before launching his attack, and Logan's reflexes allow him to respond to a surprise attack. This would require that the bad guy does not simply walk in and gun them down or shoot them through the 
very same windows that Logan is confident he will not penetrate with any missed shots.

Shortly into this project, which originally involved fieldwork at the gun store above,

I realized that many of the same stories, characters, and identity work was appearing in the

militia but was used in different ways. This latter type of data was far less accessible as

building rapport with militias is a bit of a fraught task and it therefore made greater sense

to use the existing literature to build my argument for the existence of this shared

paramilitary gun culture and focus on the uses to which a militia group puts $\mathrm{it}^{4}$.

It is a cool day in early April 2015 and I am interviewing Wade on the outside patio of a coffee shop at a local shopping center. He is the first to agree to an interview and took the opportunity to do so given that he already had to be in town for another reason today-his wife wanted to do some shopping in which he did not want to participate. We each have a coffee and proceed through a disordered version of my interview schedule. I learn that he has had many jobs in his lifetime but ended up quite skilled in construction work and concrete hauling. He tells me about how common firearms were in his younger years, explaining that in his estimation that the reality of the way people interact with guns has changed insofar as there are decreasing opportunities for people to interact with firearms at all and, consequently, so too has the perception of firearms changed. I noticed earlier in our interview that he occasionally looks behind him at the large entrance to one of the big-box anchor stores this mall relies on. The look is always brief but it is not perfunctory, he is looking for something.

He continues to talk about different approaches that people have to firearms throughout the world, using Switzerland as an example, before discussing the increasing number of mass shootings. He mentions the popular, and incorrect, idea that mass shooters target gun-free zones

\footnotetext{
${ }^{4}$ In the initial stages of this project I believed that a comparative study of paramilitary gun culture as it is performed at a gun store and in the militia would be the body of this work. However, that will have to be a future project as I eventually abandoned the gun store as a field site. This was due to three considerations. The least significant was that the site grew increasingly awkward to navigate as the presidential election grew nearer; I was known to be a liberal academic, albeit a gun owner, and despite the general amusement that Logan, Burton, and I took in our differences one of them started pointing me out to customers as a researcher and supporter of a particular candidate who was there "to study us in our natural habitat." That made a few customers and myself uncomfortable but asking him to stop would likely have come off as censoring and limited my rapport with him in the future. More importantly, several new scholarly works dealing with firearms have recently been published and upon reading them I found they had largely experienced and better documented concealed carry and the broader paramilitary culture than the gun store would allow for if my attention remained split between it and the militia (Carlson 2014, 2015a, 2015b, Stroud 2012, 2015).
} 
deliberately. As we continue to talk about various aspects of concealed and open carry, he points out that he is covering the door behind me and I am covering the parking lot for him, saying "I feel pretty safe about that." I realized at that point that I had become a sheepdog ${ }^{5}$ by association.

We talk a bit more about awareness and I ask what his favorite concealed firearm is. He says that he likes to maintain his "grandfatherly" image so he is careful to make sure he only carries fully concealable guns. He shows me his .380 that he had been carrying in his belt the whole time. A while later we end up on mass shootings again and he discusses the mass shooting in Las Vegas, in which a man and a woman had a shootout in a Wal-Mart after killing a police officer. Before this fatal conclusion, a CCW permit holder engaged them. Thinking that only the male was a shooter the permit holder approached and was subsequently killed by the female. Wade elaborates, "Ok? Good intentions, and that's a situation where I probably would have done the same thing he did. Ok, Here's the bad guy, ok [he puts his cup on the table as an indicator] you don't wanna turn your back on him, so I probably would have died in the same situation. But what I am sayin' is, and that goes with what I've said before, just have your CCW and a weapon doesn't make you invincible." I offered that we don't live in a John Woo movie. He replied "Nope. No. Hah! A tactical flight to the rear is better," we both chuckled at this comment.

Both excerpts from my field experiences above speak to a common theme throughout this project with respect to the rationale behind being proficient with and carrying firearms. I draw from those recent studies on concealed carry behavior in that concealed carry participants are enacting a citizen-protector model of citizenship which “...celebrates the protection of self and others as an everyday civic duty that is particularly compelling in contexts where alternative ways of asserting masculinity (such as being the sole financial provider for one's family) are eroding and the state's capacity to protect (through policing for example) appears precarious.’(Carlson 2015a: 19-20). Stroud (2015) and Light (2017) both address this identity work as well, albeit with different terms and

\footnotetext{
5 This term is most often credited to Colonel David Grossman, a police trainer specializing in lethal confrontation. In the metaphor there are sheep, people who simply go about their lives with little concern over the risks they face, assuming that others will take care of them; wolves, criminals who prey on the sheep, given the opportunity; and sheepdogs, those who make it their personal responsibility professionally or otherwise to protect the sheep from the wolves.
} 
emphases. In reading their work, examining my data, and seeing connections to the work dealing with masculinity, aggrieved entitlement and the growing alt-right it occurred to me that all of them are related versions of a broader form of identity work that allows people, generally white men but not always, to organize these different status characteristics in ways both novel and familiar to valorize the most relevant characteristics based on varying expectations.

I term this repertoire of action and presentation utilized in these groups' identity work messianic marginality. By this, I refer to a presentational strategy and resulting identities through which participants valorize or, at least, normalize, their personal characteristics, beliefs, values, and practices in response to feelings of increasing marginalization in an increasingly diverse United States. Accomplishing messianic marginality requires two interrelated tasks: expressing elements of identity that they feel are marginalized as well as those that are praiseworthy, and then linking these two types of element to one another and the broader society. Participants accomplish these tasks through storytelling, talk, and other actions that address the ways that they feel marginalized by outsider groups for their fears of violent crime, views on race, sex, and class, political beliefs, and enthusiasm for firearms, while also working to secure positive social positions for themselves prefaced on the civic and social value they assign to these traits. The messianic value of these traits is derived from the belief that they will allow participants to remain responsible, independent citizens rather than societal millstones, save local people in need should occasion arise, and, perhaps, save the rest of the country if need be. Which traits are linked to one another and which are centralized are core parts of the identity will vary by individual and group based on the local interactional expectations. For instance, in 
the case of organized white supremacists it is their whiteness for which they believe they are marginalized and that same whiteness that they valorize by promoting themselves as saviors of the race, based in their beliefs that white skin is associated with superior personal qualities. For some men, such as those in the men's rights movement or misogynistic groups, their masculinity is central; for citizen-protectors, it is their abilities to face lethal risks on behalf of those who cannot or will not do so for themselves. As I will show in chapter 2 , there is a comfortable fit between the paramilitary gun culture and much of the reactionary right when it comes to identifying the sources of decline in the United States, who is positioned to be marginalized by these changes, and the value of force in responding to them if need be.

The $10^{\text {th }}$ draws on all of these. They do so in ways that centralize their organizational capacities and the strengths of being in a group, and that allow them to remain distant in their own minds from those responsible for the decline in the United States as well as those whose responses to it are too extreme for their own tastes. It is an odd thing at first to consider the idea of armed militia men identifying others as too extreme but they do so and accomplish it to their satisfaction using a variety of rules for talking about and narrating their lives and activities.

Instead of locking the analysis into a theoretical framework in advance I approached this project with a theoretically-informed grounded approach (Glaser and Strauss 1967). I refer to my approach as theoretically-informed insofar as instead of developing a new theory of militia social activity based solely on the activity in the field I drew upon my experiences in the field as well as what activities participants engaged in and how they talked about and explained them and then asked which elements of my 
theoretical training had the greatest utility in explaining what was transpiring and how it related to broader social contexts. The resulting concepts became my sensitizing concepts The framework elucidated below serves as an organizational scaffold for the sensitizing concepts I found most valuable. The members of the $10^{\text {th }}$ are very much attuned to the 'outside' and limiting the theory or analysis to only what took place would break the link between their actions and the broader concerns to which they are responding. Finally, in this document I have striven to provide a combination of realist and impressionist tales (Van Maanen 2011) to capture an appropriate balance between thick description (Geertz 1973) and an analytic highlight reel (Brekhus 2003) approach to ethnographic analysis.

The self is multifaceted. In part, it is social. Others validate or reject our identities based on how well we fulfil the expectations they hold for us. Self is also internal. We experience visceral moments of doubt or elation when a performance begins to falter or exceeds expectations and it can be cerebral while we contemplate and rehearse performances both new and old. One may feel attachment to a particular configuration of symbolic and material resources as representative of an authentic self or one may feel an identity is simply another task to accomplish. Neither the performed social identities nor the accompanying senses of self-feeling, cynical or otherwise, are inaccessible psychological constructs or strictly deterministic effects of our social roles. Instead, they are social processes based in interaction and our awareness of self and the identities we fulfill are on-going accomplishments (Mead 1934). Goffman argues that the self is "a dramatic effect arising diffusely from a scene that is presented...", that a performer may very closely identify with the performance or adopt a more cynical position depending on the context, and that self-presentation is often a conscious or strategic effort to present an 
identity that "highlights the official values of the society in which it occurs" (1959:17, 35, 253). To understand the social qualities of the self and identity as people navigate and experience them, the everyday activities of people should be examined in detail as they occur in interaction.

With that said, leaving the performances of the $10^{\text {th }}$ isolated from the broader society would risk ignoring the degree to which they place themselves in real and imagined dialogs with the cultural outsiders, even when interacting in their most private settings. Stryker and Burke (2000:288) note that modern approaches to identity must account for two intertwined sets of influences: "the social structural sources of identity and the relations among identities and...on the internal, cognitive processes. They meet at the behavior that expresses identities, often in interaction with each other." Taken together with the paragraph above, for this project I approached my analysis of the identity work of the members of the $10^{\text {th }}$ with an eye for the material components of performances, the roles of cognition and self-feeling in relation to cultural expectations, techniques of selfpresentation, and the ways in which these relate to their social worlds in which participants situated themselves.

The everyday social activities of the militia take place within a nexus linking local conditions, favorable interpretations of history and historically significant changes common to participants in the paramilitary gun culture, and both real and imagined interactions with the like-minded and the hostilely skeptical. In line with Berger and Luckmann's (1967) pragmatic approach to everyday reality maintenance and construction, people engage with a number of different systems of meaning and make the most use of only those most relevant to the interactional and presentation demands of the in which 
situations they most often find themselves. Given the contentiousness of the national dialog surrounding weapons, most participants in the paramilitary gun culture, including members of the $10^{\text {th }}$, have a well-established repertoire of "accounts" (Scott and Lyman. 1967: 4662) for their activities that take the form of explanations for actions that they know outsiders consider "untoward" such as carrying a lethal weapon without any occupational requirement to do so, prepping food and emergency supplies, or participating in a militia group. Accounts here often take the form of explanatory stories and talk which justify their behaviors behavior but I argue they simultaneously serve as sense-making and selfpresentational tools. Beyond describing the world or the people in it, narratives are a crucial part of reality construction and identity construction that organize and normalize or trouble the relationships between time, characters, actions, situations, objects, and consequences according to generic conventions commonly shared among interactants (Bruner 1991). "Narrativity offers a way of conceptualizing identity that is neither universal nor essentialist, but rather temporally and culturally specific." (Hall, Neitz,and Battani 2003: 38). Furthermore, “... stories may serve as instruments of social solidarity, as tools of social protest, and as sites of identity navigation." (Katrial 2012: 278). Akinson and Delamont (2006) argue in a deliberately "polemical formulation" that there is a vital need "to focus on the social and cultural contexts in which such tales are told, and to recognize that all cultures and subcultures have narrative conventions." (165). Narratives and talk are therefore crucial to the ways in which the militia members accomplish messianic marginality. The bulk of the analysis in this work deals with what I simply term the narrative genres utilized in militia identity work. I broadly define narratives as not only formulaic stories with distinct events and temporal ordering but also forms of talk that rely 
upon the audience filling in blanks with the shared assumptions and beliefs required to position themselves and the speaker relative to other people, times, places, events, and possibilities both real and imagined germane to the identity being presented. This leaves the issue of identifying the resources used in such constructions.

Tying these sensitizing concepts above together, I share perspective of Gubrium and Holstein (2000: 161-171) that given the preponderance of overlapping statuses, environments, systems of meaning, and interactional spaces that the self is narratively realized in particular local contexts that draw on a variety of ordinary resources comprised of biographical, material, and symbolic equipment that exists at both the levels of specific local culture and at societal-level culture. Ordinary resources help to ensure that the identity a participant narratively constructs and presents is taken by the intended audience to be authentic because the elements and the organizing strategies deployed are commonly available to the both the presenter and the audience. At the same time, people do not have unlimited freedom in their use of ordinary resources as the understandings and expectations common to the social environment set limits on what can be drawn upon and how resources can be organized. To sum up, my analysis attends explicitly to the use and construction of narrative and talk in these contexts in order to explore and document precisely the narrative and talk used to frame the other practices that take place within and around this militia group in ways that macro-level studies do not yet adequately address.

\section{Data and Analysis}

Given the need for on-the-ground detail in the data, for this project I proceeded with a mixed qualitative methodology combining extensive field work, semi-structured interviews, and content analysis applied to these data as well as documents produced by 
the $10^{\text {th }}$ for training and advertising purposes. A number of scholars of the militia movement and the greater far-right have called for greater attention to the variation and sophistication found among these movements and groups as well as the ways in which they relate to more mainstream social and cultural environments (Freilich, Pienik and Howard 2001; Blee and Creasap 2010). Aho (1990), Mitchell (2002), Kimmel (2013), and Kraska (1996) have all demonstrated there is considerable value in qualitatively approaching members of such subcultures in a direct fashion and participating in at least some of their activities. My work was further informed by contemporary qualitative and ethnographic approaches that demand reflexive attention to several overlapping elements: analysis as an ongoing process Wolcott (1994), attention to variety in the uses of narrative and ordinary resources (Maynes, Pierce, and Laslett, 2008, Holstein and Gubrium 2000, 2009; Gubrium and Holstein 2001), reflexive interviewing, coding, and presentational approaches (Weiss 1994, Roulston 2010, Riessman 2008 and a reflexive approach to the changing, reactive natures of field work, notes, and analysis (Rubin and Rubin 2005, Cerwonka and Malkki 2007, Emerson, Fretz, and Shaw 2011). As such, I openly introduced myself to the group's leaders via phone in late 2014, communicated with them to arrange a meeting to discuss my access to the group in early 2015 and, upon receiving access to their proceedings later that same year I introduced myself and my project to each person present at the monthly staff meetings. In this process I relied on my statuses as a white, heterosexual, married, employed firearms enthusiast to build rapport with participants despite my statuses as an academic with progressive political commitments. I am confident that many of the less appealing comments, stories and ideas relayed to me, such as Charles' affinity for 'messing 
with people ${ }^{6}$, using bestiality-related humor, were a function of being trusted as an insider on the basis of my forthright approach and regular participation in their activities. While engaged in participant observation I took notes in a variety of pocket notebooks, writing quotations and interactions down in as close to real time as possible, which was easier than one might think given the amount of sitting and writing that takes place during staff meetings and trainings ${ }^{7}$. Through 2017 I would return home and wherever possible type out as full an account as memory allowed after leaving the field, including my own analytic notes, feelings, and impressions both positive and negative in order to explore and document at least part of the insider/outsider dynamics that allowed me access to the group in the first place.

One of Blee's (2007) most important contributions to this line of research was her decision utilize life-history style interviews in order to diminish the chances that respondents would simply explain their positions and experiences using common tropes and clichés. In line with this risk, Blee has continued to strongly advocate for ethnographic approaches to these issues on the basis that:

"from the outside, extremist right-wing movements appear to coalesce around ideas and ideologies, but internalist studies show that culture is also key to the attraction and durability of the far-right. Music, clothing, style, bodily disciplines, ritual, identity, and performances are critical for recruiting new members and solidifying the commitment of participants in far-right groups...Such groups need to convince recruits that extremist, even bizarre, ideas are valid and that a movement around these ideas is

\footnotetext{
${ }^{6}$ Messing with people amounts to engaging in verbal or physical action that the performer knows will be provocative to the audience to elicit a response. Eliciting the response, whether a positive one or a negative one is an end in and of itself but the intensity and direction of the response is taken as a gauge of how 'likeminded' the audience is, whether they are easily offended (which is a negative quality), and serves as a lowlevel status game in which the provocateur gains status relative to the person they successfully provoke, at least in their own estimation. Less academically, it is simply one of the many forms of trolling.

${ }^{7}$ Notes were also easier to take given the degree to which the leaders of the group allowed me to participate or simply observe as I felt need dictated.
} 
feasible...by creating bonds among members and normalizing the ideas and actions of the far-right." (ibid:124).

Taking her advice, my interview schedule of twenty potential questions and thirty-five potential follow-up items was designed to aid me in building rapport and encouraging respondents to speak at length about topics of interest to them in the context of walking me through different processes in their lives germane to the topics at hand. Rather than a strict guide, in most cases the schedule was a backup for lulls in conversation or to follow up on concepts that came up organically.

The data for this project comes from three sources: formal and informal interviews with militia members, extensive field notes from militia staff meetings, training events, as well as gun shows and a gun store, and documents produced by the militia in the forms of advertisements for their group, the information available on their website, and the various handouts they distribute for training or advertising purposes. The last category in particular was a valuable source of information on messianic marginality in the militia as their advertisements are designed to appeal to others within the paramilitary gun culture who they anticipate will hold similar beliefs and values but ties them into a more narrow, organized framework germane to militia activity. Over the course of the project I have solicited any and all documents that the militia leaders and members were willing to furnish although I most often received them the same way as other members - at training events as part of the course work for the day. In all, there are thirty-three militia-produced documents ranging from one to thirteen pages (as well as four maps) that have been used in this project in either the analysis or interpretive work.

The field notes are the most extensive data set used in this project and allowed me to identify several important narratives in militia messianic marginality. At the initial 
meeting with the commanding officer of the group I had asked if I might be permitted to take notes during the meetings and he admitted that he was not certain but expected that it would be fine if people knew who I was and my purpose in attending the group's activities. This was overwhelmingly the case throughout the twenty-three staff meetings and nineteen training events I attended between March 2015 and October 2017. Not counting time spent in interviews (eighteen hours and forty-eight minutes) or time at gun shows and stores (roughly twenty hours at shows and twenty hours at the store) the data includes twohundred hours of fieldwork. Staff meetings and training events were exceptionally easy to document compared to other field situations. Despite a rare exception, I was able to document staff meetings as they occurred as virtually every well-prepared attendee has in front of them a notebook and writing instrument to make notes on their upcoming teaching responsibilities, deals on food, gear, and ammunition for their "preps" more difficult to take at gun shows and the gun store and, given the degree to which these notes were fractured and that they are not the focus of this project they were not formally coded. In the analysis below I rely on them primarily as reference points for the broader paramilitary gun culture.

Interviews are the foundation of my analysis as they introduced several of the central themes and elements of messianic marginality, reinforcing and challenging my own interpretations repeatedly. Taking my cues from recent studies of concealed carry permit holders as well as literature on organized hate groups and militias I pursued semi-structured

\footnotetext{
8 "Preps" is shorthand for preparations which most commonly referred to personally procured, owned, and stored supplies meant to preserve a militia member and the members of their family through emergencies of varying sorts. As per the group's by laws "Members shall strive to be self-sufficient at all times; they must be able to sustain themselves and their families in times of crises or national emergency. A 90-day supply of dry or canned food is minimal with other essentials." (Militia Bylaws, 2014).
} 
interviews in which I asked initial questions and followed the lead of participants. It is a weakness of the study that most of the militia 44 participants I met over the course of the project did not wish to participate in formal interviews with me for reasons of distrust, privacy, or time. Despite references to an African American member of the $10^{\text {th }}$ everybody I met was white and the overwhelming majority were men. Save myself, Clint, Harold, and Henry, as well as a few occasional visitors most participants are in their 40s, 50s, and 60s, heavily favoring the latter two categories. The average age based on the ages interviewees provided is 61 . Table 1 below identifies the three ideal types of member in the group. 
Table 1: Three Types of Members in the $10^{\text {th }}$

\begin{tabular}{|c|c|c|}
\hline Core Members (10 members) & Regular Members (10 members) & $\begin{array}{l}\text { Peripheral Members ( } 24 \\
\text { members) }\end{array}$ \\
\hline \multicolumn{3}{|l|}{ Membership qualities } \\
\hline $\begin{array}{l}\text { Voted in by members/votes on } \\
\text { new members regularly }\end{array}$ & $\begin{array}{l}\text { Voted in by members or likely to } \\
\text { be/votes when present }\end{array}$ & $\begin{array}{l}\text { Not voted in/not likely to be } \\
\text { Does not or cannot vote on } \\
\text { members }\end{array}$ \\
\hline Attends most meetings & $\begin{array}{l}\text { Attends meetings when } \\
\text { interested, asked, or able }\end{array}$ & Only attends a few meetings \\
\hline Long term membership & Mixed term membership & Short term participation \\
\hline Formal and informal Leaders & Sometime Leaders & Not leaders but may know one \\
\hline \multicolumn{3}{|l|}{ Equipment } \\
\hline Tends to have most gear & $\begin{array}{l}\text { Tends to have less gear but } \\
\text { building up }\end{array}$ & $\begin{array}{l}\text { Little gear other than weapons } \\
\text { and camouflage }\end{array}$ \\
\hline $\begin{array}{l}\text { Often have surplus of items to } \\
\text { share }\end{array}$ & $\begin{array}{l}\text { Less commonly has enough to } \\
\text { share }\end{array}$ & $\begin{array}{l}\text { Least commonly has enough to } \\
\text { share }\end{array}$ \\
\hline $\begin{array}{l}\text { Gear is considered in terms of } \\
\text { 'realistic' concerns like weight, } \\
\text { size, practicality, likely } \\
\text { scenarios }\end{array}$ & $\begin{array}{l}\text { Gear is considered but still } \\
\text { developing specific criteria and } \\
\text { needs }\end{array}$ & $\begin{array}{l}\text { Gear is primarily mix and match } \\
\text { with less consideration of } \\
\text { weight, practicality, likely } \\
\text { scenarios }\end{array}$ \\
\hline $\begin{array}{l}\text { Engaged in prepper work } \\
\text { Complete uniform }\end{array}$ & $\begin{array}{l}\text { Beginning to engage in preps. } \\
\text { In stages of completing uniform } \\
\text { but wears what is present }\end{array}$ & $\begin{array}{l}\text { Unlikely to have prepped, } \\
\text { beginning stages of uniform }\end{array}$ \\
\hline \multicolumn{3}{|l|}{ Approaches to Other people } \\
\hline $\begin{array}{l}\text { Contact point for outsiders and } \\
\text { interested parties }\end{array}$ & $\begin{array}{l}\text { Occasionally deals with } \\
\text { outsiders and interested parties }\end{array}$ & $\begin{array}{l}\text { Seldom engages with outsiders } \\
\text { or interested parties }\end{array}$ \\
\hline Teaches most of the classes & $\begin{array}{l}\text { Teaches when called upon to do } \\
\text { so by leadership }\end{array}$ & Seldom teaches \\
\hline $\begin{array}{l}\text { Most likely to work on militia } \\
\text { needs outside of meetings }\end{array}$ & $\begin{array}{l}\text { Will work on militia activities } \\
\text { outside of meetings if tasked to }\end{array}$ & $\begin{array}{l}\text { Unknown, presumed unlikely to } \\
\text { work on militia needs }\end{array}$ \\
\hline $\begin{array}{l}\text { Known to be in contact with or } \\
\text { participate with other groups }\end{array}$ & $\begin{array}{l}\text { Participates in other prepper and } \\
\text { survivalist or religious groups }\end{array}$ & $\begin{array}{l}\text { Flirting with variety of groups } \\
\text { and ideologies. }\end{array}$ \\
\hline $\begin{array}{l}\text { Tends to moderate more extreme } \\
\text { talk about conspiracy, race, sex, } \\
\text { government, or violence }\end{array}$ & $\begin{array}{l}\text { Will get excited about } \\
\text { conspiracy, race, sex, } \\
\text { government, or violence but only } \\
\text { when recently exposed or } \\
\text { concerned }\end{array}$ & $\begin{array}{l}\text { Most likely to get moderated in } \\
\text { extreme talk about conspiracy, } \\
\text { race, sex, government, or } \\
\text { violence }\end{array}$ \\
\hline $\begin{array}{l}\text { Most sensitive to stigma from } \\
\text { outsiders/ understands basis }\end{array}$ & $\begin{array}{l}\text { Sensitive to stigma but less } \\
\text { understanding of basis/ more } \\
\text { focused on how wrong outsiders } \\
\text { are }\end{array}$ & $\begin{array}{l}\text { Most likely to find stigma } \\
\text { egregiously offensive and } \\
\text { symptomatic of aggression or } \\
\text { persecution/ not sensitive to } \\
\text { basis }\end{array}$ \\
\hline $\begin{array}{l}\text { Aware of shortcomings of group } \\
\text { and members in terms of } \\
\text { reliability, capability, and } \\
\text { expectations }\end{array}$ & $\begin{array}{l}\text { Less aware of shortcomings of } \\
\text { group and members but open to } \\
\text { the conflicting expectations }\end{array}$ & $\begin{array}{l}\text { Least aware of groups' } \\
\text { shortcomings in terms of } \\
\text { capabilities but very sensitive to } \\
\text { expectations }\end{array}$ \\
\hline $\begin{array}{l}\text { Most realistic about what group } \\
\text { can accomplish in terms of } \\
\text { public activities and in } \\
\text { emergencies }\end{array}$ & $\begin{array}{l}\text { Closer to core members than } \\
\text { peripheral }\end{array}$ & $\begin{array}{l}\text { Least realistic about what group } \\
\text { can accomplish in terms of } \\
\text { public activities and } \\
\text { emergencies }\end{array}$ \\
\hline
\end{tabular}


Slightly more than half of the participants over the course of this project did not show up more than a couple of times or appeared at intervals such that I rarely encountered them despite my reliable attendance. Rather than a weakness of this project it reflects the dynamics of the unit directly. Core members and regulars frequently complained about lackluster attendance, occasionally pointing to me as an example of someone who managed to reliably attend despite not being a "real member" of the group. Additionally, after contacting two leaders repeatedly for access to the group I did not want to push peripheral members who already distrusted me for interviews until they were generally familiar with me. Those caveats aside, I secured formal interviews with nine members of the group most of whom (77\%) were leaders and core members with the remaining two being a regular and a new recruit respectively. Five of these interviews spanned between two and three hours, three more were just shy of two hours, and one lasted for a forty-minute lunch period during a training event. Of these data, I was permitted by participants to record six of these interviews in full and transcribe them while the remaining three were transcribed as they occurred and with missing information transcribed immediately thereafter. The data skews towards the key members considerably but in light of the fact that such participants are overwhelmingly responsible for shaping the group and its practices their views are valuable data indicative of the main participants' views and identities.

In concluding this introduction, I will present on outline of the remaining chapters. In chapter two I will trace an outline of the economic, social, and cultural changes beginning in the late 1960s that led to the legitimacy and popularity of the symbolic and material ordinary resources used across the different paramilitary gun culture environments, including the militia movement in both the 1990s and today. In brief, the 
changing leadership of the NRA helped in the development of a second amendment fundamentalism that occurred in the late 1970s and continues to this day. This combined with a growth in popularity of military weapons, terminology, and cultural forms that developed during the Cold War and served as a refuge for men and women who felt their social positions eroding as a result of neoliberal economic policies as well as changes in the racial and sexual status hierarchies with which they were familiar. The sense of marginalization many white men began to feel has been maintained by media outlets and politicians that emphasize these perceived encroachments and encourage a politics of resentment. Part of the response has been the continued push for liberalization of firearms regulation, which is often framed in terms of constitutionality, risk from crime, and distrust of the government and militarized police but expressed in terms of personal responsibility and that creates a messianic identity for white men in particular as the de facto protectors of society.

Chapter three will detail the structure of the $10^{\text {th }}$ and analyze its public documents designed to advertise the group to outsiders. Core members and regulars maintain the group and do most of its work while peripheral members show up a few times and then tend to vanish. I argue that the majority of the lattermost group are not willing to or comfortable with the rules regarding messianic marginality in the militia as they are organized by the core members. These rules are embedded in the narratives and talk in their public documents and performs a messianic marginality designed to appeal to other participants in paramilitary gun culture by presenting the group as a public service designed to help people in the local areas and distancing themselves from groups that, were they to be associated with them, might further marginalize the $10^{\text {th }}$ or its parent organization. 
Chapters four and five will each deal with the identity work, ordinary resources, and specifics of the militia unit during their staff meetings and training sessions respectively. These are data driven chapters in which thick description and interview material will be presented via a combination of detailed thick description and analytic highlight reel formats. These presentations will demonstrate to utility and importance of messianic marginality as it relates to the ways in which participants at these locations navigate their selfhood with respect to race, class, and citizenship relative to one another as well as people they see as threatening. An important contribution of these chapters will be demonstrating that the increasingly private settings of these different sets of practices and identities mean that presentations in different settings sometimes conflict with one another as well as with the most public presentations as well as the interpretive expectations of the core members.

In the concluding chapter, I will explore the larger social consequences, both potential and actual, of these practices and how they position participants for political and social action using additional ethnographic data from a local firearms retailer and gun shows. One of the ongoing concerns that has become especially pronounced is the increasing risks presented by the ways in which ordinary resources common to this cultural group overlap with elements of the political right that have become more overtly racist and radical as well as the continued delegitimization of the government on these bases. In the short term, some of these combinations have already led to terroristic activities, as they have in the past, and a loss of faith in democratic processes. In addition to summarizing the findings of the project, its contributions to the field, its shortcomings, I will suggest future directions for similar work. 


\section{Chapter 2}

"Who wants to have to apologize to their wife or kids that they couldn't protect them?":

Ordinary Resources, Narrative Genres, and Messianic Marginality in the Development of Paramilitary Gun Culture. 
"Harry Thompson was awakened as two of his children leaped across his bed, terrified. 'Daddy, there are two men climbing into our room,' one said. Thompson picked up a handgun and confronted one burglar who, despite a warning shot, came at him until the homeowner wounded him and held him for police. Thompson said that he is disabled after being mugged seven times in four years." (National Rifle Association 1986, cited in O' Neill, 462: 2007)

This led to a downtrodden but significant discussion pertaining to how the events in [a sizeable city that had a recent series of protests in which police exercised levels of force that met with further public outcry] have impacted law enforcement. Nobody at the meeting immediately problematized the behavior of police. Instead they focused on the idea that nobody would want to be a police officer before long because 'doing their job' could get them in permanent trouble...Arthur and Brock both suggested that police recruiting is down because of the public criticism following events like these. Another topic that members brought up was that it already takes police too long to get to a crime that is occurring. Arthur summarized, "when seconds matter, police are minutes away," and everybody seemed to approve of this sentiment. After a little while (no more than a minute or two of reiterating the importance that people have the capacity to defend themselves and collective agreement) he went on to ask, "who wants to have to apologize to their wife or kids that they couldn't protect them?" (Author's fieldnotes from a militia staff meeting, August $10^{\text {th }}, 2015$ )

This chapter will establish the broader trends in the civilian gun culture from which my militia participants draw resources, learn the strategies for narratively organizing them and presenting them, and perform messianic marginality. Given the realities of gun violence it may seem beside the point to focus on the talk and storytelling around guns. If one stops to consider how very many firearms are there are in the United States and how little of the activity depending on them involves firing them it becomes quite clear that the bulk of the social interaction involving arms is, in fact, talk and storytelling. There are several genres of speech and storytelling I will define throughout this dissertation; a summary table can be found at the conclusion of this chapter. Each narrative genre will be broken down in terms of its form, referring to the ordinary resources and organizational rules associated with it and its functions, referring to the interactive and identifying 
purposes it serves in messianic marginality. I would like to note here that these genres are not used in isolation from one another in actual talk and storytelling. They are analytic constructions based on my analysis that serve to isolate specific configurations of ordinary resources that the participants used to perform certain aspects of messianic marginality. In practice, members of the 10th combine different genres with one another to suit the needs of ongoing interaction based on who is present, the purpose of the interactional space, what aspects of messianic marginality are relevant, and the degree to which the proceedings are public or limited to other members. My foci in this work should not be taken by readers to in any way to diminish the injurious consequences following their use but to instead point out that even the significance of murders, suicides, and mass-shootings relies on the talk and stories surrounding them more than the physical realities of the events.

As per my points in chapter one, the United States is the only nation among its peers commonly characterized as a gun culture. There is backing for the claim. Other nations have firearms, militaries, police, and criminals who arm themselves with modern firearms but by most empirically reliable accounts the US far exceeds other similar nations when it comes to both private firearms ownership and rates of firearms-related injuries and deaths including accidents, suicides, and homicides associated with both privately owned weapons as well as those utilized in militarized policing. That there should be a significant gun culture under these conditions is unsurprising although leaving the analysis at the physical realities of the situation would be a dramatic oversimplification. Even the polarized public debates surrounding only the material realities of firearms and the harm they can, and do, produce, fail to adequately address symbolically and socially potent, with significance that extends far beyond their mechanical qualities. 
As with the rest of social life, the cultural practices, symbolism, and significance of firearms in the United States are all complicated by the fact that people infuse even mundane daily activities with meaning that best suits their local sense-making needs. It is a rare person that cannot imagine the wider world and their relations to it in at least vague outlines. It is also common for each of us to at times extend the significance of ourselves, our lives, and our social worlds forwards and backwards throughout time and space. Most of the time, however, it is sufficient for us to focus on our local, immediate social worlds and consider the rest of the world only insofar as it intersects with our own activities. That firearms, then, should have such profound significance is an especially vexing, albeit fascinating, phenomenon given my focus on the importance of localized daily activity as the main nexus for identity work. Reiterating an earlier point of information, contemporary estimates of households with a firearm in them and individuals who personally own a gun suggest that the idea of guns as an everyday part of life would likely seem strange and quite dangerous to members of roughly half to two-thirds of American households (Azrael, Hepburn, Hemenway 2017). Compared to previous generations, average U.S. citizens are less likely to hunt animals for food and sport, have to defend themselves from dangerous animals during travel, and despite claims to the contrary from some segments of the populace, generally depend on professional soldiers or police to utilize state-legitimized violence to defend them should ever the need arise. It seems that most gun owners hold largely to these trends with the exception that there been a growing emphasis on firearms as a prophylactic measure against criminal violence, $76 \%$ of American gun owners cite personal protection as their motivation for ownership (ibid). These trends reflect common views among my participants regarding the nature of good government, citizenship, and 
personal responsibility; views that they also feel put them at odds with an outside society demanding they abandon identities based in a world they grew up in and understand for new identities based in a world they believe is in moral, spiritual, and social decline. In sum, while the material consequences surrounding firearms are a crucially important matter of study that will require a great deal of additional investigation in the coming years, scholars will simultaneously need to further our understandings of how the comparatively small populations of people who do own them go about integrating firearms into their everyday lives, to what representational ends firearms are put, by whom they are thusly used, and how these tasks are accomplished.

To grasp the social significance of firearms under such conditions one must attend to the ways that people relate to them, situate those relations in time and space, and interact with others on these bases using resources common to their social positions and peers. Germane to this point the many varieties of firearms-related practices have in recent decades come under the sway of cultural and market forces that encourage the use of semiautomatic firearms. Paramilitary gun culture is a crucial analytic pillar in this project and refers to a shared collection of material objects not limited to firearms, organizing narratives, identity strategies, practices, and evaluative standards through which people assign moral, civic, and practical value to acquisition and training with weapons. It can be articulated through shooting sports, in the context of acting as a profession agent of state power, and in idealized forms of citizenship that many of my participants tie to carrying personal firearms and serving in the militia unit.

Productively investigating the dominance of paramilitary gun culture over other current firearms-related practices, including those of members of the $10^{\text {th }}$, requires an 
accounting of how changes in legal, political, and cultural domains of participants and their responses to them have coalesced into their specific forms of identity work. I argue that paramilitary gun culture is an outgrowth of changes in the masculinities accessible to primarily white men in the context of broad national changes in the economic, racial, and sexual hierarchies in the United States as they are filtered to down to local levels. At local level, such as the mostly small towns from which members of the $10^{\text {th }}$ hail, the problems social justice advocates seek to address are largely invisible to participants, or simply not considered problems. Consequently, the boundaries between public and private life and visibility and invisibility have shifted too. These changes in the social positions of men and in their abilities to maintain the combinations of privacy and visibility to which they have grown accustomed helped to produce a renewed valorization of masculinities and identities based in the ability to defend oneself and subordinate others against lethal threats. This most recent iteration of the associations between armed men, threats, and protecting others was initially re-popularized through the necessity of militarizing domestic policing in service to the 'wars' on crime and drugs, as well as the militaristic talk, stories, and worldviews that helped generate support for these policies. These trends also became closely linked with a conservative politics based on leveraging aggrieved reactions to the changes outlined above into a shared sense that the United States must be restored to some earlier, more authentic state that has been displaced. Throughout the last several decades these revalorized, protective masculinities and the weapons they depend on became increasingly commercially available and far less dependent on state sanctioning for their legitimacy beyond increasing liberal laws surrounding concealed-carry and lethal selfdefense. Subsequently, among people sympathetic to these views, this helped produce the 
resources for admirable, respectable identities for anybody willing to arm themselves as a form of taking responsibility for protecting themselves and others in a time of societal decline. In this type of messianic marginality, participants feel that as responsible citizens they ought to be respected and trusted as they prepare to step in where incompetent or corrupt governments and a disintegrating society both fail to provide for the safety and security of others who cannot or will not take care of themselves. Paramilitary gun culture therefore represents a significant avenue by which people integrate firearms with hierarchies of race, sex, and gender as well as politically energize and express these relationships in daily identity work.

The identity resources utilized in paramilitary gun culture consists of three major families of material: first, firearms as valuable, maligned tools of personal and public safety; secondly, sets of dichotomous social categories including urban/rural, bad citizen/ good citizen, irresponsible/responsible, liberal/conservative, female/male, nonwhite/white, and non-Christian/Christian in which all of the latter categories are linked together and valorized (explicitly or implicitly) relative to the former categories; and finally, the broadly shared organizing principles used in talk and storytelling used to accomplish positioning these objects in relation to one another. These resources are combined in numerous ways participants in this study but there are several overarching patterns and rules which serve as a shared orthodoxy for appropriate identity work. The orthodoxy relies on understanding of a particular vision of the role of guns in American history, against whom and for what reasons firearms should be used, and the people whom participants see as belittling, devaluing, or actively sabotaging the identities and ways of life suggested by these organization strategies. 


\section{"It's not an assault weapon until you assault someone with it.": Semi-automatic Firearms and Paramilitary Gun Culture}

The quote in the subheading above is something that I overhead during a gun show in a major city about two hours from my home in central Missouri. I have also heard it now and then from participants in the militia. It is one of the many quotable memes that circulate throughout paramilitary gun culture. Generally speaking this meme and others, such as "I carry a gun because a cop is too heavy," and "There is nothing in this house worth dying for," serve to tersely recapitulate shared views in which the devices, practices, beliefs, and identities associated with paramilitary gun culture are indicative of personal and social responsibility in a dangerous world. Although such quotes fail to capture the complicated nature of the empirical relationships between firearms, crime and self-defense they encapsulate the importance that many participants in paramilitary gun culture, including members of the $10^{\text {th }}$, place on the acquisition and presentation of knowledge pertaining to firearms as a means of demonstrating to one another their statuses as responsible, capable, patriotic citizens who are fit to weigh in on firearms and their consequences. In the first instance above, the central point is that the designation "assault weapon" is legally ambiguous, of contested origins, and, many participants believe, a product of gun control groups who seek to make others afraid of weapons and the people who own them. Some go on to suggest this is a means of eliminating private firearms ownership, leaving the whole of the population susceptible to tyranny and oppression. Built into either vision is the assumption that weapons are not inherently dangerous. Instead, participants believe that those who wield them are the point of articulation where any weapon may become dangerous to specific people and, depending on the moral character of the user, under what conditions the threat of violence is morally or legally appropriate. Any mechanical qualities 
of a firearm, whether the lethal potential of the projectiles it is designed to fire or how many it can fire between reloads, exist apart from the human operating it until they are assigned a moral character in the context of real or imagined uses of the weapon - until they are put into talk or a story. In cases of criminal violence, the criminal is to blame and in cases of violence judged to be virtuous the weapon only enhances the capacities of the wielder to behave responsibly. In the spirit of pithy summaries: a good guy with a gun creates morally appropriate danger for bad guys who, with their own guns, create morally inappropriate danger for good guys. Such understandings and presentations are also important in intragroup comparisons to those who do not understand, appreciate, or take seriously these nuances 9 .

For many outsiders and particularly those concerned with the amount of harm that modern weapons can cause in the hands of a motivated gunman, this position is profoundly frustrating. It frequently seems a callous rhetorical dodge with the aim of dismissing legitimate concerns in service to protecting the interests of a diminishing population of enthusiasts and manufacturers. I am certain that for some marketers, lobbyists, and media personalities it is precisely this. For the members of the $10^{\text {th }}$ and many of the other people I interacted with over the course of this project these are not dodges but expressions of deeply-felt identities and feelings of persecution which fit squarely into a worldview in

\footnotetext{
${ }^{9}$ Much of the ineffective conversation and debate surrounding firearms, and particularly after mass shootings, centers on the technical capabilities of the firearms available to the public. On the one hand, critics and those who are skeptical of the value of private firearms ownership often point out, correctly, that these commonly available weapons are capable of firing many projectiles designed to cause grievous injuries in relatively short order which makes them particularly dangerous as implements of violence-righteous or otherwise. Every so often a politician or public figure will refer to the general category of semi-automatic firearms weapons as "automatic" or "military" weapons. In response, gun enthusiasts argue that critiques centered on technical information are misinformed at best - most often a failure to know the minute differences between military and civilian versions of the weapons - and fundamentally mischaracterize these weapons and those to whom they are important. This has the effect of diminishing these arguments and concerns as ignorant, fearful, and unworthy of serious consideration.
} 
which firearms, their owners, and people who share their characteristics are constantly under attack or, at the very least, not respected by people that might otherwise benefit from their knowledge and skills.

I call this genre Technical Specifications or Tech Specs. Technical Specifications take the form a detailed presentation of intricate knowledge about the object, which can be a firearm or other gear, its utility, shortcomings, and interesting qualities. The genre can be broken down into Gun Talk or Gear Talk depending on the object under discussion. The genre serves to identify the speaker as responsible and knowledgeable, marking them as a trustworthy owner of that object. This serves to render the speaker messianic compared to others because of their personal efforts to develop these competencies and is meant to downplay the marginalizing effects of such dedication and an object's association with dangerous people or situations. A within-group subgenre also exists, Show and Tall, where a cultural insider presents a device to other insiders, demonstrates their knowledge of it, and allows the audience to handle the object. This is a convenient segue, with respect to both the uses to which members of paramilitary gun culture and the $10^{\text {th }}$ put this genre it is crucial to identify that it is prefaced on a material reality: the availability and marketing of semi-automatic weapons to the civilian population in the United States. While seemingly obvious, the proliferation of this style of firearm as not only available but preferred by many firearms enthusiasts is a crucial base from which the rest of paramilitary gun culture has developed.

It is informative to start with manufacturing data supplied by the US Department of Justice and the Bureau of Alcohol, Tobacco, Firearms, and Explosives. Regardless of who owns these weapons and what characteristics they possess as individuals and as a 
group, the raw facts of which weapons are produced and sold speak to the demands that manufacturers are encouraging and then answering. I assume that regardless of the balance of demand as manufactured or natural, the character of the weapons being produced tells us what capabilities are expected of these weapons and how they have changed over time. Figure one reveals two of the central trends in firearms as a material resource since the mid-1980s. First, the number of firearms manufactured per year has significantly increased since 2008. Secondly, the data clearly demonstrate the growing accessibility and popularity of semi-automatic firearms, most clearly handguns, which are a central material component of paramilitary gun culture. ${ }^{10}$ Federally licensed firearms manufacturers are required by law to report information about production and exports each year. Here we see the number of firearms manufactured in the US increased through the late 1980s, dropped, rose to another high point in the 1990s, then dropped until 2001 after which is has been rising consistently. Of those listed, pistols and rifles are of special interest with respect to paramilitary gun culture insofar as these firearms are most similar and in some cases virtually identical to those used by soldiers and police ${ }^{11}$.

\footnotetext{
${ }^{10}$ Bear in mind that these data do not include firearms manufactured for the U.S. military but it does include those manufactured or purchased for domestic law enforcement. In looking at these numbers it is also important to bear in mind that firearms are durable goods, meaning that they tend to remain operational and in circulation for long periods of time; this means that many of the millions being produced and sold in the US are not merely replacing those that have worn out, broken, or otherwise been rendered inoperable; they are being added to the existing population.

${ }^{11}$ According to the definitions utilized in the required paperwork, a pistol is designated as a "weapon originally designed, made, and intended to fire a projectile (bullet) from one or more barrels when held in one hand, and having (a) a chamber(s) as an integral part(s) or permanently aligned with, the bore(s); and (b) a short stock designed to be gripped by on hand and at an angle to and extending below the line of the bore(s)." A revolver is "a projectile weapon, of the pistol type, having a breechloading chamber cylinder so arranged that the cocking of the hammer or movement of the trigger rotates it and brings the next cartridge in line with the barrel for firing." Rifles are defined as weapons "designed or redesigned, made or remade, and intended to fire from the shoulder, and ... to use the energy of the explosive in a fixed cartridge to fire only a single projectile through a rifled bore for each single pull of the trigger...". While shotguns have multiple military, policing, and hunting applications they do not hold the same prestige in paramilitary gun culture as do semi-automatic handguns and rifles. The miscellaneous category includes pistol grip firearms, starter guns, and mechanically significant portions of firearms like frames and receivers which cannot operate
} 
FIGURE 1: Firearms Manufactured in the US, 1986 - 2015.

Data from Annual Statistical Update of Firearms Commerce in the United States, Department of Alcohol, Tobacco, Firearms and Explosives, 2017.
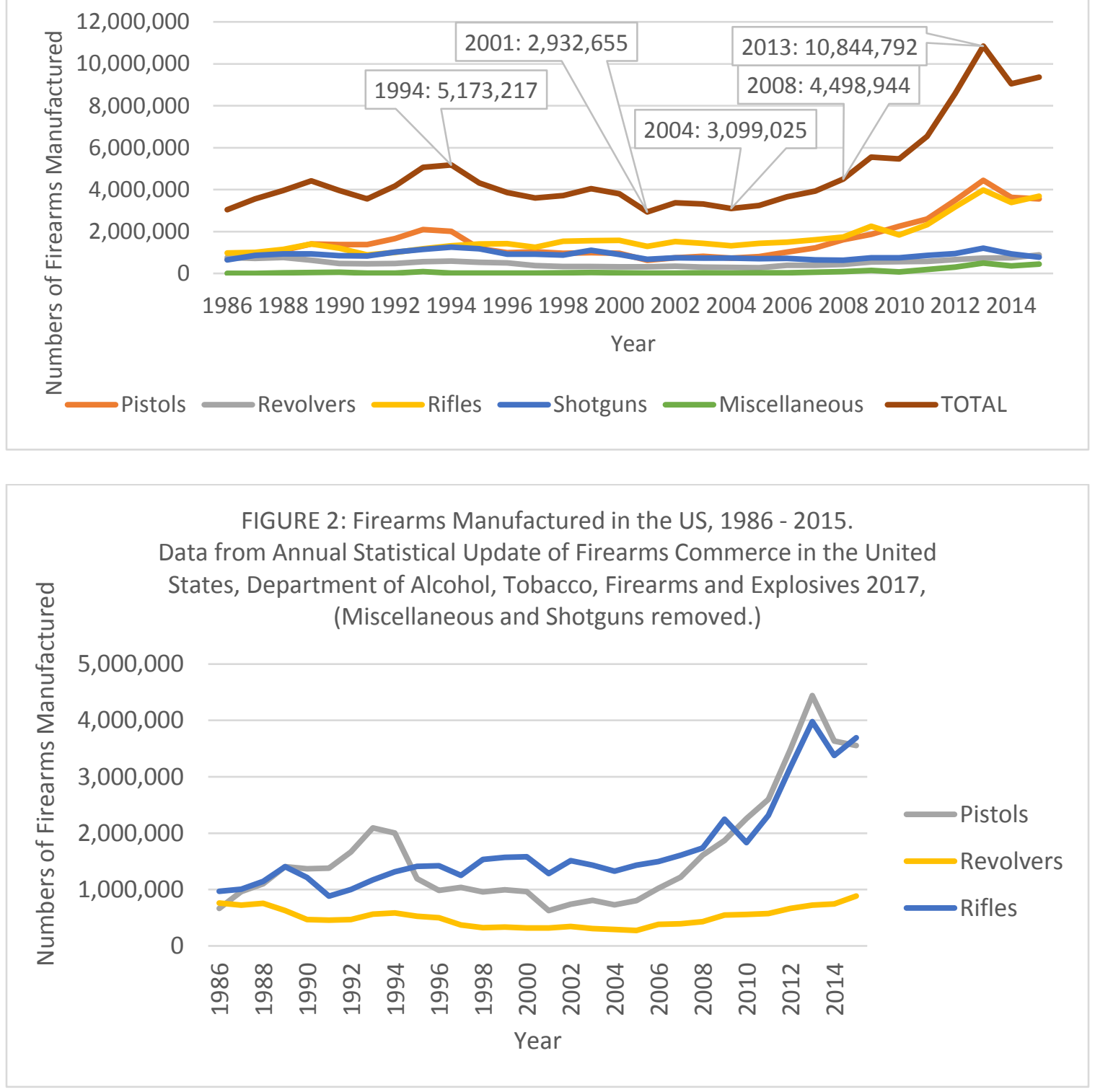

Another significant trend is clearer in Figure 2: the bulk of the growth in firearms has been centered on pistols and rifles. Quite simply this means that since the planned expiration in 2004 of the Public Safety and Recreational Firearms Use Protection Act,

as firearms unless assembled. For simplicity, I have removed shotguns and miscellaneous categories from figure 2 . 
colloquially referred to as the assault weapon ban and a subpart of the Violent Crime Control and Law Enforcement Act of 1994, the overwhelming majority of firearms manufactured have been semi-automatic handguns and rifles. These are precisely the sorts or armaments that the legislation largely prohibited from civilian ownership and sales, in part, due to their utility for criminals and mass shooters as they are generally quite similar to the weapons used by the police and military. The primary difference between those weapons in a civilian market and those in a military and police market is that the latter are typically capable of firing continuously as long as the trigger is depressed while the former are not legally permitted to do so save for very specific circumstances. Examining the export and import information presented in the figures below yields additional information.

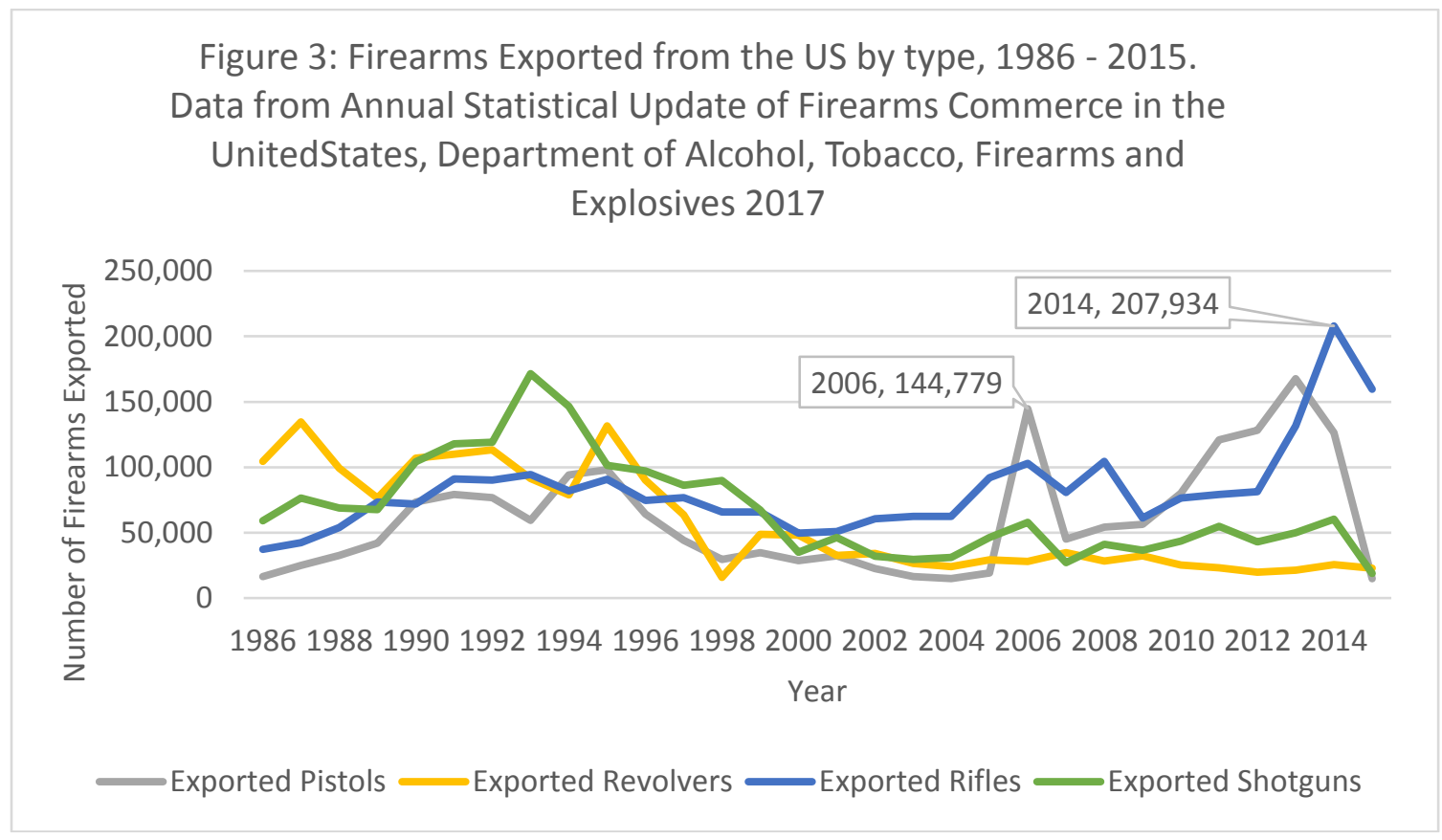

It is clear based on these figures that a sizeable number of firearms being produced in the US are being exported. With that observation, however, must quickly follow another. Even with the export of 144,779 pistols in 2006 or the 207,934 rifles exported in 2014, 
these are only about $14 \%$ and $6 \%$ of the 1,021,206 pistols and 3,379,549 rifles manufactured in those years. The importation data sheds additional light on the population of firearms in the US.

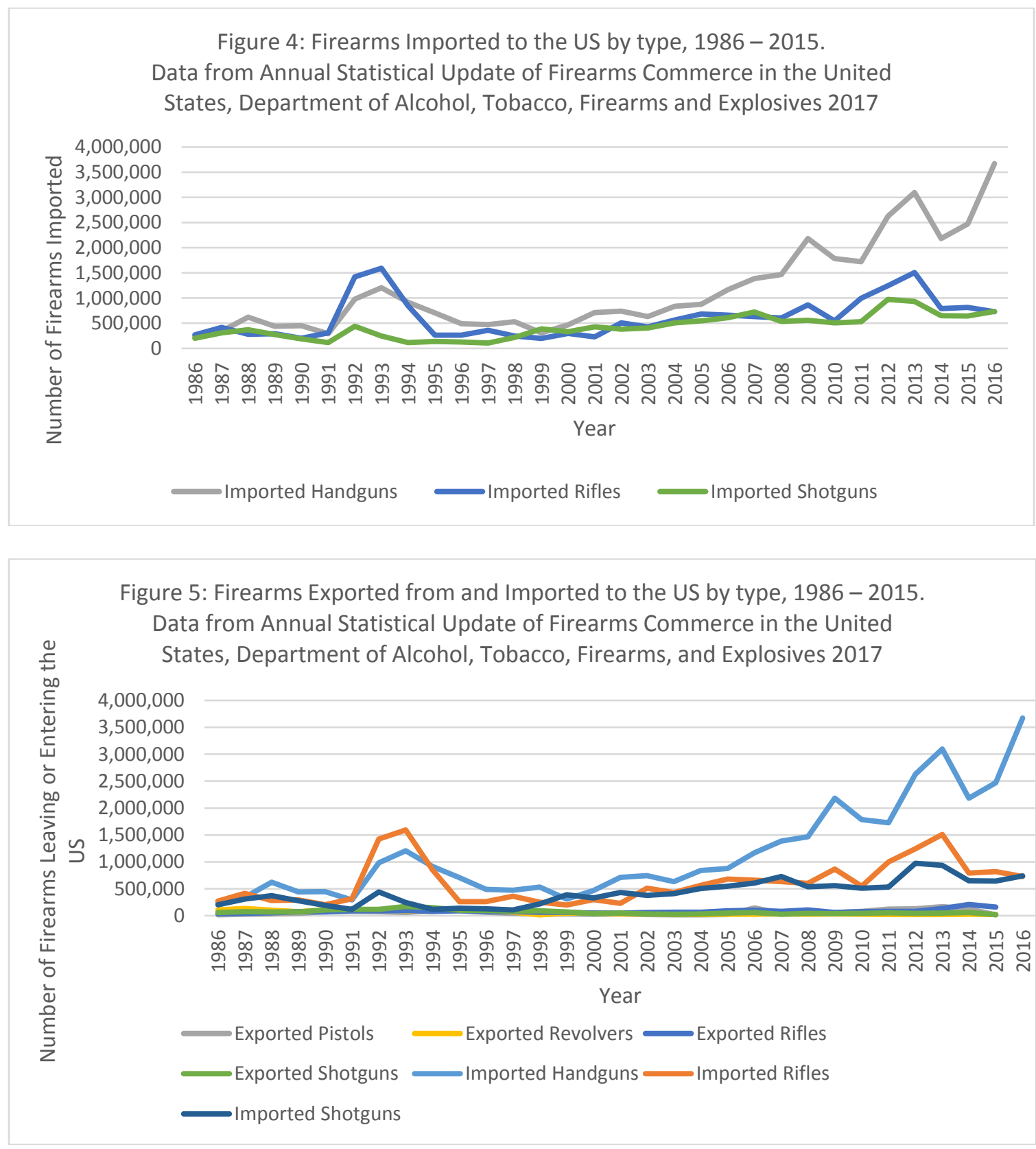

For illustrative purposes, I have combined the data in figure five. Examining figures three, four, and five demonstrate that in addition to domestic manufacturing of handguns and rifles increasing dramatically over the last several decades, the majority are not exported 
and many more still are imported. Taken together, these data represent a significant increase in the number of semi-automatic handguns and rifles available in US markets.

Gun Guys and Gals: Increasingly Concentrated and Dedicated Owners

As I explained earlier in this document, accurate, reliable information about who owns firearms, how many, and to what uses they are put is surprisingly difficult to come by, which in no small way contributes to the complexities of firearms policy and debate. There are several important patterns but the actual estimates upon which these patterns are established are often question by scholars associated with pro-firearms stances as well as firearms proponents. It seems a simple point to say that for a country with so many guns it seems odd that we know so little for certain; but that in and of itself is suggestive of the degree to which civilian firearms ownership is taken for granted. One of the most common resources in firearms scholarship is the General Social Survey which has been measuring firearms ownership and related behaviors since 1972 .

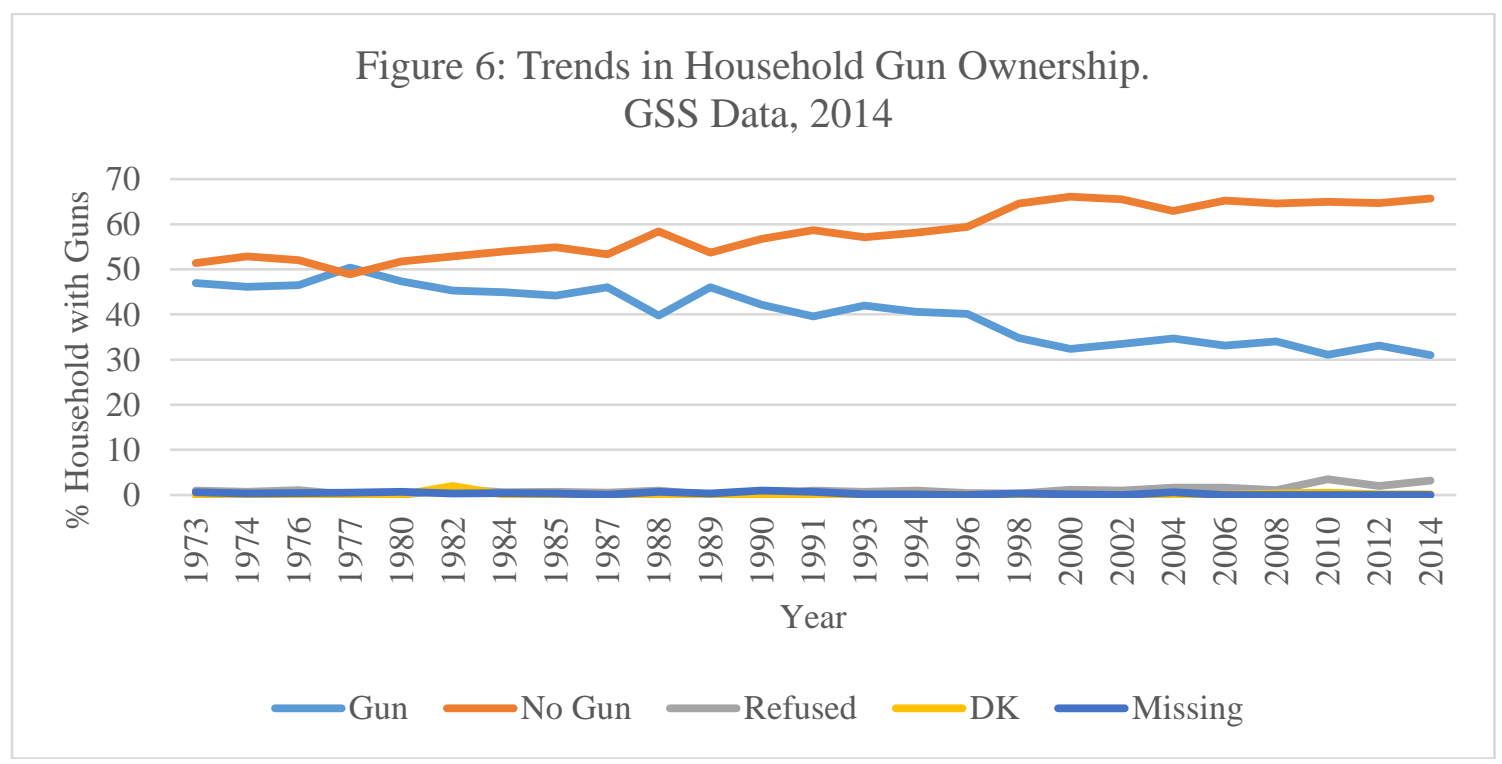




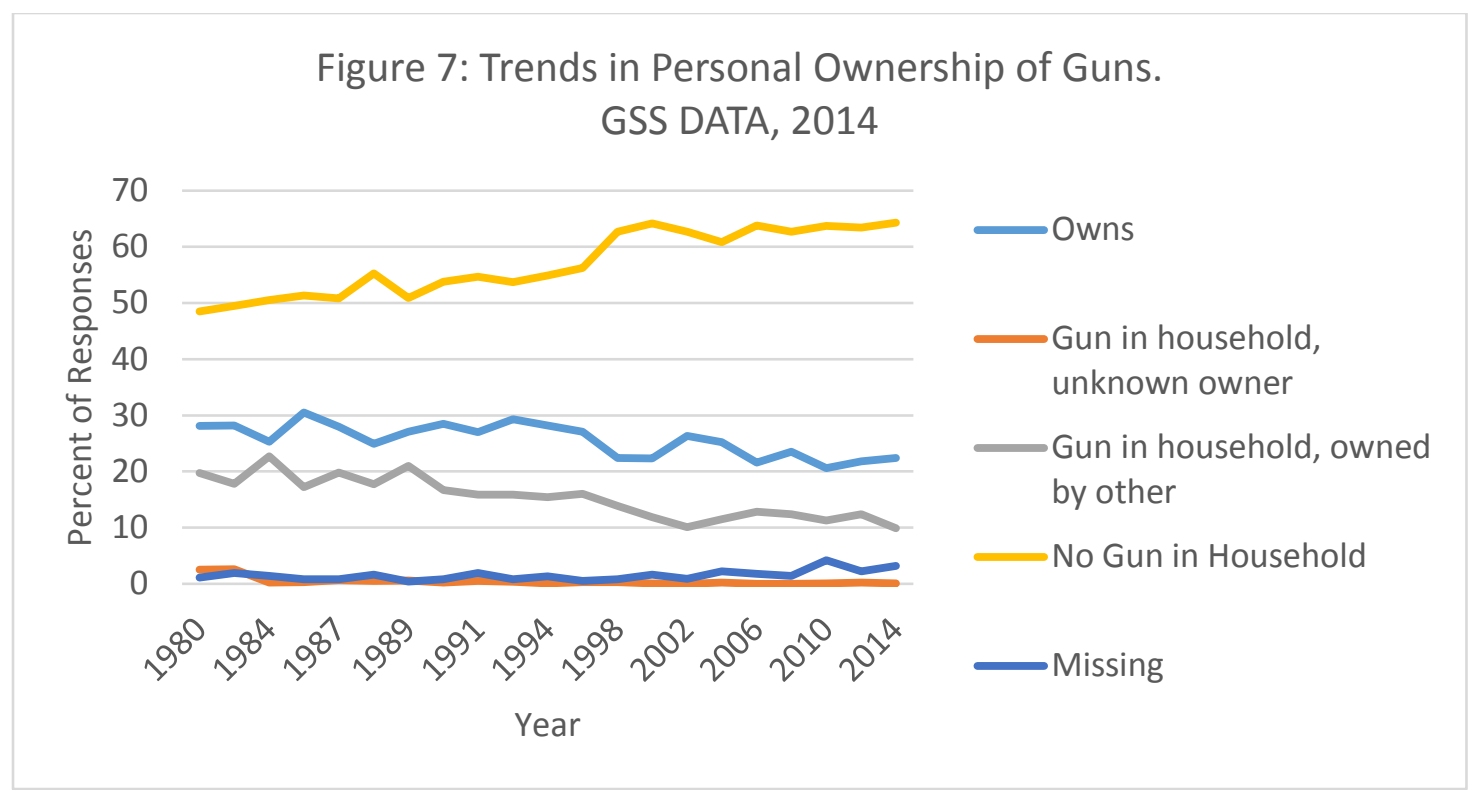

As one sees, Figures 6 and 7, gun ownership is declining overall, both in terms of households with firearms as well as individual owners.

Other than these data I referred previously to several surveys on firearms ownership that have been performed by periodically by a relatively small group of scholars. I will not reiterate their findings in full here other than to summarize that they all indicate that ownership is becoming increasingly concentrated among relatively few owners and the most common cited reasons for ownership have shifted from hunting and sport to personal safety, particularly for handgun owners (Cook and Ludwig 1997, Hepburn, Miller, Azrael, Hemenway, 2004, 2015). In all cases, these surveys concur on the general characteristics of gun owners: "Consistent with these surveys, we find that gun owners are disproportionately male, older, non-urban, and from the South.” (Hepburn et al. 2015: 44). Based on the data presented thus far one suspects that a couple of things are occurring. First, that the increasing number of firearms, particularly semi-automatic firearms, are being purchased by a diminishing number of dedicated firearms enthusiasts. Second, and given the overall downward trends in violent crimes, that the firearms being purchased are 
being utilized in ways that do not necessarily involve their mechanical purposes-that is to say the largely white, male, rural people who own many guns are not likely to be shooting or carrying all of them.

As a matter of clarity, I shall term this group gun enthusiasts. Every member of the $10^{\text {th }}$ with whom I had reliable interactions fit this moniker. By this, I refer to people who, when compared to non-gunowners, more casual dabblers, the curious, and even hobbyists and single-gun owners such as myself, cultivate and experience a stronger affinity for firearms in terms of felt desires to purchase them, utilize them, identify with them and who endeavor to integrate them into their lives and identities. To briefly elucidate, there are people who own one or perhaps a couple of firearms because they briefly had an interest in them but for whom the objects hold no particular significance with respect to their senses of identity or belonging. An analogy can be drawn between this and the way that somebody might have a guitar they occasionally play or own a DVD player but do not identify themselves and are not identified by others as a guitarists or movie enthusiasts respectively. For gun enthusiasts, owning, operating, and discussing firearms are important elements of personal identity, group membership, and their perceptions of safety and security. Gun enthusiasts in my project often express their affinities for rural or small-town life, selfsufficiency, conservative views on social and economic issues, as well as differing levels of distrust for those they see as outsiders. There are of course women, people of color, and people with centrist, liberal, progressive, and leftist politics who also utilize and appreciate firearms but the genres of narrative and talk common to paramilitary gun culture most clearly favor use by people who align well with the earlier demographic categories. 
In the patriarchal gender orders shared between paramilitary gun culture and the $10^{\text {th }}$, masculinity and its associated characteristics are a crucial point of departure for the rest of the gender order, work, familial arrangements, and the relations between the public and private life. It is common throughout the literatures on firearms, militia groups, and scholarly examinations of citizens whose views range from central-right to the far-right to explain at least some portion of their worldviews and motivation for participation firearmsrelated activities, including militias, in terms of challenges and changes to the social order that have diminished the social and economic positions of heterosexual white males (Aho 1990, Gibson 1994, Abanes 1996, Dees 1996, Stern 1996, Dyer 1997, Haider-Markel and O’Brien 1997, Mack 1998, O’Brian and Haider-Markel 1998, Kimmel and Ferber 2000, Crothers 2002, Gallaher 2002, Van Dyke and Soule 2002, Kelly and Villare 2002, Freilich 2003, Mulloy 2004a, 2004b, 2008, Weeber and Rodeheaver, D. 2003, 2004, Vertigans 2007, Kellner 2008, Meltzer 2009, Kimmel 2012, 2013). The preponderance of the evidence indicates that this is correct, but there remain questions as to the specific ways in which these characteristics interaction and how participants make sense of them. Subsequently the research has been criticized by myself and others as not adequately dealing with the experienced interrelationships between these threats and different economic, technological and economic conditions, inconsistent operationalization between studies and overgeneralizations (Frielich, Pienik and Howard 2001, Freilich and Pridemore 2005, 2006). Churchill (2009) argues that most of the existing literature on the militia movement has suffered from an overemphasis on their potential for violence, association with organized racism, and apparent distance from other Americans in light of a long history populist groups using rhetoric of insurrectionary violence, too often paired with 
action, in the United States. He echoes the concerns of Chermak (2002) and Mulloy (2004a) that much of the work uncritically relies and what he refers to as 'the narrative of 1995' which they theorize excessively pathologizes militias, their membership, and others who share their characteristics based illusory uniformity and the tendency to focus attention on the most vocal and disturbing voices found within such groups (ibid:7-11). These latter critiques have shaped my arguments in both this chapter and this project profoundly; I agree that there is a need to historically situate the ideas that members of the $10^{\text {th }}$ draw upon as, frankly, it is easy to ignore that many of their identity resources have been common fixtures throughout United States history and, as recent elections have shown, are not so uncommon or outlandish as outsiders might prefer to believe.

\section{Masculinity, Rural and Urban Spaces, and the "Conservative Lifestyle"}

Two of my participants in the militia specifically referred to their appreciated for something the both termed the "Conservative Lifestyle", which upon interrogation, to them meant a heterosexual household located in or near enough to rural area in which they could practice self-sufficiency and adhere to their religious beliefs in relative peace from outsider critique or influence. One immediately sees that sex and gender, politics, and religion integrated with firearms in identity work. Increasingly there are spaces for women and people of color to participate in paramilitary gun culture but these appear to be contingent in varying degrees on sharing the same affinities for an idealized rural self-sufficiency, firearms, and ideas regarding sex and gender that are considered traditional by other participants. Although the participants in my project would vary in terms of the degree to which they would agree or disagree with the idea that masculinity is a central element of paramilitary gun culture it is nevertheless a crucial point of reference for much of their talk 
and narrative, particularly in combination with ideas about rurality, and its association with socially conservative positions on religion, marriage, and morality.

As an interactionist at heart, I hold that gender is "an achieved property of situated conduct...carried out in the virtual or real presence of others who are presumed to be oriented to its production." (West and Zimmerman 1987: 126). As gender exists, or, rather, as people bring it into existence in everyday life, it is not a static set of personal attributes that determine the behavior of people who possess them. Consequently, any given production of masculinity is a structured yet flexible processes of impression management within a specific context and its attendant normative expectations for appropriate masculine behavior (ibid: 127). Returning to the broader, more structured portions of the identity resources that the $10^{\text {th }}$ draws upon, the United States has had a documented historical procession of the gendered organization of social practices as they relate to the reproductive arena and that are structured by relations of power, production, and emotional attachment (Connell 2005). I also hold to the understanding of masculinities a plural and, at this abstract level, as "... simultaneously a place in gender relations, the practices through which men and women engage that place in gender, and the effects of these practices in bodily experience, personality, and culture." (Connell 2005: 71). As such, there are at any given time many hierarchically organized masculinities tied to a legitimating hegemonic masculinity which justifies the positions of superordinate men relative to subordinated men and women (ibid: 71-77). As Connell and Messerschmidt (2005) explain:

"We think the critics have correctly pointed to ambiguities in usage. It is desirable to eliminate any usage of hegemonic masculinity as a fixed, transhistorical model. This usage violates the historicity of gender and ignores massive evidence of change in the social definitions of masculinity...[A]mbiguity in gender processes may be important to 
recognize as a mechanism of hegemony. Consider how an idealized definition of masculinity is constituted in social process. At a society-wide level..., there is a circulation of models of admired masculine conduct, which may exalted by churches, narrated by mass media, or celebrated by the state. Such models refer to, but also in various ways distort, the everyday realities of social practice...At the local level, hegemonic patterns of masculinity are embedded in specific social environments." (838-839).

Most men will consistently fail to perform hegemonic masculinity to the broadest cultural standards because " $[\mathrm{H}]$ egemonic masculinities can be constructed that do not correspond closely to the lives of any actual men. Yet these models do, in various ways, express widespread ideals, fantasies, and desires." (Connell and Messerschmidt 2005: 838, Messner 2007). Because inequalities in societies fundamentally limit access to the social, cultural, and economic capital expected of any elite positions, idealized or otherwise, the persistent achievement of broadly accepted hegemonic masculinity by any given man is a virtual impossibility. Masculinity identity performances are further complicated by the ambiguous and shifting nature of the expectations for doing so depending national, regional, and local factors. This, too, has been addressed by a wealth of scholarship demonstrating that masculinities are combinations of local, regional, and even global standards (Connell and Messerschmidt 2005), and that the dominant masculinities in a given context, like a rural area, are influenced by but not entirely determined by broader social changes in the economy, politics, or other hierarchies (Bell, D 2000, Campbell and Bell, M. 2000, Woodward 2000, Brandth and Haugen 2005, Bell,S., Hullinger, and Brislen 2015, Filteu 2015.) To put it differently, a wealthy businessman living among similar economic elites in a large metropolis and a retired veteran who does odd jobs around his hometown of a couple of thousand people may very well be drawing upon a partially shared repertoire of masculine identity resources, like capability in their work or maintaining an appropriately masculine body, but end up producing very different masculinities due to 
variations in local resources for masculine performances and the expectations for integrating them with societal-level ones.

Until the 1960s or so, American hegemonic masculinity at a national level took a form that Kimmel (2012) terms "The Self-Made Man" whose identity and masculinity are dependent on his ability to achieve wealth, or at least stability, success, and social mobility via activities in the public sphere. This form of masculinity arose in American during the $18^{\text {th }}$ and $19^{\text {th }}$ centuries as a solution to the masculinity crises resulting from expanding capitalist markets and urbanization which limited access to masculinities based upon previous economic and political arrangements that were more explicitly attuned to agrarian life, some level of martial prowess or the willingness to develop it, and strict racial and sexual hierarchies (ibid: 13, 17, 89). In the 1960s however:

"the erosion of confidence in a masculinity based on martial virtues that attended our involvement in Vietnam was on part of the problem for American men in the 1960s and 1970s. Men were besieged at home; the social movements of those two decades - the women's movement and the civil rights movement, and the gay liberation movement-all offered scathing critiques of traditional masculinity and demanded inclusion and equality in the public arena" (ibid 2012: 196)

Hitherto that point, the self-made man archetype relied upon the ability of white males to secure and maintain superior access to political power as well as productive agricultural and industrial work compared to men of color and all women, though, of course, the positions any particular man might occupy still varied by region and economic class with this broader pattern. In any case, these positions allowed men the greatest access to material success and therefore the self-made identities dependent on it thus appearing to justify their elevated status and positions compared to women and subordinated masculinities. The struggles for equal rights and treatment for women and African-Americans in the 1960s 
and 1970s challenged these strategies and made more visible the structures upon which this set of masculinity practices and positions relied.

Masculinities exhibit a general tendency towards contradictions and instability at macrosociological levels because they are always a product of sociohistorical contingency and the daily activities of people living in them. But, because war and human struggle are common throughout both of these levels of analysis, it is similarly common for masculinities to been dependent on dominance or competency in dealing with threatening things such as nature, crime, or warfare. In the next section, I will demonstrate that during the growth of neoliberal economics and ideology in the 1980s and the erosion of broader access to the economic means to achieving a self-made man status the response appears to have been a cultivation of masculinities prefaced upon martial capability as an alternative way of indicating personal responsibility and worth. The contemporary paramilitary gun culture, then, in addition to the increasing availability and attractiveness of semi-automatic firearms, also appears to have roots in a masculinity crisis resulting from social changes during 1960s and 1970s and yet a 'man's man' in the militia or in the paramilitary gun culture is potentially quite a different sort of man than an urban-dwelling cosmopolitan man even if both are heterosexual, Christian, fathers, politically conservative, own firearms and are responding to similar pressures using similar resources at a broader analytic level. Furthermore, they must each link their salient characteristics such as race, class, sex, and physical location to one another in ways that make sense to their audiences.

The National Rifle Association, Right-wing Populism, and Militarized Policing: Firearms as a Tool of Masculinity and Security

The Second Amendment is subject to more everyday conversation than perhaps any other amendment besides the First Amendment, particularly by participants in the 
paramilitary gun culture. Their interpretation serves in their own views to substantiate their ownership of particular firearms via historical and legal tradition. Given its importance to the sorts of martial masculinities crucial to their identity work, it is no surprise that their interpretation is celebrated vigorously and defended through appeals to their vision of authentic American history. This vision of history has been further developed by many people operating throughout the strains of reactionary conservative politics mentioned earlier in this chapter and it is now closely linked it to firearms, Christianity, and neoliberal visions of personal responsibility in all things as an ideal characteristic of masculinity and, more broadly, citizenship.

The Second Amendment, "A well regulated militia, being necessary to the security of a free State, the right of the people to keep and bear arms shall not be infringed," is central to the paramilitary gun culture. The wording of the amendment includes a preamble and an operative clause that are not explicitly related to one another within the text of the amendment itself. Because the type of security provided by a militia and the way in which an armed populace is to organize towards this end are not specified within the amendment itself it lends itself to two differing interpretations. These competing interpretations each hinge on the relationship that their advocates posit between the two elements. Historically, the preamble has been the focus of judicial interpretations and prior to the late $20^{\text {th }}$ century and the general consensus was that the amendment established a collective right of citizens to own firearms insofar as such people could be organized via state or federal governmental action to provide a counter to foreign aggressors if need be and, in a very limited capacity, the potential abuses of power on the part of the federal government in the early Republic. United States v. Miller, 1939, is the second of three Supreme Court decisions pertaining to 
the matter, and often cited as supportive of this interpretation insofar as it characterized the amendment as pertaining to a right to bear arms with military purpose rendering them germane to participation in a well-regulated militia under the authority of either a state or federal government.

One of the key building blocks of paramilitary gun culture and, by extension, much of militia activities including those of the $10^{\text {th }}$, is the second interpretive position, that the amendment was designed to protect an individual right to possess and carry arms for the purposes of personal self-defense and a much broader assertion of a right to insurrectionary resistance to the federal government. The second interpretation serves as a basic orthodoxy for my participants and, presumably, many other gun owners, gun rights activists, and militia participants. It appears to have ascended to prominence in only the last 30 or so years although elements of it have been present for much longer to a much more limited degree, as I noted with respect to the first interpretation. Here, though, the focus is on only the clause of the amendment, "the right of the people to keep and bear arms shall not be infringed." Quite often at firearms expositions, in speeches, literature, and consumer goods pertaining to the subject, and in everyday talk only the clause appears. The effect is to suggest that the preamble is either insignificant to the meaning of the amendment or merely an implicit demand to interpret the preamble as referring to an unorganized militia of which every citizen is believed to be a part. It is worth noting that the latter strategy most often involves drawing post-hoc boundaries that separate moral, lawful citizens from problematic others who should not be armed nor considered citizens with the same insurrectionary right. The second interpretation was granted a moderate amount of judicial backing by the Supreme Court in the majority opinion in District of Columbia v. Heller, 
2008 , in which a 5-4 majority decision held that the preamble does not preclude a right to the ownership of personal firearms for self-defense. Despite this, the majority opinion also noted that this interpretation did not mean that the right to bear arms is unlimited. More than any other specific group it seems that the National Rifle Association is responsible for the ascendancy of this second interpretation as well as the liberalization of concealed carry laws, both necessary conditions for the civilian paramilitary gun culture.

The NRA is a longstanding interest group that has undergone several important changes throughout its one-hundred and forty-six-year existence and its changing framing practices, relationships with members, the public, other institutions such as the government, and its organizational efforts can be broken down into four distinct periods but it is primarily the most recent iteration that is the source of many ordinary resources and generic conventions in the paramilitary gun culture (O'Neill 2007) ${ }^{12}$. Crucial to their political action, framing, and stories is the notion that the ability to own and operate firearms outside of the direct control for the government is a key to American freedom itself. This portion of the development of the modern resources common to paramilitary gun culture began in earnest in 1968. Congress responded to the assassinations of Martin Luther King Jr. and Robert Kennedy, as well as John F. Kennedy five years earlier, the lattermost of which was perpetrated using a rifle procured via mail order, by pursuing firearms restrictions for the first time in a third of century in the form of the Gun Control Act of 1968. Prior to this point, national legislative efforts to address firearms violence through regulating ownership of military weapons and criminal access to firearms had been

\footnotetext{
${ }^{12}$ The first is an early period between 1861 and 1871 focused on prepared men to utilize rifles effectively during military service. This is followed by a transition to promoting and supporting civilian marksmanship as a form of recreation between 1862 and 1962. In turn this was supplanted by a somewhat dormant decade of spilt attention between advocating for gun enthusiasts and deciding upon a future direction.
} 
supported by the NRA ${ }^{13}$ but here the group quietly opposed the legislation (Cook and Goss 2014). Later, in 1977, Harlon Carter led a group of NRA hardliners in orchestrating the replacement of more moderate leaders and the organization shifted into a social movement (see Melzer 2009) focused on expanding what are now referred to as 'gun rights'. Their framing and presentation, which is also used by other, newer gun rights groups, suggests that they are merely protecting existing rights or restoring those that have been unjustly curtailed by malicious governmental and popular forces. Despite the fact that what they have actually accomplished has been the dramatic expansion and liberalization of laws pertaining to firearms ownership, this framing aligned well with the broader, restorative framing common throughout conservative politics for the last several decades and continues to serve the same purposes today.

Much of the success that the NRA and other gun rights advocates achieve in these efforts rests on their ability to present the issue of firearm ownership in compelling terms of daily risk and life-or-death struggles that their audiences believe they may encounter in a society. Presented as immersed in out of control, drug addicted or impoverished criminals, a media environment replete with unfair or inaccurate characterizations of both guns and those who own them, and a federal government that is, somehow, simultaneously inept in controlling these dangerous elements but quite adept at endangering the lives of its citizens through its overextension and incompetence. These framing devices aligned well

\footnotetext{
${ }^{13}$ The National Firearms Act of 1934 focused on the manufacturing and sales of what are now called destructive devices - meaning suppressors, explosives, short-barreled rifles and shotguns, machine guns and similar miscellany. The Federal Firearms Act of 1938 sought to limit who could buy and sell guns via federal licensing for sales and establishing federally prohibited categories of buyer. Both of these were generally supported by the NRA as at the time they were concerned with the limited uses of firearms for shooting sports. They quietly opposed the Omnibus Crime Control and Safe Streets Act of 1968 and the Gun Control Act of 1968. By this point the group had started shifted towards its contemporary aims and consequent framing practices.
} 
with the broader development of the New Right, to which I now turn, and the belief in the decline of America.

American politics has shifted significantly to the right and become deeply polarized as grass-roots social movement groups and organized oligarchs have pulled their respective parties further in their ideological directions - in the case of Republicans, an increasingly organized, questionably populist, white resistance to myriad civil rights movements and the New Left in the case of Democrats (McAdam and Kloos 2014: 104). The New Right is an amalgam of "...free-market enthusiasts, libertarians, anticommunists, and social conservatives..." (Blee and Creasap 2010: 272). To this list I would add various groups of that make up the Christian Right that arose in the 1970s and 1980s that premised much of their political activity on their obligations to advance "Christian Citizenship" as a form of resistance to governmental policies and social changes that aligned them with restorative conservative politics (Green 1999). In the interest of clarity, it is clear that the various groups in the New Right, including the Christian Right and the Far Right, hold competing and even conflicting views when it comes to race, sex, and economics but they share in common a narrative and collective identity of victimization and decline. These identities are intertwined with concerns over their fears of feminization (though few would specifically address it as such) and feelings increasing marginalization due to real demographic shifts away from a white, Christian majority (Jones 2016). These tendencies found earlier expression in Nixon's Southern Strategy but continued in the presidencies and policies of Reagan and George H.W. Bush, as well as more recently in the Tea Party. As time has gone one, this dynamic has itself become embedded in a growing rightist media ecosystem whose business is prefaced on linking feelings of real and imagined 
dispossession and economic hardships portrayed as betrayals of the exceptional qualities of the nation itself or those of the target audiences of these outlets (see Lepore 2010, Formisano 2012, Skocpol and Williamson 2013 for excellent treatments of the subject in a historical context). The recent presidential election and public reemergence of white supremacist, separatist, and nationalist movements in conjunction with the increasingly conspiratorial and racial nature of right-wing media sources is not a new dynamic, then, but merely a growing continuation of this trajectory (Hochschild 2016, Neiwert 2017). Summarizing my argument thus far, throughout the 1960s, 1970s, 1980s, and into the present the NRA, firearms manufacturers and marketers, ideologs, media companies and personalities, and politicians all latched onto these impulses and feelings, expounding upon them by integrating firearms into the story as a necessary response to the risks associated with America's decline, often in Decline Talk.

Decline Talk is a genre that take the form of a presenting real or hypothetical evidence of how aspects of the social order have changed for the worse. It may involve specific examples or it may simply be an expression of the belief that this is the case. The function is to mark the speaker as somebody who understands what has been lost via changes in society, why these outcomes are negative, and how significant the changes are. There is also a subgenre of Personal Decline that may link changes in personal economic, political, or social standing to the broader changes above or, most often, serves as a way of contextualizing the process and consequences of aging, usually humorously.

This is the soil from which the initial militarization of civilian police and subsequent paramilitarization of civilian gun culture have grown but the first seeds took root in foreign and domestic policy framed using narrative devices and resources now 
widely used in paramilitary gun culture. The policy influences of the New Right's battle to restore America, or at least prevent its decline, can be seen in many policy decisions but the militarization of foreign policy since the Vietnam War, the growing popularity of military-style values, discourse, and products, and as well as the linking of patriotism to military service and, more recently, personal firearms ownership are those most relevant here (Gipson 1994, Kellner 2008). Citing Kraska (2007: 3), Salter explains that militarism is "an ideological commitment to "the use of force and threat of violence as the most appropriate and efficacious means to solve problems' as distinct from militarisation, which is the implementation of this ideology." (2014:164). Militarism and militarization became increasing "culturally unmoored" from state-sanctioned representatives in the military and, in line with the theses of Gipson (1994) and Kellner (2008), closely intertwined with postcold war American civilian masculinities and practices (Salter 2014: 165). The period of time over which this transition has occurred aligns well with the claims of Cowen and Sicilano (2011), who point out that "underemployed racialized men are at the centre of contemporary politics of security... and the resurgence of public masculinities that seek to both valorize and discipline subjects and populations" (1516). Kraska and Kappler's work (1997) helps set the stage for this and demonstrates that during and since the 1960s and 1970s there was an immense growth in both the number of paramilitary police units and their use, by $199589 \%$ of police departments has such units (ibid: 6). In the context of the 'war' on drugs as well as what Chambliss terms a 'moral panic' over crime which followed from the conservative valorization of 'law and order' through the 1960s these militarized units achieved significant status among other police as "very serious bad-ass individuals" (Chambliss 1994: 177, 190); within a few decades, SWAT officers were elevated to levels 
of masculine prestige similar to those previously reserved for soldiers (Kraska 1996, Kraska and Cubellis 1997). Through the 1980s and 1990s civilian gun markets, aided by the framing of the new NRA, responded to these social forces and began selling a vision of masculinity to the general public through which they too could reassert their masculinity via the cultivation of their martial capacities (Gipson 1994).

This phenomenon is not limited to the United States. The application of military technology and tactics to domestic policing is a part of neoliberal government policy being in many industrialized nations. When neoliberal policy decisions are made from the assumption that it is every individual's responsibility alone to provide for their economic well-being and limit the burdens they place on others through using governmental programs (Harvey 2005) the balance of overt state power, such as it is, appears to increasingly shift to security interests, such terrorism and crime. Any government will fail in these tasks at least occasionally given that it is fundamentally impossible to end crime or prevent all criminal violence and terrorism, no matter how much money and effort dedicated to the task. As a consequence, in addition to their economic responsibilities, citizens are also tasked with helping these governmental efforts through personal, private efforts aimed at preventing their own violent victimization, usually relying on solutions provided by a market, such as firearms (Garland 1996, Andreas and Price 2003, Hill and Beger 2009, Carlson 2015b). This latter process Carlson calls "responsibilization," which is marked by "the reorganization of collective responsibilities as private duties" (2014 :336). What is different about the United States is the degree to which a civilian market for the materials of responsibilization-modern firearms, ammunition, and various forms of 
talk and storytelling - has been fostered, celebrated, and tied to individual and group identities.

Paramilitarization and its resulting influence on gun culture is the process of applying the commitments of militarism throughout civilian society beyond policing and other forms of state-controlled violence. Paramilitarization is characterized by the erosion of the distinction between civilians and militarized state-sanctioned agents of force; the distinction being that the latter group is by virtue of the state monopoly on violence permitted to and even encouraged to resolve disputes lethally while the former has typically been discouraged from doing so. This erosion has been accomplished by means of using the politics of decline and identity resources associated with gun rights to extend the tools and practices of militarized violence to average citizens and encouraging their use via cultural celebration and legislation. Since the 1980s in particular, these frames have been the foundation for much of the militia movement, gun rights advocates of differing stripes, and similarly minded right-wing populist movements throughout the 1990s and unto the present. In both the past and present, the NRA and those who draw on these material and symbolic resources bracket firearms violence into two categories, violence primarily enacted by criminals in a predatory fashion and firearms violence that is performed by people who are not preemptively assumed to be criminal - that is to say the 'responsible gun owner' archetype-whose violence is considered virtuous insofar as it is idealized in such a way that it is only visited upon the deserving. This dichotomy serves as the basis for a narrative genre common to the $10^{\text {th }}$, Good Guy vs. Bad Guy. This genre takes the form of a situation in which the speaker or another Good Guy with a gun is tasked with ascertaining, adjudicating, and responding responsibly to a Bad Guy in any number of 
situations. The function of this genre is to mark somebody as one of the messianic few willing to undertake those risks for themselves and others despite the degree to which outsiders malign them for their interest in using firearms to protect themselves.

In defining paramilitarization, I draw from one of the most recent studies on concealed carry behavior which posits that participants are enacting a "do-it-yourself security-citizenship" by means of the loosening of concealed carry laws and those surrounding self-defense (Light 2018: viii) or citizen-protector model of citizenship (Carlson 2015a: 4-5, 19-20). The citizen-protector is the most accessible pairing of a responsibilized, armed masculinities, personal identity, and practices associated with paramilitary gun culture as it extends the privileged, masculinities of police and soldiers to other men without the formal institutional baggage associated with working on behalf of the government, which many participants feel has sold people like them out for others who have for decades been diminishing America's exceptional qualities. In other words, the vision of responsible citizenship common to paramilitary gun culture requires providing for their own security, and that of those they identify as in need of their services, by arming themselves thereby reducing their reliance on shared resources such as the police.

These developments are gendered and raced projects, as the idealized protectors are treated as paragons of virtuous masculinity and the threats are often racialized threatening 'others' against whom it is easier to justify the use of such violence (Chambliss 1994, Kraska 1996, Young 2003, Salter 2014). Historically, Light's work pertaining to the racial and sexual exclusions on legally-mandated self-defense demonstrates that rights to lethal force outside of state authority have typically extended only to heterosexual white males maintaining the racial and sexual orders of their times indirectly in incidents defined as 
self-defense (2017: 8-12). Light's analysis thereby demonstrates that despite its framing as universal, the "selective right to lethal self-defense" has reliably been couched in discourses of necessary control or protection provided by white men against dangerous or otherwise inferior others as defined by the common race and gender hierarchies of the time. The modern version of these tendencies are a continuation of these historical patterns. Neoliberal responsibilization is characterized by color-blind stories of wars on crime and drugs, each of which has continued to have profoundly negative consequences for African Americans and other demographic minorities and served to create an industry of crime control and security that, through paramilitarization, normalizes the idea that men require firearms as the individual defenders of themselves, their families, and society from racialized criminals (Christie 2000, Rios 2011, Alexander 2012, Omi and Winant 2013, Balko 2014). Even when my participants earnest disavowed racism, sexism, or organized hate, most of my participants do, this leaves them in a position of supporting and defending policies, practices, and ideological positions that produce structural racism and sexism including the civilian gun culture.

There is one more point to raise here. It is a typical experience that gun enthusiasts do not get to handle, let alone fire weapons as often as they would like (Baum 2013:29). I myself can testify to the expense in money and time required to do so. This is likely changing with the recent successful pushes for the expansion of concealed and open carry practices but even so, there is little reason to believe that many people are put in the position of firing these weapons in the defense of themselves or others. Ergo, the behaviors and expectations emanating from paramilitary gun culture, to say nothing of the identities and masculinities dependent on them, involve surprisingly little actual practice in line with their 
ideals of defending themselves and others. Based on this I will conclude this chapter with an argument that it is through talk and narrative that most participants in the paramilitary gun culture perform these identities without having to physically engage in the defense of themselves and others on a regular basis; these presentations constitute a significant practice in and of themselves.

\section{Messianic Marginality: Storying an Armed Self in a Declining America}

This background information above was lengthy but it was necessary for understanding messianic marginality, to which I now turn. This term encapsulates the identity practices and resources used in the $10^{\text {th }}$, the broader paramilitary gun culture and, arguably, the current and past collections of alt-right and far-right social movements. Intersections between culture, changing status characteristics and hierarchies, and practice bear heavily on self and identity. Participants in the paramilitary gun culture and the militia more specifically are tasked with organizing identity markers such as race, masculinity and femininity, political orientations, geographic areas, religious orientations and social class in appropriate, satisfying identities. At any given interactional moment these elements intersect within a set of historical conditions that may render particular intersections visible, invisible, contested, or settled. Gun ownership and enthusiasm are far from universally accepted self-presentation resources in the United States. Elevated levels of appreciation or interest in firearms are often marginalized as pathological, the purview of 'gun nuts' and 'ammosexuals', rather than results of the regional disconnects and deeplyfelt, if often misplaced and excessive, concerns. This likely exacerbates the feelings of marginalization that accompany the increasingly precarious economic situations and sense of betrayal to which participants in the paramilitary gun culture are responding. The way 
resources are narratively deployed in a given context come to inform a person's understanding and experience of their personal subjectivity. When a person who is used to deploying these resources in particular ways enters into interactive dialog in a setting with different standards for understanding and deploying them it has the potential to disrupt the person's ability to perform their identity work.

In response to the disruptions that the changes enumerated earlier in this chapter, members of the $10^{\text {th }}$ organize their identity resources in ways that make sense to them personally based on their own backgrounds and experiences but simultaneously fit in to the broader story of the United States as they and their main audiences see it. Hochschild explains the "deep story" that many people on the American right relate to as a series of scenes depicting their pursuit of the American dream of progress:

"You are patiently standing in a long line leading up a hill, as in a pilgrimage...Just over the brow of the hill is the American Dream, the goal of everyone waiting in the line. The American dream is a dream of progress - the idea that you're better off than your forebears just as they superseded their parents before you...you've suffered long hours, layoffs, and exposure to dangerous chemicals at work, and reduced pensions. You have shown moral character through trial by fire, and the American Dream of prosperity and security is a reward for all of this, showing who you have been and are - a badge of honor... The sun is hot and the line is unmoving. In fact, is it moving backwards? You've taken the bad news in stride because you're a positive person. You're not a complainer. You count your blessings. You wish you could help your family and church more, because that's where your heart is. You'd like them to feel grateful to you for being so giving to them. But this line isn't moving. And after all your intense effort, all your sacrifice, you're beginning to feel stuck. You think of things to feel proud of - your Christian morality, for one. You've always stood up for clean-living, monogamous, heterosexual marriage. That hasn't been easy...Liberals are saying your ideas are outmoded, sexist, homophobic, but it's not clear what their values are. And given a climate of secular tolerance, you remember better times, when as a child you said morning prayer and then the flag salute-before 'under God' had to come out-in public school." (2016: 136-137.) 
She explains that waiting in line is the first scene, followed by "The Line Cutters", in which the protagonist sees women, immigrants, people of color, and even endangered animals advance ahead of them. This transitions to "Betrayal" wherein the protagonist finds that the government is responsible for these advancements. The story ends with the disruption of the recession and "Catcalls" where the person in line discovers that they are the subject of criticism and ridicule for their views and identities and realizes that they feel like a "stranger in their own land" and Hochschild argues this was the foundation for the Tea Party and serves as a foundation to which many on the right build their identities (2016: 136-143). In the case of the militia unit I worked with as well as the broader conservative right I argue that narrative and talk are highly significant and underexplored modes of accomplishing identity work and that the resulting identities are permutation of an overarching messianic marginality that relies on their shared deep story of decline.

Messianic marginality is a both a social and personal identity, prefaced on taking identity markers that a speaker believes are stigmatized or marginalized by outsiders and presenting them instead as personal virtues that, through their own sacrifices and effort, are linked to their own personal and social value. It is accomplished through action, including narrative and more general talk, all of which relies upon symbolic and material resources the audience and speaker have access to and value and that they believe to be worthy of greater relevance and appreciation. It is a way of saying 'despite the fact that people no longer value or respect this quality that I have it is valuable to me and, should circumstances arise, valuable to the very same people who malign it.' Logically this requires that every identity marker has two elements attached to it: a marginalized element based on the stigmatized interpretation outsiders are believed to hold and a messianic element based in 
the rehabilitation of the identity marker as valuable. The belief that personal identity markers are stigmatized is sufficient for performing messianic marginality, but it is highly effective to be able to point to indicators or evidence that the stigmatization is real; the deep story of victimization and betrayal above is a great example of how empirical fact and felt truth are interwoven among people who practice messianic marginality. 
Table 2: Messianic Marginality Components Utilized by the $10^{\text {th }}$

\begin{tabular}{|c|c|c|}
\hline Identity Marker & Marginalized Element & Messianic Element \\
\hline Firearms Enthusiasm & $\begin{array}{l}\text { Firearms are considered by } \\
\text { dangerous and only of special } \\
\text { interest to those who have a } \\
\text { bizarre fascination with violence, } \\
\text { risk, and being dangerous. }\end{array}$ & $\begin{array}{l}\text { Firearms are a bulwark against } \\
\text { crime and those who undertake to } \\
\text { understand them and operate } \\
\text { them responsibly can save people } \\
\text { that the state no longer can. }\end{array}$ \\
\hline $\begin{array}{l}\text { Restorative "Conservative" } \\
\text { Politics }\end{array}$ & $\begin{array}{l}\text { Conservative views like } \\
\text { individual responsibility, small } \\
\text { government, and low } \\
\text { governmental spending are } \\
\text { looked down on by liberals and } \\
\text { progressives who want } \\
\text { everybody to be dependent on the } \\
\text { government. }\end{array}$ & $\begin{array}{l}\text { Conservative views are realistic } \\
\text { solutions to problems that others } \\
\text { ignore and that are bringing the } \\
\text { US to the point of collapse like } \\
\text { government spending, crime, } \\
\text { racial tension (on the part of non- } \\
\text { whites), and political correctness. }\end{array}$ \\
\hline $\begin{array}{l}\text { Traditional Views of Sex and } \\
\text { Gender }\end{array}$ & $\begin{array}{l}\text { Traditional gender roles are no } \\
\text { longer as important and even } \\
\text { shameful. Men are attacked for } \\
\text { being men and women are able to } \\
\text { enter areas that they are not as } \\
\text { capable as men. This erodes the } \\
\text { independence of the family. }\end{array}$ & $\begin{array}{l}\text { Traditional gender roles are the } \\
\text { basis for American society. The } \\
\text { nuclear family is how the nation } \\
\text { achieved its prosperity and } \\
\text { maintains discipline, } \\
\text { independence, and the broader } \\
\text { social order. Masculinity and } \\
\text { femininity are biological based. }\end{array}$ \\
\hline Religiosity & $\begin{array}{l}\text { Religion is under attack as hate- } \\
\text { speech and treated as hopelessly } \\
\text { backwards. Those attacking it are } \\
\text { misinformed or outwardly hostile } \\
\text { secular people who want to erase } \\
\text { Christianity from American life } \\
\text { and institutions or render it equal } \\
\text { to other religions. }\end{array}$ & $\begin{array}{l}\text { Religion is crucial to the } \\
\text { founding of the country and } \\
\text { central to America's success as a } \\
\text { nation. Christianity is } \\
\text { fundamentally good religion that } \\
\text { should be made central to the } \\
\text { policies and intuitions of the } \\
\text { country as it used to be. }\end{array}$ \\
\hline Rural lifestyles & $\begin{array}{l}\text { People are being taught though } \\
\text { living in, crime-filled cities to } \\
\text { become dependent on the } \\
\text { government and technology } \\
\text { which puts them at risk should } \\
\text { either one become corrupt or } \\
\text { collapse. }\end{array}$ & $\begin{array}{l}\text { Rural life requires self-discipline } \\
\text { and responsibility but affords a } \\
\text { safe, natural existence. These } \\
\text { benefits mean that being a rural } \\
\text { person will provide greater safety } \\
\text { in the event of societal issues. }\end{array}$ \\
\hline $\begin{array}{l}\text { Self-sufficiency and } \\
\text { Independence }\end{array}$ & $\begin{array}{l}\text { Too many people are becoming } \\
\text { dependent on others through the } \\
\text { auspices of the state and this } \\
\text { erodes the overall capabilities of } \\
\text { those people to provide for } \\
\text { themselves. This produces } \\
\text { burdens for others who can but } \\
\text { whose opinions and needs are } \\
\text { considered less important. }\end{array}$ & $\begin{array}{l}\text { Being self-sufficient and } \\
\text { independent is responsible and } \\
\text { morally praise worthy because it } \\
\text { means not being a burden to } \\
\text { others and requiring no help to } \\
\text { manage life. This gives you } \\
\text { greater power over the direction } \\
\text { of life and the ability to choose to } \\
\text { help others. }\end{array}$ \\
\hline Race & $\begin{array}{l}\text { Whiteness is a visible racial } \\
\text { category and treated as a problem } \\
\text { or a signal that you are } \\
\text { automatically racist. Other racial } \\
\text { groups are more racist towards } \\
\text { whites than whites are to them } \\
\text { and this imbalance is supported } \\
\text { by the federal government. }\end{array}$ & $\begin{array}{l}\text { Whiteness and all races should be } \\
\text { invisible, individuals should be } \\
\text { judged as such. Noticing that } \\
\text { some groups have more trouble } \\
\text { than others is demonstrative of } \\
\text { awareness of risks but people } \\
\text { should not be treated differently } \\
\text { based on this. }\end{array}$ \\
\hline
\end{tabular}


These basic identity resources listed in Table 2 are usually deployed in line with narrative expectations that firearms are crucial to men's abilities to fulfill a supposedly natural obligation to defend themselves, their dependents, and other law-abiding people from two forms of risks: violence that would otherwise be visited upon them by a criminal underclass that is often racialized and attacks on their freedom from an overbearing, urbanized, feminizing, federal government. Many participants in the $10^{\text {th }}$ would problematize this description as they prefer to present themselves as reasonably openminded people who do not judge people or institutions in terms of race or sex but rather, simply recognize certain obvious truths about the world; the connections here are not entirely visible to them and when they are temporarily made visible, as we will see in later empirical chapters, participants often take care to distance themselves from organized racism and sexism but they remain part of the larger tapestry of the New Right and utilize many of the same resources in their own messianic marginality work. In the next chapter I will analyze this most public forms of messianic marginality which the $10^{\text {th }}$ uses to advertise itself and its activities to one of the only groups they feel is likely to be a sympathetic audience, other members of the paramilitary gun culture. 
Table 3: Summary Table of Narrative Genres used in Messianic Marginality

\begin{tabular}{|l|l|}
\hline Narrative Genre & Subgenres \\
\hline Who Talk & $\begin{array}{l}\text { Busy Talk, Responsibility Talk, } \\
\text { Normalization Work, Contribution Talk, } \\
\text { Legitimacy Talk, “Man-Talk", Race Talk }\end{array}$ \\
\hline Scenarios & $\begin{array}{l}\text { Emergency Response, Good Guy V. Bad } \\
\text { Guy, Civil Unrest, Terrorism, 'Tyranny', } \\
\text { TEOTWAKI }\end{array}$ \\
\hline Decline Talk & Personal Decline, National Decline \\
\hline Technical Specifications & Gun Talk, Gear Talk, Show and Tell \\
\hline
\end{tabular}




\section{Chapter 3}

"In Time of Need": Private Work for the Public Good: Messianic Marginality and Narrative Work in Public Spaces 
My partner and I are strolling the parallel aisles of the largest gun show we've attended for this project. It is a travelling show that moves throughout the midwestern parts of the country, setting up in a new locale each weekend. Vendors rent tables and spaces for a couple of hundred dollars and set up on Thursday night or Friday morning. Vendors with the largest, fullest tables are often representing larger gun companies and stores in the area. Others are clearly family businesses, indicated by the presence of partners and children hanging out in space between the aisles and tinkering with tablets and smart phones. Whether especially young or closer to their teenage years, children are almost entirely uninterested in the proceedings around them and much more focused on mobile games, hide-and-seek, and snack. Occasionally they will interact with attendees but mostly they keep to themselves. Nobody has talked to me about how the overheard costs of doing business under the auspices of the show affects their earnings; members of the $10^{\text {th }}$ so far have shared the same ambivalence in discussing their finances. These are private matters.

As is the case with many such shows, this show is staged a convention center on the edge of one of Missouri's major urban centers; the building itself a pair convention rooms, each about the size of a football field. They are connected by a much smaller central passage that doubles as a food court and ticketing area. We arrived a little after 9 in the morning and the parking lots were already filling up. Tickets to the show were $\$ 12$ per person. For that price an attendee buys access to both wings of the building. From the entrance, the right main room of the building has been filled by dozens upon dozens of tightly packed folding tables - of both particle board and plastic varieties-arranged in parallel rows surrounded by an outer perimeter that runs the around the entire room aside from the small area occupied by a concession stand. Some vendors sell only handguns, some sell only rifles, and fewer still sell a mixture of both. Nearly the entire aggregate surface area of this army of tables consists of firearms save for a few tables around the outer edges of the room and a few more closest to the concession stand. Later in the day on of these peripheral vendors will try to sell my partner a taser shaped like a cellular phone. We end up buying a reusable match instead. I find it is rare to arrive at a travelling gun show and find the entire space dedicated to functioning firearms. Traveling gun shows seem to serve in part as traveling flea markets. The left convention area houses considerably fewer tables, similarly arranged, most of which have literature, rocks and minerals, knives, coin collections, and other miscellaneous items. From this side of the show my partner purchases a bottle opener made from a deactivated .50 caliber bullet nearly the length of my hand. Still other vendors have collections of devices that are nonfunctioning joke firearms or historically interesting but useless otherwise.

While my focus by this point in the project is the $10^{\text {th }}$, gun shows remain an informative locale to visit when I can make time as the cultural practices and materials there speak to the broader sense of undeserved marginalization, risk, and victimization that run throughout the $10^{\text {th }}$. My other aim today is to see if they have set up a booth at this show. Like other militias, the $10^{\text {th }}$ commonly advertises itself at gun shows. Whether or not they are fully aware of it, their public presentations and recruitment material relies heavily on the narrative genres common throughout some of the prominent strains of conservatism and paramilitary gun culture.

As we walk, my partner wants to look for cheap books about gardening and other hobbies on the left side of the building so we part ways. I remain on the right and continue 
to weave in between the different lines of people looking over the firearms and other sundries on display, drifting between the faster flow of people in the center of the aisle and the slower-flowing lines directly next to vendor's tables. Superficially, should I interact with a vendor beyond exchanging small talk, I'm looking for a rare handgun that I want. This is true and it is false. It is true that I've been looking for a specific type of handgun for years and rarely ever see one. The few enthusiasts who tend to buy them also tend to hold on to them. It is also true that I cannot afford one new or used, they cost at least $\$ 600$ if purchased from the manufacturer and seldom sell for less than $\$ 500$ when you can find them used. It is also false that the search is my only purpose at the show, the true story of searching for the gun makes for an easy excuse to engage with people who, if they knew that I was not only a handgun enthusiast but a sociologist, would be much more likely to see me as an unwanted interloper seeking to discredit and mock their lifestyles, religions, politics, and identities. I've been told as much by employees at a local gun store whose employees would not even speak to me unless I promised to 'tell the truth' about them. When I inquired after what this meant they warned me that a journalist had come by and ended up smearing them in her story by claiming they sold "assault rifles" when, instead, they sell "contemporary sporting rifles."

Most handguns for sale at this show rest on top of rigid plastic cases, secured to the tables with steel cables running through their barrels, magazine wells, trigger guards, or a combination thereof. The few that are not arranged this way merely sit upon the tables with plastic zip ties running through their barrels and chambers. Either arrangement prevents somebody from walking off with the merchandise and disables loading or operating them in any significant way. Rifles tend to be unsecured, resting on small stands, their original boxes, or on their sides atop the table. Usually there is a brightly colored plastic zip tie running through the chamber, rendering the bolt immovable. Like handguns, this prevents people from operating the weapon and demonstrates to everybody walking by that this is the case. The specific rules around handling weapons vary by vendor. Some have signs that invite any passersby to pick up and handle whatever they want while other signs warn that potential customers must speak to the vendor to touch anything. Regardless of vendor rules, everyone is outwardly quite friendly but also keeps a close eye on people palming their wares. The lines around the former tables tend to slow down the most as people pick up and fiddle with the various pistols despite that there is very little fiddling that anybody can do with the pistols secured to the tables as they are. The lines never stop moving entirely because when somebody stops to handle something the rest of the line just moves around them. Very few attendees interact with anybody other than the vendors or the people with whom they came to the show.

From an outsider's perspective gun shows are often a nest of contradictions. The rules for entering the event are posted outside and dictate that no loaded concealed firearms are allowed into the show. Presumably unloaded concealed weapons are fine. Inside there are dozens of decorative placards and signs emblazoned with phrases like "I don't dial 911", "I carry a gun because a cop is too heavy", and "Do you speak English or do I have to repeat myself in 12-gauge?" Each of these signs has a silhouette of a firearm next to the text. Several signs are not mass-produced metal ones; their content been seared into wood by a local artisan in a display of impressive craftsmanship. One vendor in the corner is selling two semi-automatic .45 pistols that are welded side by side to form a 
single, double-barreled pistol. I do not ask the 50-something year old man selling it if it functions, assuming that even if it did the gun is so unwieldly as to be useless for any purpose beyond admiring its ridiculousness. Finding such items is a common phenomenon despite the popular refrain that firearms are 'tools' with specific purposes. He is also selling a revolver with its barrel bent backwards. It is labeled, "For criminals or exwives." Few people stay at his booth for very long. Many vendors are selling handguns in smaller calibers with pink, polymer grips. Firearms manufacturers and holster businesses market such weapons directly to women as specialized for their personal defense needs. These products and sales tactics are parts of a push to represent and sell guns as tools for women to empower themselves; most advertisements suggest directly or indirectly that this protection is against males they do not know. One vendor sells concealed carry holsters which are capable of securing a small defensive pistol under a woman's bust. This breaks up the outline of the weapon so it is easier to conceal but requires the carrier to lift her shirt up to draw the weapon. The product is called Flash Bang-an attempt at humor.

I wander past a vendor selling CD-ROMS with various survivalist information stored on them. I ask the vendor "What about a grid down situation? What good is a CDROM without electricity?" She replies, "Well, ideally you'd read it all before that." "Fair enough," I say as I browse through the Velcro patches she is also selling. Most are representations of faux-military units or comic book character logos recolored in Olive Drab or digital camouflage. Two of them stand out to me: one with representations of Arabic script on it and the English words "American Infidel" and another next to it that reads, "Team America, Fuck Yeah!" This is a quote from the satirical film Team America: World Police, which pokes fun at militarism, ethnocentrism, and the ineffectiveness of the war on terror. I buy the second one despite being unable to tell if the manufacturer is ironically quoting the film.

My partner texts me to let me know that the militia has set up a booth in the other area. I head that way and she points the booth out to me. It is in the far corner of the room, situated between a stand selling aroma therapy products and another selling insurance for concealed carry permit holders. The militia's booth has a large PVC sign above it that announces the name of their group. They have covered the table itself is completely with their literature. Mission statements, group bylaws, equipment requirements, history of the group, and some political/historical documents establishing the legal and moral legitimacy of the group. The papers are organized by type into neat stacks.

Two men clad in woodland camouflage fatigues occupy the booth, one younger and the other older. As I try to unobtrusively approach the booth with the rest of the line of people moving past it I notice that the unit listed on the sign indicates that this booth belongs to the state-wide command unit that is nominally in charge of the $10^{\text {th }}$. One of these two men is likely "The Colonel". "Colonel Wilson" or simply "The Commander" is how members of the $10^{\text {th }}$ have referred to him. I cannot attest to whether this was his actual rank during his time in military service but given the seriousness with which the members of the unit I work with approach situations of stolen valor I expect that there is more truth than fiction to his claims. As we get close I notice that the younger of the two men is not interacting with attendees, he seems mostly occupied by something on his phone. I do not think he's any older than in his thirties, at most. His hair is brown and short but longer than regulation cut. The older man is greeting and interacting with everybody that stops 
long enough. He is most likely in his mid-to-late 50s, with salt and pepper hair, glasses, and a tall, stout build. I expect that this is the commander of the state organization. Seeing an opportunity to gather literature I finish my approach, start picking up copies of each of their documents, and he engages me. He is gregarious and asks me if I am familiar with the group:

"I am, actually. The $10^{\text {th }}$ is nearest to me."

"Is that right? They're good guys, good group. I've known Charles for a while. He didn't serve, but I did, as a soldier and as a contractor. Real fighting, you know? I think his head's on straight. So, you think about joining up? You know, it's good to be prepared, you never know what can happen."

"I've not really decided to..."

"Well, I'm Colonel Wilson. I run things at the state level and the unit around here. We're a good group - none of that anti-government stuff, anarchy stuff. Although, you know, if things don't work at the ballot box, right? There's always the ammo box."

I stare at him, failing in my typical face work. Nobody in the group had yet said anything like this to me. As an experienced public face for the group he could see immediately from my reaction to the idea that if goal of restoring American culture and government to forms more in line with ideals imagined by people like him fails politically then force is the next logical step was not going to work for me. Quickly, he shifted to a more community-disaster oriented approach which is much more common among my participants:

"I'm sorry, you know? It's stressful times, I thought you'd like that joke, I didn't mean any offense. Ok? Nobody would, at least in my unit, ever take seriously that sort of idea. Everybody feels frustrated by politicians and politics and what-have-you and blows off steam about it but stuff beyond that it's not ok. Most of what we do, my unit and the state units, is tornado relief, disaster relief; we only go somewhere if we are asked to. That's another thing. We never self-deploy."

"I see. Yeah, I mean, no, you are right that that humor isn't my cup of tea. It 's... anyway I know Charles, he's a good guy. I mostly came by to meet you and ask if I can take this literature."

"Oh yeah! Sure! Take as many as you want, there's plenty. My contact information is on there too, along with all of the unit leaders throughout the state. Get in touch with them too, if the $10^{\text {th }}$ isn't for you. They don't joke around as much as some of us, they do the work and keep the rest of it to themselves."

I thank him and walk off as he continues to greet and talk to the people behind us. I look back a little later and he's definitely not paying attention to me but I find myself worrying that he will tell Charles that I'm some kind of infiltrator that needs to be told to leave the group's orbit. While I am walking around looking at the sundries around me I see a man 
who stands out. He is no older than 36 or 37, probably younger, a little overweight, with close cropped hair and dressed in a black button-up work shirt and black denim. Other than me, he's the only person I've noticed wearing all black today. Where we differ significantly is I do not have a tattoo prominently displayed on my neck like his, which simply reads "88". The number is often used in white supremacist circles as a representation of $\mathrm{HH}$, meaning "Heil Hitler". He is walking to the concession stand holding the hand of his young son of perhaps 5 or 6 , who is reminding his father that the stand is where hot dogs can be found. It is about 1:30 so my wife and I decide to go get lunch somewhere other than the show.

I use "staged" in reference to the gun show deliberately; the space a show occupies is transformed by vendors and attendees. Beyond the necessary reorganization to the physical requirements of the vendors, the cultural expectations of attendees and vendors in ways that allow the fullest degree of identity work while adhering to the ordinary resources required to perform messianic marginality. As with the paramilitary gun culture, the behavior of members of the $10^{\text {th }}$ usually appears somewhat contradictory to outsiders. This is often based on the discrepancies between members' comments and behaviors and their outward presentations of the group as neutral on political, sexual, religious, and racial grounds. Colonel Wilson's comments and explanation for them are a good example. Rather than treat his walk back of his joke, or similar examples in my data, as dodges or lies that other groups along the alt-right use to hide or playdown more sinister white-supremacist or deliberately misogynistic agendas I argue that among members of the $10^{\text {th }}$ this is more often a product of the larger contradictions inherent to their messianic marginality work ${ }^{14}$. Members of both the paramilitary gun culture and the militia are attempting to situate themselves in a changing society with the materials with which they have the most skill

\footnotetext{
${ }^{14}$ This does not mean that nobody involved in the $10^{\text {th }}$ might support ideologies like these, but everyone who interacted with me would deny that they do so intentionally. From my perspective they indirectly support them insofar as many far-right and alt-right attempt to normalize themselves through appeals to visions of society that members of the $10^{\text {th }}$ feel is more authentic than the current state of affairs but based on my experiences with them over the last few years I would be genuinely surprised if any of the core or regular members became invested in groups explicitly oriented towards active, targeted violence.
} 
and knowledge but these resources no longer align as well with the broader public as they once did. Beyond this, the range of views and grievances represented as legitimate in public discourse has changed over the course of their lives insofar as women, racial and ethnic minorities, and people whose concerns have been historically ignored have received greater attention. Citizens who favor these changes see this as a positive movement towards a more just society but for members of the $10^{\text {th }}$ it reminds them that those ordinary resources and identities they are most attached to are no longer invisible, hegemonic standards and the meaning of their activities and identities is no longer completely under their control. Contradictions arise from the balancing act between members' vision of the militia as inclusionary and the exclusionary limits tied to their own feelings and sense regarding how ordinary resources can be legitimately arranged.

This chapter will demonstrate the ways in which the apparent contradictions that arise from the militia's most public narratives and talk involving messianic marginality are navigated in the groups' public materials in ways that allow them to emphasize their real and imagined positive qualities in ways designed to appeal to their target audiences within the paramilitary gun culture. Most often participants manage these apparent contradictions by drawing boundaries between overt racism or other forms of intolerance that members designate as excessive and abusers of legitimate concerns. In this way they can preserve the integrity of their own identities and resources while leaving socially and politically progressive views responsible for the decline of American society.

Publicly and privately the members of the $10^{\text {th }}$ make efforts to align themselves with some elements of a society progressing towards egalitarianism, although only to a degree they feel is not a betrayal of their own feelings and identities and using ordinary 
resources to which they are accustomed in which unequal outcomes are the result of either individual qualities or governmental meddling. To the outsiders, the efforts are significantly lacking given that participants do not acknowledge the degrees to which inequalities and risks become embedded in institutions and are disproportionately visited upon people who are unlike them in most ways. In this way their identity work contributes to the maintenance of discourses and policies that produce racially and sexually discriminatory results without putting members of the $10^{\text {th }}$ in a position to see or acknowledge these implications beyond any personal efforts they might make toward those ends. The privacy the group creates through its organizational patterns and the preemptive sorting they accomplish by advertising primarily to members of the paramilitary gun culture make these contradictory impulses easier to manage without confronting them. Within their own social and cultural circles their views are considered reasonable by the "like-minded ${ }^{15 "}$ people whose company they prefer to keep. By this I do not mean that members refuse to speak to outsiders. They try to live up to their claim that they welcome public attention but still prefer to interact with people who are unlikely to marginalize their ordinary resources in ways that echo the broader society they feel at is at odds with them.

The messianic marginality of the $10^{\text {th }}$ is an identity enmeshed in tensions, navigating where one fits in a changing society, who is a good citizen or responsible, and where the lines between public life and private life should be. As a result, in the $10^{\text {th }}$ there are degrees to which they hold the public at an arm's length and ways in which members are socialized into the public-friendly way that core members and leaders organize ordinary

\footnotetext{
${ }^{15}$ Like-minded was a term that came up from time to time. It is a marker that delineates a boundary between the imagined community (Anderson 2006) associated with correctly understanding whichever elements of messianic marginality are at work and those who do not.
} 
resources in producing a messianic marginality appropriate for the militia. In meetings and trainings these standards are still foundational but there are also more laid-back and flexible forms of messianic marginality that participants believe would hazard negative reactions from those who do not share their feelings about appropriate jokes, opinions, and concerns about government, city-dwellers, liberals, and religious, ethnic, and racial minority groups. The effect is a public emphasis on narrative and talk that promotes their shared image of the group as a positive force in their communities or, at the very least, in their own lives. As people who undertake the individual effort to move closer to the unit itself, they are socialized into a more cautious, specific set of stories and talk more accurately demarcating the lived boundaries of the group.

This chapter will proceed by elaborating on the qualities of the core and regular members of the group, as they serve as the most public faces and are the most experienced and dedicated to utilizing messianic marginality in ways that appeal to the broader culture and maintain the integrity of their organization. It will also demonstrate how the group presents itself in its public literature as a public good provided by patriotic, dutiful citizens in ways that align with the broader paramilitary gun culture using three key genres of talk and narrative: Who We Are and Who We Are Not, Legitimacy Talk and Scenarios. I will conclude the chapter with an analysis of how the most private of the public documentsmembership questionnaires - begin to clarify some of the rules of militia messianic marginality in ways that are not expressed in more public presentations.

\section{Not Keyboard Commandos ${ }^{16}$ : How the Militia Introduces Itself in Literature}

\footnotetext{
${ }^{16}$ This is a pejorative term used to refer people who make bold claims about their martial prowess, firearms and military knowledge, and willingness to utilize them on the internet but in reality, lack all of them.
} 
Referring to the end of the excerpt from my fieldnotes that opened this chapter, that was the first and last time I saw an avowed, overt white supremacist during this project. If I have met others that managed to join the core membership or the regular members of the $10^{\text {th }}$ they have not been evident to me despite years of studying the far right. The tendency within the militia, and the broadest strokes of paramilitary gun culture by extension, is for participants and enthusiasts to distance themselves from organized and overt racism while remaining ambivalent or hostile to the idea that their views and practices reproduce status hierarchies. Race, sex, religion, and politics have been topics of formal and informal conversation and a few participants have made comments that I found offensive throughout the course of the two-and-half years I have been involved with this project. At the same time, the group and its key members have reliably distanced themselves from organized hate groups.

Some of the literature on the militias focused upon 'below-ground groups,' and the link between them and organized racism. Typically, scholars and interested parties pinpoint this connection in a 1992 meeting in Estes Park Colorado, sponsored by Christian Identity leader Pete Peters, at which key figures in both the racist right and the anti-government parts of the paramilitary gun culture met and organized a framework for leaderless resistance in which racism and antisemitism would be publicly toned down and replaced with the ordinary resources of anti-government rhetoric in order to attract recruits (Abanes 1996, Crothers 2003, Dees 1996, Dyer 1997, Stern 1997, Kimmel and Ferber 2000). White supremacists still draw upon this strategy today but understanding the $10^{\text {th }}$ requires another approach. 
An alternate thread in the literature on the first wave of militia activity troubles this connection in informative ways. George and Willcox (1996) point out that:

"If one were to select at random a group of actual members of militias, five categories would probably be represented in the following order of frequency:

1. People generally conservative in outlook, although not very ideological, who are worried about what they see as a repressive government imposing all manner of strictures on them from unfair taxes to gun control.

2. Would-be adventurers-generally nonideological weekend-warrior types who like to wear camouflage and play soldier in the woods. They watch movies with western and military themes and like to hunt and fish.

3. Libertarian-conservatives who accept some government on the local or state level, but who oppose federal regulations of almost all kinds.

4. Anarcho-libertarians who consider virtually all government as repressive and overbearing. They refer to themselves as 'freemen' or 'sovereigns.'

5. Hard-core extremists who harbor an obsessive conviction that the United States, indeed the world, is in the death grip of an all-powerful conspiracy." (249).

Aho (1990), working in the very earliest stages of these developments in 1985, found something similar: in his study the militia groups in Idaho a variety of groups with eclectic ideological leanings that ranged between Christian supremacy with and without racial emphases, and issue-oriented people, as well as groups characterized by overlapping attention to each (ibid: 11). Tying the two threads of the literature together, it seems very likely that militia groups organize and perform identity work based on the preponderance of concerns their actual members have, the audiences they seek to reach, and the sorts of actions that make sense in according to local ordinary resources rather than a subterranean, widely-shared theocratic racism or antigovernment bent. This assumption goes a long way towards explaining infighting among various far-right groups as well as the differences between outwardly similar militia groups. 
The $10^{\text {th }}$ belongs to an overarching organization of about 13 units organized under a larger state unit directed by Commander Wilson, whose unit is based in a large metropolis a little over two hours away from the city in which I lived during this project. that has a sophisticated website detailing its overall orientation and activities, as well as information about the evolving regional units. In my experience the website primarily follows the training and activities of the Commander's unit to the exclusion of others. ${ }^{17}$ One page is dedicated to providing contact information for each regional unit, including the names of the unit leaders and phone numbers that can be used to reach them. In the case of the $10^{\text {th }}$, these are the unit leaders' actual names and phone numbers and this leads me to suspect that the rest are likely accurate as well. It is difficult to pin down the precise number of regional units as it varies when units disband or form. Presently the number is fifteen but it has been as low as 12 over the years I have been examining the group. Both the statewide organization and the $10^{\text {th }}$ are archetypal 'above-ground' militia groups (Chermak 2002) insofar as they publicly advertise their organization at gun shows and via social media, operate under a state-wide, hierarchical chain of command, and explicitly frame the group as defensively-oriented, non-racist, and, from their own perspectives, adhere to moderate positions on social and political life. The website and various pamphlets the group produces and distributes this further substantiates my argument that they are an above-ground militia whose ordinary resources align closely with the color-blind

\footnotetext{
${ }^{17}$ While one might suspect that this myopic focus is a function of the commander's ego or the self-importance of that unit's members I suspect instead it is a function of the loose hierarchy the group exercises over the regional units and the fact that the Commander's unit appears to be the most populous and active given it is in one of the largest population centers in the state; I expect this also means they have more members willing to donate their time to updating the website
} 
combination of libertarian and conservative populism common to the broader paramilitary gun culture.

The members of the $10^{\text {th }}$ that I worked with and particularly its core members and leaders are quite sensitive to public perceptions of the group and its members insofar as they imagine them. They engage in a great deal of boundary work to distinguish themselves from earlier and contemporary militia groups as well as organized racists, Neo-Nazis, and "anarchists" or "radicals." The latter two categories serve as residual categories for protestors and any other militia groups that they and those they feel are problematic or related to the decline of the nation. These distinctions seemed odd at first, but they make sense to members of the $10^{\text {th }}$ because their views generally align with the neoliberal individualist, socially conservative, risk-filled worldview of paramilitary gun culture. Under the assumptions common to such worldviews, certain degrees of economic, sexual, and racial, hierarchy are viewed as natural byproducts of differences in individual effort and discipline within a market-based, free society. Consequently, the views of many members of the $10^{\text {th }}$ also align well with the broader neoliberalist views that naturalized these hierarchies and from thence argue that their practical efficiency and moral functioning can be perverted through what they view as governmental correctives to the failings of immoral, irresponsible citizens ${ }^{18}$. The $10^{\text {th }}$ expands upon these ideas and where they intersect with paramilitary gun culture. They accept notions that individual effort and responsibility for personal safety are necessary duties to oneself and to others but, beyond

\footnotetext{
${ }^{18}$ To be certain, may elements on the far-right that have as of late achieved greater visibility also tie these ideas to hierarchy their arrangements tend to tie race into these views explicitly in order to emphasize race and religion as explanatory factors in individual effort and support explicitly racist paradigms (Neiwert 2017, and Kimmel 2013). Here, opinions and feelings that outsiders identify as racist are not treated as central to the messianic marginality performance and, indeed, overt deliberate racism is often treated as antithetical to being a good, color-blind American.
} 
this, members of the $10^{\text {th }}$ also believe that these private efforts should be organized through a group and trained if either they or their skills are to be effective as community resources.

Within the $10^{\text {th }}$ the core membership group reliably consists of fewer than ten to twelve members at any given time and they make up the bulk of the unit's official and unofficial leadership ${ }^{19}$. Core members are very engaged with the $10^{\text {th }}$; as a deeply-invested minority of members they tend to be long-term participants who attach a great deal of personal significance to the group. These members are central to the group's activities and interactions at both staff meetings and in the field, a trait strongly associated with their nearly perfect attendance at both staff meetings and trainings and the degree to which they see to the organizational needs of the group. Compared to other types of members the core members also tend to have and wear completed uniforms, own the most carefully considered gear and firearms, instruct most of the classes, and organize the unit's training and meeting schedules. Several of them are friends outside of their activity in the militia and in a couple of cases they have known each other for the majority of their lives such as Charles, fifty-fifty five years old, who I described in the introduction, and Cypher, a fiftysix-year old teacher of robotics and technology. Because of their levels of involvement relative to regulars and peripheral members, the views and identities of these core members are strongly reflected in the messianic marginality that appears in recruitment materials as well as the training curriculums and activities of the group.

\footnotetext{
${ }^{19}$ I draw a distinction here between official and unofficial leaders based on the fact that their formal leaders are elected but other core members perform many of the same tasks and have a significant voice when it comes to group decisions.
} 
Core members are all either already full members ${ }^{20}$ of the 10 th or quickly achieve the position if they joined part of the way through my time with the group. Peripheral members whose sense of messianic marginality and uses of ordinary resources already align closely with those of the core and regular members tend to advance quickly due to the speed with which they can be socialized into the militia's rules for messianic marginality. Pierce, a sixty-three-year-old military veteran, and trained therapist, who "feels like he is thirty-five," was a peripheral member when he initially joined the group but based on how closely his experiences and identity matched with the group's he quickly rose to leadership and is now the acting leader. Similarly, Alaine, in his thirties and running a small construction business, enthusiastically adopted the group's standards despite his complaints that there is not enough hands-on activity.

As leaders, albeit sometimes reluctant ones, core members are usually the main points of contact for outsiders, recruits, interested parties, as well as the leadership at the state level. Leaders can be reluctant for several reasons, usually pertaining to the fact that usually have a high number of outside obligations. All the core members save for Audrey and Arthur are employed full-time. Based on the data I have every core and regular member of the group is either employed full-time, part-time, or engaged in very busy retirements. Similarly, all core members who granted me an interview also have spouses and in most cases children and grandchildren. They each also have at least a few other clubs, social obligations, and hobbies all of which vie for time with their activities with the group. Based on the combination of these characteristics not surprising then that the core members take

\footnotetext{
${ }^{20}$ Full membership in the group requires that several conditions be fulfilled: attendance at three training events and a unanimous vote of confidence by other full members who are present at a meeting or training during which the vote is called.
} 
seriously the time they dedicate to the group and want it protected from negative attention that could follow from others highlighting aspects of its identity work and ordinary resources that they believe are marginalizing.

When either the $10^{\text {th }}$ or the parent organization advertise at gun shows it is their most public interactional space and as a result the narrative and talk deployed the literature they distribute more stringently adheres to rules of messianic marginality in the broader paramilitary gun culture than the rules used in their own venues and events. This shapes their literature in ways that balance their desire to ingratiate themselves with those who share elements of their identities and their desire to distance themselves from those who, despite sharing at least some ordinary resources, would either deliberately emphasize the more alienating elements likely to limit their messianic claims and further marginalize them in the eyes of the public. More concretely, their most public displays of messianic marginality advertise their responsibility, legitimacy, appropriate levels of interest in firearms, and skepticism towards power while also distancing them from organized racists and aggressive, hostile militias.

The combination of outward friendliness and constant wariness demonstrated by the vendors at the gun show appears to be a contradiction, much like the idea that women should exercise agency through self-defense that adheres to the male gaze. These outsider's conflicts emerge from the discrepancy between an outsider's perspective and the assumptions about the world that a person makes in order to perform messianic marginality in both the paramilitary gun culture and the militia. Learning how to place adequate emphasis on the messianic elements of firearms ownership, gender relations, and 
responsibility shifts the conflict from one arising from internal contradictions of the culture to one between insiders who 'get it' and outsiders who do not.

Making no personal efforts to remain vigilant for the potential emergence of threats places the threated party at a disadvantage, turning laziness and irresponsibility into personal and social liabilities. The conflict between being internally 'on' in condition yellow (Baum 2013) and scanning for potential threats while maintaining an outward position of welcoming availability to the show's public attendees does not appear if one internalizes a view of the world and the people in it as inherently risky. Assuming that a threat exists in advance is believed to provide a greater chance of allowing an immediate response to it. In terms of messianic marginality, this represents achieving a superior moral position compared to others through cultivating personal responsibility and discipline. Remaining open and courteous in the face of the danger that is simultaneously everywhere and nowhere until action collapses it into one or the other is taken as a sign of taking responsibility in the face of a society that cannot and should be responsible for one's personal safety.

The pervasive belief society cannot effectively provide for personal safety and, moreover, the belief that demanding that it do so is an abdication of personal responsibility and personal liberty are common throughout the talk and stories in the research on concealed carry (Light 2017, Carlson 2015a, Stroud 2015). It is a foundation for messianic marginality in the $10^{\text {th }}$. Wade described it well during our interview outside a local mall:

"When I was a medic one time, I was working here, we were doing CPR class, or something inside, doing one of those deals where ambulances and fire trucks were all around. Everybody's walking through them and having a good time. Some guy came running up, he says, 'A guy just broke into my 
car.' It's like, 'What do you want me to do?' and he's says 'Call somebody.' I'm thinking, 'You call somebody.' That wasn't our deal. But I'm saying that, relating that story to that, just because there's a lot of stuff going on, doesn't mean a crime won't be committed. Hopefully it won't be you, or I, or your wife, or girlfriend, or anybody else, but it's going to happen. It just will.

If you have a firearm, you at least have the option of...you have a chance and a last-ditch effort to save your life in a bad situation, as opposed to none. If you're alert and aware of what's going on, it's probably better. Right now, I'm covering this door over here for you, and you're covering the parking lot for me. I feel pretty safe about that. Don't give the bad guys more chances than they already get. If you've been to a conceal carry class with people that have been around this before, the law enforcement agencies or around [the city] long enough, they will give you some ideas of what these people that commit crimes are doing. When they're: 'You got a cigarette?', 'Can I use your cell phone?', 'You got a couple bucks?', it's called bumping. Just seeing what your reaction's going to be, see if you're a viable target."

This vision of the world requires a person to make a series of assumptions: first, a responsible person assumes that threats can appear any time; second, they should assume that they can be capable and comfortable enough in their abilities to recognize and respond to threat appropriately so to as not allow the constant tension to make them rude or paranoid; third, they must also assume that these requirements have positive social and personal value. Whether or not these assumptions are supported by evidence is important to the extent that most participants in the paramilitary gun culture can cite a couple sources that substantiate their views ${ }^{21}$ but is secondary to the story that they allow a person to tell themselves and others about the world and their relationship to it. This is the work required in any messianic marginality relying upon the idea that the confidence and responsibility that come from carrying a firearm does not also add to the risk in the world. Instead risk is

\footnotetext{
${ }^{21}$ John Lott's More Guns, Less Crime: Understanding Crime and Gun Control Laws (1998) is by far the most common point of reference used in this capacity. The critiques and methodological debates around the work are not discussed and I've seldom attended a gun show at which at least a few well-worn personal copies were not available for sale.
} 
diminished because the 'right' people are armed and paying attention to the 'wrong' armed people $^{22}$.

One simply does not know if a person is a threat or not until they become one through action but this does not stop participants from constructing preemptive stories about threats or accepting post-hoc justifications for a shooting. These too rely on shared ways in which paramilitary gun culture and the militia organize responsibility, race, and sex. That people of color are more likely to be seen as threats regardless of specific actions is not discussed or something that most participants would agree with except in terms of the stereotype of the criminalblackman (Russell-Brown 2009: 3, Stroud 2016). Because maleness is believed to produce greater natural aggression this makes men both the most likely threats and the best suited to conduct protective violence. Properly disciplined through religious piousness or economic and familial responsibilities this aggression becomes tied to messianic male risk-taking and competitiveness. Appropriate masculinities mean demonstrating through responsibility in all the above domains that one is an appropriate protector for the women, children, and less masculine men - all feminized, subordinated categories of people. Conversely, to many participants, this also means that populations that their experiences and media diets have taught them to stereotype as having high concentrations of undisciplined, irresponsible men, are more likely to produce threatening men who commit violent crime to meet their needs. This leaves invisible that what becomes defined as threatening behavior, ranging from mere physical proximity to

\footnotetext{
${ }^{22}$ To draw on another example, this logic is also why the idea that we should respond to mass shootings by arming teachers and expecting them to simultaneously prepare to nurture their students or shoot students does not seem contradictory to its proponents. Teachers are assumed to be responsible for the children under their care, responsibility is assumed to include providing for their physical safety regardless of the origin of the threat, and people who engage in just lethal force are assumed to have a clear conscience in the aftermath of a defensive shooting, or at least the foundation upon which one may be built.
} 
actual actions, privileges the experiences and feelings of largely white males. This plays out in police action and private self-defense (Bonilla-Silva 2001, Light 2018, Stroud 2016), in ways that, once highlighted by outsiders, is taken to mean that outsiders believe armed white men are all racist, and violent; this produces the sense of marginalization that counters the messianic components of armed masculinities who believe their actions are natural, appropriate, and services to others.

Similarly, encapsulated by Flash Bang, ideal femininities appear contradictory because they are those that are appropriately aware of the dangers of the world from the perspective of paramilitary gun culture but retain their femininity despite preparing to face those threats. Almost all of my key informants have at one point or another talked about concern over the decline of the nuclear family they view as traditional, morally superior, and one of the pillars of United States. As was the case with race, there is not really an organization of these ordinary resources that acknowledges that such an arrangement, especially in the cases of armed men, places women in a subordinated position commonly associated with domestic violence (Light 2018). Instead, there is a feeling of marginalization associated with believing this arrangement is morally and socially correct to the exclusion others. Here then, women are assumed to exercise agency in being able to lethally defend themselves and any charges under their care from threats but this ability does not detract from the assumption that such women also find their social value and selfworth as nurturers and objects of male sexual desire. The contradiction between a femininity defined by attractiveness to men and the risks from men it is assumed to present and a femininity defined by lethal capability is temporarily collapsed into a single category that links sexuality, gender, and lethal threat in such a way that armed women are to be 
feared by imagined male assailants and yet remain subordinate potential partners for men practicing martial masculinity and messianic marginality.

Moving now to the militia's public documents and how core members align their own militia-oriented messianic marginality work with these broader trends. For most of my participants the website was not their first contact with the group. Like me, they largely encountered members at a gun show distributing literature and from thence found the website or contacted one of the core members. In light of this I will begin this portion of the analysis by examining the narrative genres utilized in the material the $10^{\text {th }}$ uses to advertise itself and demonstrate how they draw upon ordinary resources of paramilitary gun culture but reframe them in ways that explicitly center link their social value to their individual value. In this way the $10^{\text {th }}$ challenges the most individualist visions of responsibility, recognizing that they can collectively do more good than if unorganized and alone.

The $10^{\text {th }}$ 's introductory handout is quite small, a piece of paper no more than five inches high and three inches wide. It has a watermark in the form of an illustration depicting a militiaman from early American history. Printed on one side is a series of points under the heading "Who We Are." On the reverse is another series of points pertaining to "Who We Are Not." Examining the reproduced text from their handout below is an informative departure point for several narrative genres (all bold text and punctuation is identical to the original document): 


\section{"Who We Are}

We are all volunteers-we receive no supplies, equipment, funding or monetary compensation of any kind.

We are civic minded-even though our structure and some of our training has a very paramilitary flavor, our main mission is to assist local citizens and law enforcement in time of need.

We are diverse - our members come from all walks of life. We have factory workers, retirees, engineers, and even a PGA golf pro

We are authorized to exist under both the U.S. and Missouri state constitutioncopies of the statues are found at our web page @ (webpage omitted, present in original).

\section{Who We Are Not}

We are not anti-government — we are law abiding productive citizens with a desire to be prepared to help in time of need.

We are not racist-membership is open to any non-felon over 18 yrs old regardless of race, gender, or religious beliefs.

We are not secretive-all training sessions and meetings are open to the public and observers are welcome.

Still have questions?

Feel free to contact us via info listed below. (Contacts omitted, present in original)"

This document is the inspiration behind my identification of Who Talk as a narrative genre in militia identity work. Who Talk refers to stories and utterances whose form is one of explicit or implicit comparison between the presenter, and others that, whether positive or negative, that positions the speaker, audience, and point of comparison into moral, civic, and social relationships with one another. In the case of the pamphlet, at face value the two presentations, "Who we are" and "Who we are not", appear as grammatically distinct sets of statements. Analytically and practically they both rely on simultaneously understanding matching sets of positive messianic and negative marginal elements commonly shared between the paramilitary gun culture and the militia. The function of this genre is two-fold: the affirmative form of this talk highlights and integrates positive messianic qualities which members believe showcase virtues of responsibility, duty, and contributions to their communities; the denial form explicitly distances the members from the marginalized sides of these qualities that they believe that outsiders would otherwise apply to them. 
"We are all volunteers who receive no supplies, equipment, funding or monetary compensation of any kind," accomplishes several messianic aims. In the first case the text makes explicit to the readers, others that they expect hold similar views of personal freedom and responsibility, that the members of this group have not been conscripted by some authority and are not obligated to participate in whatever the militia does, which here is left unclear. In other words, the $10^{\text {th }}$ is comprised of individuals who choose to participate based on the personal responsibility they feel to do so. The second portion of the line is designed to make clear to the audience that the members of the $10^{\text {th }}$ are not 'takers' who draw resources from their communities to accomplish their aims. Instead, they are people who also prepared to do for others without being bid to do based in their own abilities to provide for their needs. They can help others because they do not need help themselves. Accomplishing both the preparation and action needed to help others while drawing only upon personal resources is common messianic element that reframes the self-interest involved in owning firearms, stockpiling food, water, and emergency supplies. Instead of marginalizing personal selfishness these practices are a positive form of selfishness that allows a performer to provide for others should they choose to do so. Again, Wade addresses this well:

Daniel : "If you have a preference[regarding the next topic of conversation], I'm going to go with that. Would you rather talk about the militia or guns? And they're kind of, in some ways, they're alike.

Wade: Yeah. I'd preface part of that by saying that in most areas, the closest thing that you would have to a militia is a volunteer fire department. They are a community service group, as is the [militia]. We're never as active as we should be. We should be doing more service, but being humans, we're lazy and we get out of the habit of doing things. But to serve your area, some of the things we should be doing more of is primarily education. The more people in any given area that are self-sufficient, well let's bring up Joplin for an example, the more people in that area that are self-sufficient and can 
do things for themselves and help their neighbors, the less they depend on outside influences or entities.

We went to Joplin to do work there. We went to Orrick last year and worked up there after a tornado, that was just kind of a one-dayer. Because of the size of the town and the intensity of the tornado, damage wasn't bad, it was still plenty bad.

Daniel : It was still a tornado.

Wade: Yeah, roofs gone, mobile homes overturned. You got trees on top of stuff. It's a mess. So, you go up and you do what you can do. But like in Joplin, and Hurricane Sandy, who helped there, was it militia? No, it was FEMA. There's people up there that are still waiting for money, or something, and that was what, two or three years ago? FEMA just didn't come through. I saw pictures of Michael Bloomberg walking through, doing the photo ops, and he chased out one of the national guardsmen just because they were armed. Okay? It is the National Guard. It's not the fire department, and that's what a militia or a national guard is. We do public service work, and we're also armed. We also believe strongly that any citizen who wants to, should be armed. Not necessarily to ... I mean that in a good way, and some people can't fathom that no matter how they think about it. One of the sayings here is an armed society is a polite society, and I believe that."

Their material also plays on positive associations they want the audience to make between their group, the storied Revolutionary militias of America's founding, and the ways that both are infused with self-sufficiency that is transformed into a social benefit through risk. American history is an important ordinary resource in American society and even more so in the $10^{\text {th }}$. The way in which the $10^{\text {th }}$ 's advertisement makes this association explicit through the watermark and this first statement creates a positive historical and emotional link between the two groups despite the temporal gap between them. In the United States there is a very long tradition among politicians and the general public alike presenting themselves in terms of having a special relationship with or understanding of people and ideas of the country's past-particularly those associated closely with the "Founding Fathers" (Lepore 2009). In the case of the $10^{\text {th }}$ and paramilitary gun culture, 
knowledge of American history is a very valuable ordinary resource to use in messianic marginality work. These popular historical narratives are an ordinary resource used throughout paramilitary gun culture which I term historical capital. Historical capital is specific, cultivated knowledge, including interpretive and presentational schema, that allow a person to use it in claiming a certain status in society among people who share this knowledge. This includes the status extraordinary 'Americaness' and praise-worthy masculinities that many participants in the paramilitary gun culture claim based on the significance they attribute to their increasingly visible practices.

The mythic, popularized version of The Revolutionary War wherein relatively few patriotic colonial citizens took up their personal arms and at great personal risk forcibly separated themselves, their families, and their fellows from the tyrannical British monarchy is a nigh-constant point of reference. This is the source of the notion that the Second Amendment has embedded within it an insurrectionary philosophy that legitimates citizen overthrow of the government. Deployments of these ordinary resources are often supported by strings of popular quotes both real but out of context and fabricated that suggest the founders of the nation believed that citizens needed sufficient weapons to overthrow their government because any central power tends towards tyranny. Crothers addresses this mythologized militia quite well:

"In this myth, gentle, selfless people (including women, African Americans, and even Native Americans) leave their homes (taking their weapons, of course) to volunteer to fight an oppressive foe. They have no ambition to impose their political will on others; rather, their dream is to be left alone to take care of their farms and families. They are motivated only by the kind of righteous rage against oppression that inspires heroism but avoids the oppression of others." (2003: 25). 
Any use of history in this way is political and an exercise in power. This involves including and excluding people from the mnemonic communities that shape these narratives and the identities that can be produced using the ordinary resources associated with them (Olick and Robbins 1998, Eichstedt and Small 2002, Gordon 2008). In the appropriation of the broadly understood American heritage the members of paramilitary gun culture can claim dignity and moral virtue in the face of their sense of marginalization without having to address the ways in which race, sex, and economics relate to the events they reference or the pervasive forms of inequality that persisted afterwards. Two notes need to ought to be made here. First, this sort of historical capital is not limited to the paramilitary gun culture; their use of it is highly specific and directed but American history finds use in the identity work of people throughout the nation on all sides of the political spectrum. Secondly, there are numerous other ordinary resources that the participants in this study draw upon.

This position of being a dutiful volunteer is explicated further in the second instance of Who Talk, "We are civic minded—even though our structure and some of our training has a very paramilitary flavor, our main mission is to assist local citizens and law enforcement in time of need." This presentation makes explicit the notion that the militia wants its existence and activities to be viewed as a safe, public good while simultaneously it implicitly distances itself from marginalizing elements of paramilitary gun culture. By admitting to their paramilitary practices, the group attempts to preemptively frame it in the eyes of the reader as an aesthetic choice rather than an essential quality; the flavor of their activity rather than its content. Distancing themselves from a marginalizing view of militias as pretenders to military service and its attendant prestige seeks to make the messianic 
notion that they are a support group for law-abiding society and local police more palatable by contrast. Delimiting their "mission" to actions that occur during "time of need" further reinforces the idea that this is a group that volunteers their time, resources, and energy to their communities and the people who otherwise protect it, despite the aesthetic they choose to use in doing so. Note that this iteration of Who Talk also includes a specific situation in which the identities and relations that the $10^{\text {th }}$ is positing are situated. Like most other forms of human talk and storytelling, people combine elements of different genres and, sometimes, unite them, to express relationships and situations that any given genre by itself cannot quite organize in a sufficient way.

This leads us to another key genre in militia messianic marginality that is frequently linked to Who Talk, Scenarios. Scenarios take the form of references or detailed depictions of periods of danger which must be resolved by capable people. There are subgenres of Scenarios that detail different man-made dangers, like civil disorder, a good-guy versus bad guy encounter, or organized violence, as well as natural threats, such as environmental catastrophes. In all cases, the genre takes the form of identification of the source of danger, who is in danger, who is responsible for responding to it, and what might happen should they fail to do so. The function is to integrate different messianic components germane to responding to the situation with interpretations of the value they will provide in that situation. Within the vague "time of need" Scenario because the is $10^{\text {th }}$ prepared with supplies and armaments they can respond to whatever a reader might imagine, through which their organization and participants transforms them from individual firearms owners into a collective good in their own eyes. 
Skipping to the last statement on the front side of the pamphlet, "We are authorized to exist under both the U.S. and Missouri state constitution — copies of the statues are found at our web page," combine historical capital with another narrative genre. Appeals to legal statues, legal knowledge, like references to United States history are common throughout the paramilitary gun culture and militia and are used in Legitimacy Talk. Legitimacy talk takes a simple form with little variation: a speaker makes reference to legal or historical knowledge in connection to their own actions and attitudes and to a sympathetic audience, this presentation functions to bolster the credibility of the speaker and their positions while reinforcing the interpretations of law and history that the talk has invoked. Legitimacy Talk is a subgenre of Who Talk and, as such, participants can readily combine it with Scenarios to create elaborations on messianic marginality suited to a wide range of interactional venues. Depending on the audience and the identity work required, speakers may establish formal, direct connections, or leave it to the audience to infer the appropriate implicit connections. The above reference to the law and historically significant documents is an example of a very general type of Legitimacy Talk. Again, the degree to which these legal statutes actually authorize the group's activities is secondary to the idea that they do. The additional fact that it is not clear how often states and counties attempt to legally address militia groups within their borders lends additional legitimacy to such interpretations.

The appeals to history in Legitimacy Talk aid in framing the paramilitary orientation of the group by recasting it as historically precedented and part of the nation's beginnings. That both federal and state constitutions are mentioned is indicative of the value that participants often place on what they colloquially identify as "state's rights" but more specifically signifies their assumption that the federal government has far exceeded 
the boundaries the founding documents and their authors outlined. These views are common throughout the paramilitary gun culture. It is also meant to distance this group from other militias and organizations that they and others find untrustworthy, irresponsible, and undeserving of legitimacy. Invocations such as these are a messianic move that positions the group and its membership as people willing to utilize their time and resources to benefit themselves and others within the letter of the law, as they interpret it, which in their worldview marks them as responsible and trustworthy. Responsibility and trustworthiness are messianic in the sense that to participants in this project these qualities represent personal effort and discipline which, again, are simultaneously personal virtues and contributions to society. The marginal element of this construct depends on the assumption that these qualities are not as common as they once were and this lack places an unfair burden on those who pay attention to the latter of the law them by placing them at political, economic, and social disadvantages compared to those who lack them. Examining the corresponding first and third points on the reverse of the document further clarifies this positioning and how different genres can be readily combined.

"We are not anti-government—we are law abiding productive citizens with a desire to be prepared to help in time of need," and the final statement, "we are not secretive-all training sessions and meetings are open to the public and observers are welcome" both speak to distancing the group from marginalized identity components. The key members of the group are keenly aware of the stigmas attached to militias those who join them. To be objective, this stigma is largely based on concern regarding the dangers that many of the underground groups and public hate groups readily present as vehicles for distributing knowledge, skills, and ideologies that are associated with racially, religiously, and 
politically motivated violence. These are concerns that leaders of the unit I worked with generally share regarding other militias and non-militia racist organizations, at least within the scope of their understandings of racism, religion, and politics. Their own worries about more extreme groups encourages their efforts to distance themselves from marginalizing identity components. Distancing themselves from the label "anti-government" relies on the audience being aware of the marginalizing 'anti-government' viewpoints associated with the militia movement are shifted behind the messianic qualities of responsibility and support for the rule of law. Their emphasis on transparency further enhance this transition. From a background social order in which privacy is more often a privilege than a right, the groups' evident willingness to forgo their own privacy is designed to dispel the marginalizing notion that militias are full of secretive, unwelcoming people via an emphasis on the messianic nature of their openness and willingness to engage with the public.

"We are diverse—our members come from all walks of life. We have factory workers, retirees, engineers, and even a PGA golf pro" makes clear that the unit is aware that an audience may see militia as monolithic along various dimensions of diversity and they seek to head this off. One notices however that they have limited the idea of diversity here to differing professions and employment statuses rather than along any other demographic categories. There is a persistent and widespread belief among the main participants in the $10^{\text {th }}$ and the broader population that uses these resources that there exists a critical mass of people in the United States who do not have a work ethic sufficient to provide even the basic necessities of life for themselves, let alone to contribute to their communities; such people are often indirectly presented as African Americans and 
immigrants (see Lamont 2000 and Quadagno 1994 for more detailed analyses of these processes). Messianic marginality in this context ties racial components into this basic question of independence and government but most often, race is not discussed by anybody in the $10^{\text {th }}$ in such a way as to specifically identify a racial category. Instead, context clues like geography or dependence are used to code races without naming them specifically. Truncating diversity to varieties of personal economic productivity aligns well with the more common views on race, politics, and government common among the members I have worked with. Of the positive Who Talk invocations that exist in my data and field experiences there are few that have been emphasized as strongly as individual work ethic. An individual's willingness to work in difficult jobs and under difficult positions is a central components of messianic marginality work in the militia. Many of my key participants made clear in interviews they are deeply proud of their work ethic, Cypher is an excellent example here:

Daniel: "So, I guess that brings me to the biggest problem that you see people facing these days. What would it be?"

Cypher: "I don't want this to sound racist, ok? I think, I think everybody, everybody [his emphasis], is capable of being equal. But I think that welfare sets some ethnic groups up for failure, alright? Everybody is capable of being equal but when people think they can just get check and party or whatever and make just as much as if they were working that sets them up for failure and I think that's a big problem that people face and it sets people back. You know what, I have something that I want you to write down. I want you to write this down: 'I have never been unemployed from age 17 on.' I'll give you a second. Yeah. I have never been unemployed since I was 17. Not once. I didn't always like the job, and it didn't always pay what I thought it should, I didn't always make enough but I always had a skill that I was using. I see kids now, in my classes and around, I see these kids and they think they have no skills. People take my class [on robotics and electronics] because they think it sounds better than English or history or something. I wish that weren't true, but they think they have no skills at all 
so it's not like they think there's something for them to do, alright?" (Excerpted from interview with Cypher on 1/21/2017).

Cypher's answer to my question speaks to several important ways in which race, sex, and class intersect in messianic marginality. First and foremost, his initial point speaks to the relationships the he, and other members of the group, see between race, independence, and government. In terms of messianic identity components, ideal citizens and men in particular are not dependent on government at any level. To depend on the government for protection, let alone a livelihood, is to become politically and personally compromised as a self-interested, responsible economic actor; it is coded feminine. It is a common belief among my participants that people compromised in these ways can be expected to vote for giving the government more power to provide for them so they can avoid having to do so themselves. Conversely, there is a related marginal position insofar as Cypher and others who hold to these positions tend to believe that despite their own hard work to achieve responsible independence this quality makes them targets for taxation used to fund social programs for people they believe cannot or will not work. To reiterate an earlier point, the extent to which these concerns are true in a factual sense is not as important to the narrators as the stories that can be told and the messianic marginality work that can be accomplished through them. This is why for participants there is no serious contradiction between many of the other government services or jobs that members may have access to, present or past. Their identities as responsible, hard-working people makes them feel less susceptible to the risk of dependency should they who work for the government or receive benefits from it, given that they have already demonstrated they do not need it.

His answer also demonstrates another common belief among members of the $10^{\text {th }}$ that specifically identifying racial categories, even as targets of oppression or in need of 
assistance, is the first step to others identifying them as racists. I posit that this is another reason that item pertaining to diversity ignores race as a possible category. Even referring to a race explicitly risks marginalization by outsiders in their eyes. Any inequalities between racial groups as they have been defined in the US here become interpreted through the naturalized hierarchies connected to neoliberalism so government activity meant to alleviate systematic inequalities is taken as interference. Hence Cypher's explanation that government action taken to alleviate poverty and other inequalities primarily targets racial and ethnic minorities and are liabilities because they reduce the abilities of recipients to develop their own work ethic and responsibility.

The literature for the state-wide unit has clearly informed that of the $10^{\text {th }}$, but it is clear that the $10^{\text {th }}$ has elaborated on some elements in their own pamphlets (identifying details removed but all other formatting is present in the original document):

"'Every citizen should be a solider. This was the case with the Greeks and Romans, and must be that of every free state.' T Thomas Jefferson"

\section{"The [Militia]: What is IS}

The [Militia] is a volunteer organization formed to train and act as a reserve component to the National Guard, with the intent to act as the State Defense Force (SDF), as the is currently no SDF for Missouri. The militia is classified as a civilian volunteer organization and therefore will carry out operations in the absence of orders as dictated by necessity during a crisis with professionalism, integrity and the utmost respect for others at all times.

Missouri law makes provisions for the Militia in the Missouri Revised Statutes, Title V, Chapter 41: Military Forces - sections 41.030, 41.050, 41.060, 41.720.

\section{"The [Militia]: What it is NOT}

The [Militia] is NOT an extremist group. We do not indulge in conspiracy theories and wild speculation. Illegal activity will not be tolerated, nor will discussion of overthrowing any Constitutional Government. Regardless of our individual personal political beliefs or philosophy we are sworn, just as our US military service men and women are, to support and defend the Constitution of the United States against all enemies, foreign and domestic, bear true faith and allegiance to the same, and obey the orders of the President of the United States and the orders of the officers appointed over us. 
The [Militia] is NOT a hate group. Bigotry of any sort will not be tolerated. All law abiding, qualified citizens are welcome to join our ranks regardless of political affiliation, race, gender, sexual orientation, and religion (of lack thereof).

The [Militia] is NOT secretive. All meetings and training are open to the public and all are welcome to attend. We especially welcome local and state law enforcement and elected officials." (Militia Literature, 2016).

Compared to the literature distributed by the $10^{\text {th }}$, the state-level literature makes it more explicit that they see themselves as comparable to the military, past and present, have a legitimate reason to organize, and are not like below-ground militias. The Who Talk here is more specific in its references to specific laws and governmental entities which they hope serves to enhance their Legitimacy Talk. Because the latter references are only to armed service professions the state organization manages to avoid linking themselves to the types of government action that other within the paramilitary gun culture would be likely to consider illegitimate. As earlier, government-sanctioned uses of force linked to policing or controlling dangerous others are among the only types of government activity that participants in the paramilitary gun culture are likely to consider legitimate.

These presentations are designed to further assuage audience concerns by legitimizing the group by drawing on historical capital in the forms of images of Revolutionary-era fighting men and the partial Thomas Jefferson quote ${ }^{23}$. This serves to

\footnotetext{
${ }^{23}$ I characterize it as partial because the full quote is from Jefferson's correspondence with James Monroe and reads "it is more a subject of joy that we have so few of the desperate characters which compose modern regular armies. but it proves more forcibly the necessity of obliging every citizen to be a souldier. this was the case with the Greeks \& Romans and must be that of every free state. where there is no oppression there will be no pauper hirelings. we must train \& classify the whole of our male citizens, and make military instruction a regular part of collegiate education. we can never be safe till this is done." ("Thomas Jefferson to James Monroe, 19 June 1813," Founders Online, National Archives, last modified April 12, 2018, http://founders.archives.gov/documents/Jefferson/03-06-02-0188. [Original source: The Papers of Thomas Jefferson, Retirement Series, vol. 6, 11 March to 27 November 1813, ed. J. Jefferson Looney. Princeton: Princeton University Press, 2009, pp. 209-210.]). The entire quote taken in context would challenge both their presentation of the militia as voluntary as well as their comparison to the profession military but it is not clear if the omission is deliberate or a byproduct of finding the quote elsewhere and failing to further investigate.
} 
further foreground the group relative to acceptable governmental actions and further discourage a reader from lumping this group together with what they believe members the public would consider 'bad militias'. The $10^{\text {th }}$ reinforces the importance of this balance between the messianic and marginal in their recruitment questionnaire. Given that the original includes identifying information, I have reproduced it below omitting that information. 
FIGURE 8: Reproduction of Membership Questionnaire for $10^{\text {th }}$ Recruits

1. Have you ever been convicted of a felony?

2. Have you ever been convicted of a misdemeanor? Please explain!

3. Are you currently or have you even been involved with members of the KKK, Aryan Nation, NEO Nazi Party, Black Panthers, LaRaza or any other ethnic or government hate group?

4. Do you currently have a concealed carry permit?

5. In what state are you licensed? Can you produce the paper work?

6. Do you currently possess any illegal weapons, explosives or components of any kind?

7. Have you even been in a situation that you felt is necessary to draw your concealed firearm to protect your life or that of a loved one's?

8. Do you currently possess any fully automatic firearms or components to convert to fully automatic?

9. Can you produce the proper documentation and permits required by law?

10.Are you currently of have you even been asked by Federal or State Law Enforcement Authorities to work as an undercover agent in any capacity?

11.Do you currently use illegal drugs? 12. Have you ever possess any illegal drugs for the purpose of distribution?

13. Have you ever been adjudicated or treated for mental illness?

14. Have you ever been arrested or treated for domestic violence?

15. Have you ever had a restraining order placed upon you by a court of law?

SIGNATURE:

PRINT NAME:

DATE:

ALL INFORMATION SUBJECT TO REVIEW AND
$\mathrm{Y} / \mathrm{N}$

$\mathrm{Y} / \mathrm{N}$

$\mathrm{Y} / \mathrm{N}$

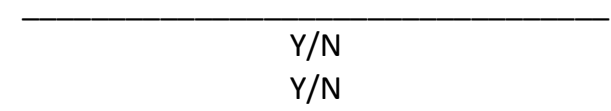

$\mathrm{Y} / \mathrm{N}$

$\mathrm{Y} / \mathrm{N}$

Y/N

$\mathrm{Y} / \mathrm{N}$

$\mathrm{Y} / \mathrm{N}$

$\mathrm{Y} / \mathrm{N}$

$\mathrm{Y} / \mathrm{N}$

$\mathrm{Y} / \mathrm{N}$

$\mathrm{Y} / \mathrm{N}$

Several key elements of militia identity work are reiterated in this questionnaire.

First are the number of the questions deal with potential criminal records and charges that typically limit a recruit's chances of membership in the unit, such as felony conviction, 
illegal drug use, or domestic violence. In a practical capacity these allow the leaders of the group to screen potential members for legal issues that may either draw legal scrutiny to the group or create a criminal association that would confirm what the leadership thinks of as the negative stereotypes about militias. Preventing these associations in the first place makes the Who Talk and Legitimacy Talk harder for outsiders to challenge and preserves the integrity of the messianic marginality work. Merely asking recruits to produce this information reinforces the distinction that members of the group see between themselves as 'law-abiding' citizens and dangerous 'criminal' elements which in turn aids them in recapitulating the dichotomous categories common to their worldviews.

The second point of interest is that there are several questions pertaining specifically to firearms and other destructive devices. Although the $10^{\text {th }}$ as group does not typically publicly emphasize the firearms used in their activities, this is possible precisely because they are everyday objects common, taken-for-granted aspects of their lives and identities. Firearms only become visible when participants in the group need to discuss them as part of their personal or group activities or when firearms ownership itself is called into question through restrictions or challenges to it. In other words, firearms are presupposed parts of militia activity. Questions pertaining to explosives and other destructive devices screen for people that believe the militia is considerably more militarized than it is and, furthermore, may not realize or care that without licenses this equipment is illegal to own.

Returning again to the ways that race and sex plays out in the militia's messianic marginality, in evidence is the false equivalency that many participants see between white supremacy organizations and civil rights organizations that pursue equality for racial and 
ethnic minorities. Regardless of the broader histories of discrimination, harm, and inequality that shape race relations in the United States any group that explicitly identifies itself as pursuing the interest of a specific racial or ethnic category is viewed as contrary to the idealized, color-blind image of equality based on individual effort and discipline. Interestingly, groups focused upon women's rights, broadly defined, are not included here. There are several potential reasons for this but the most likely combination of factors based on my data is that most members do not consider women's organizations as threatening or particularly important. As we will see in the next chapter, there are very few women in their group and most of the women to whom they are close are spouses or their own children who are largely subordinates considered under members' protection. Any grievances or concerns about systemic inequality are not considered serious problems. Rather, they are simply issues that men and women have either always disagreed on based on what members believe are natural differences in their respective experiences and outlooks or the results of changes to the gender order brought about the broader national declines since the 1960 s.

In concluding this chapter, I have demonstrated the ways in which the $10^{\text {th }}$ relies on ordinary resources common among the paramilitary gun culture to perform white-coded masculinities that they associate with providing social value through their dedication to personal responsibility and limiting the burdens they place on others. To accomplish their identity work, members of the $10^{\text {th }}$ use narrative genres such as Who Talk, Legitimacy Talk, and Scenarios to organize, link together, present and valorize the ordinary resources firearms ownership, race, sex, class, and United States history. These results are often tied to a broader, modern reactionary 'deep story' of a society that participants feel highlights 
their personal characteristics as problems and encourages others to fear, mock, and misunderstand them rather than respect them for their efforts. In their resulting messianic marginality work, participants position themselves in distinction to same society because it remains blind to its own decline; despite their own marginalization participants dutifully prepare a messianic set of skills to deliver at least their local communities should it fall to them to do so. Core members and leaders in the $10^{\text {th }}$ use narrative genres in the militia's most public appeals to others within the paramilitary gun culture, but arrange them in ways that downplay any of their qualities that they believe the public associates with organized racists and dangerous groups. In spite of participants personal feelings about the importance of equality through opportunity, these strategies also ignore the ways in which whiteness, sex, and class are institutionally articulated and perpetuated in ways that make it difficult for insiders to see the privileges that their own identity work depends upon. Publicly, the messianic marginality the present and the organization of resources they use to accomplish it are flexible enough that many members of the paramilitary gun culture can identify with the organization. As we see in the questionnaire, upon personal contact with the group this dynamic begins to shift and the $10^{\text {th }}$ immediately begins clarifying the ways of organizing these resources that the group expects members to learn. I will demonstrate in the following empirical chapters that $10^{\text {th }} \mathrm{s}$ more private standards are stricter in some ways and more open in others but only to a point at which core members feel that certain arrangements of messianic marginality push too hard against the boundaries of acceptability. 


\section{Chapter 4}

“That's Not Really the Point of This": Negotiating the Boundaries of Messianic Marginality at Militia Staff Meetings 
The man who greeted me when I arrived at the first militia staff meeting, Wade, is the second-on-command for the unit for much of the early portions of this project. He has been attempting to reduce his role as the group's secondary leader; he has since succeeded in this. While remaining occasionally available to the unit, he primarily spends his time working and moving towards retirement. When I met him, I asked if he would be willing to discuss his age and he coyly responded, "old enough to draw social security pretty soon" and then joked that the age assigned by the Federal Government is too old. Wade is about my height and dressed in jeans, a yellow t-shirt and sand colored work boots. Save for when they train or deploy casual dress is common among the $10^{\text {th }}$. Wade has been an emergency medical technician and a trucker, presently he hauls concrete for his living. Eventually other members arrive and we go inside.

Five members of the militia are sitting in the staff meeting room while I take notes and think about what to say. The meeting opened with a prayer, led by Wade. I wrote it down after the fact because everybody in attendance leaned into the table, bowed their heads after removing their "covers", closed their eyes, and clasped their hands. I followed suit so as not to offend as is my custom in mixed religion situations.

"Lord, we ask you bless this meeting of the $10^{\text {th }} \ldots$ and bless us with sharp minds and strong hearts, in Jesus' name Amen."

Charles presides over the meetings as required of the $\mathrm{CO}$ and made a motion to call the meeting to order. His motion was seconded but very quickly Cypher cracked a joke. He pointed out that the minutes from the last meeting were not present as they in the possession of Clint, who was among a number of people they had expected to be present that had yet to arrive. Continuing, Cypher argued, "I say that we motion to approve the minutes 'as not-read." "Wade immediately seconded this to a collection of chuckles., although Charles smiled at this he said he was going to disregard the motion as unofficial.

We enter another period of premeeting small talk. People occasionally glance outside to see if anybody else has arrived. Apparently, they are waiting for somebody else from the J school as well as potential "new guys 24 " who had been texted directions to the location but had never responded. Charles, Wade, and Cypher took turns speculating as to why this might be-the consensus seemed to be that they were probably afraid that the FBI or somebody was watching them, getting phone numbers, or some such thing and so it was no surprise that attendance was a bit sparse.

\footnotetext{
${ }^{24}$ The members of the group often refer to new arrivals to the group as "new guys" out of convenience and the fact that most of them are men but I would argue further that the masculine coded activities of the group also lend themselves to language that assumes masculine subjects.
} 
Charles said to Cypher that they may as well discuss "comms" now so they will not "bore whoever else shows up to death."

Comms is shorthand for communications. Evidently, at a previous meeting Cypher had offered to look into solutions for short range, portable communications but he had yet to find budget solution that was mobile and durable. At this meeting, I tried to follow as best I could but it the conversation was mostly contained between the two of them and conducted in their shared patois of radio technology. The main point was discussing different ways that they can produce their own transmitters using PVC and various components. The goal was to find a combination of ideas and materials that would be cheap to make, easy to carry, and effective for short range transmission of information during exercises or activities. Wade, ever a joker, asked rhetorically if I was having any trouble following. I smiled and replied it just went to show me how little I really knew or could do when it came to that kind of stuff. Audrey who, like us, was not involved in the talk either, laughed and told me to not feel alone in that.

Much later in the meeting Charles invited me to formally introduce my project to the group. As I explained to them that the literature suggested there is a variety of militias and there is not a lot of detailed data about their basic activities Cypher asked if I knew that there were different groups in the state. I nodded and he offered, "I would never want to be part of groups like those." Other members echoed this sentiment and Charles pointed out that "there are some guys, they go in weird directions with this stuff and they don't tend to last long in our group." Later, after the formal meeting was over, Charles returned to this subject and talked about the last time someone was observing their group. They 'had a guy like that, weird, and he was pretty thick so we started gently suggesting he had something else to go do.' The man had not understood that they were telling him off. Cypher added to Charles' point that "most of our battles are fought with chainsaws and tools... against trees," such as after "the Joplin tornado."

After relaying to me at some length the tasks they performed in Joplin they concluded their organizational capacity was a boon for other people who wanted to help their community. This was confirmation to them that their time training and learning was well-spent. Cypher explained the importance of this preparation, 'the better we are able to organize and [help] ourselves then the less we need to rely on the government and FEMA to get there and then leave later.' Nobody present objected to this and he added they were, most often, like a "volunteer fire department but, unlike volunteer firefighters who look down their noses at carrying guns we are proud to be able to use guns." Wade remarked that he could not see why volunteer firefighter do not carry weapons, producing a brief din of guffaws 
and affirmations. Cypher elaborated on this further, adding that they only go where they "are summoned, really," and the only violence they would have a reluctant interest in would be if "a tyrannical government put them in that position and even then, they would be responding, not attacking first." He also brought up recent protests in a nearby major city as a counterexample, saying that some people had tried to call them there but that was not a thing they wanted to be involved with-Charles added they really only cared to respond to official calls or local calls for their groupnot just 'any nut that thinks they had an idea of what the group does.'

They talked about any of their membership that may be camera-shy so I assured them that no photographs would appear in my data. After a few jokes, again, started by Wade on the subject of his lack of photogenic qualities, "the back of my head, that's my best angle," they seemed to agree that one of their guys was probably pretty photogenic. This shifted the topic of conversation to a recent government report on militias and the exceptions they took to its instructions that law-enforcement should be careful about people with Gadsden Flag or Ron Paul stickers on their cars. Charles asked if I had seen this report. I responded honestly, "Oh, the MIAC Strategic Report?" [affirmative responses] "Yeah, yeah, I have a copy of that myself." Charles added, "I have a copy too, in case you didn't." Cypher jumped back in and further explained that their group was dedicated to their openness and that all meetings were open to public inspection so he really could see any problems with any of part of my project dealing with themWade mentioned that because of this the 'sunshine law' is foundation for the group.

\section{“Volunteer Firefighters" with Guns: Militia Staff Meetings as a Space of Negotiating Militia Messianic Marginality and Normalization Work}

As I noted in chapter one, there are three primary activities that members of the $10^{\text {th }}$

participate in, a training event on the third Saturday of each month, a staff meeting on the

Monday prior to the training event, and an annual or semi-annual joint training exercise (JTX) with the other units in the state ${ }^{25}$. Staff meetings are vital to the $10^{\text {th }}$ as a foundation

\footnotetext{
${ }^{25}$ It is a minor weakness of this study that I did not attend the lattermost events. I was personally uncomfortable placing myself in the position of being a potentially unwanted interloper in the views of participants in units other than $10^{\text {th }}$ - whose members I've come to know, generally trust, and have agreed to this study. These events take place over a weekend and involve militia members from other regional units who had not have agreed to be part of the project thus complicating fieldwork, notes, and the data and, moreover, my presence may have proven invasive to the point of disruption for members who might be deeply suspicious of my intent. This weakness is also mitigated in part by the fact that most members of the
} 
for socializing potential recruits and peripheral members into regulars and core members. This progression requires that new people learn the organization's expectations regarding arranging ordinary resources from the paramilitary gun culture and the militia in ways that align with messianic marginality as the $10^{\text {th }}$ uses it. Compared to the broader paramilitary gun culture, the militia's approach has a considerably greater focus on their value to their communities in the event of emergencies, consistent efforts in building up to and maintaining self-sufficiency, and protecting the moral and legal integrity of the group and its members. As we see in the previous chapter, the publicly accomplish this by distancing themselves from others who draw on the ordinary resources common throughout paramilitary gun culture. Staff meetings are both public and private, however, and this makes them the primary point of socialization for new members and, compared to the public venue of gun shows, staff meetings are space where members, recruits, and leaders negotiate the boundaries of messianic marginality in the militia.

There are three stages to each meeting, which I term: premeeting socialization, the meeting proper, and the post-meeting goodbyes. In this chapter I will proceed chronologically through the stages of a meeting, drawing on my fieldnotes and experiences over the course of the twenty-three staff meetings I attended. I will draw upon interview data to substantiate my interpretations and analysis of the ordinary resources and narrative genres at work. A chronological presentation allows me to better present two analytically significant points: first, the dynamics of transforming a public space into more private militia space through boundary work signifying that the rules for messianic marginality are

$10^{\text {th }}$ also do not attend JTX and rely on a few core members to attend, learn, and report back to them at the unit's own meetings. 
those for the militia rather than those of the paramilitary gun culture or other cultural groups with similar political, theological, and ideological dispositions. Second, the ways in which core, regular, and peripheral members negotiate those boundaries as well as the ones between them and the broader public within militia space. The privacy of staff meetings affords members more leeway in their talk and narratives, especially in the premeeting and post-meeting phases. During the meeting itself this flexibility still exists, but to a lesser extent and in most cases only up to the point that things move too far abreast from the principles outlined in their most public documents. In short, the staff meetings provide a balance point between public and private space in which leaders can meet new members and conduct militia business that highlights the ways in which the group is a public one and diminishes the degree to which they maintain boundaries between themselves and outsiders.

\section{The Location}

Staff meetings take place in a reserved room in a building in Centerville, a small, primarily white town of about 4000 people $^{26}$. To the west of the building is a strip mall occupied by a restaurant, a local grocer, and next to these is a corporate-owned farm equipment store. To the east is one of the increasingly common discount stores where most goods sell for a dollar. Next to it is a drive-through ATM for a local bank. Headed west down the state highway that serves as the main thoroughfare on that side of town, you come across a chain pizza restaurant, a chain burger restaurant, a local graveyard, a gas station, a local Mexican restaurant, and, finally, a cigarette outlet before reaching the edge of town.

26 Based on Census estimates for 2016 the population was 4027 people, 96.5\% white. https://factfinder.census.gov/faces/tableservices/jsf/pages/productview.xhtml?src=CF 
The opposite direction presents the local water treatment center, a golf club, and immediately thereafter the other end of town. Most of the homes that make up the rest of Centerville are south of the highway. To the North are state highways crisscrossing fields, wooded areas, and farmhouses. A few weeks before Christmas the town holds a tractor parade wherein local farmers and other more casual tractor owners decorate their rigs and haul festive flatbeds through town. Most members of the $10^{\text {th }}$ live in similar towns or, if they live in some of the larger nearby towns, appreciate towns like Centerville and what they represent - a idealized lifestyle in a town populated by heterosexual nuclear families who know their neighbors, there are at least some jobs, racial tensions are primarily a thing of the past save for a few 'extremists' here and there, and government influence is not overt, obvious, and typically considered only at the local level ${ }^{27}$.

Centerville is the locus for staff meetings for several reasons. First and most practically it is nearly equidistant from the homes of most of the key members who live in other towns between twenty and sixty minutes away. It is nearly the center of the region of the state that the $10^{\text {th }}$ is meant to service according to the state organization. Given the level of turnover in the group there are exceptions to this, like Theodore, a bespectacled white preacher in his $60 \mathrm{~s}$, who travels from about two hours away to attend meetings when his

\footnotetext{
${ }^{27}$ During my phone interview with Charles while we were on the topic of the family unit and small-town living he said, "Well, you look at modern, television, ok? And you look at Mayberry, or the Waltons, you have the grandparents living there, everybody's close by, when I was growing up my grandparents were pretty close. On my mom's side there were, aunts, and cousins, they were around quite a bit. In my personal life, now, aunts and uncles are not a major influence, we're all spread out. They come hunting, and I can influence them, around those times, and they can influence my kids, help them out, but only really major events give that opportunity."

Cypher, BG, and Peirce expressed very similar sentiments in their own interviews when I inquired as to the greatest contemporary problems that they think people face.
} 
health and work schedule permit it. Virtually everybody else hails in from one of the thirteen counties surrounding Centerville.

It is also a location with which they have long-term arrangements. Whether the owners of the building know what the group uses the room for or not I do not know but they have used it for longer than I have been spending time with them. Even with a regular meeting place regulars and core members will sometimes have trouble getting there on time and on the correct day. It would be considerably more difficult to organize the groups' business if the meeting location changed regularly ${ }^{28}$. The room in which the $10^{\text {th }}$ holds staff meetings occupies one half of a building, the other half of which is a small medical clinic. The room is shared, in turns, by a local Narcotics Anonymous group that has been there since the beginning of the project, an AA group, as well as an early childhood development center that has only been reserving the space in the last year and a half or so. Prior to this final addition the room was a bland one, originally meant to serve as a waiting room should another group of medical professionals come to occupy the rest of the space. The particle board tables and wire-frame chairs suggest somebody with an eye for the budget helped to make the space into a meeting area for local groups. Since the early childhood development group has started occupying the space it now includes a small collection of toys and stuffed animals, brightly-colored plastic bins holding what appear to be several different sets of building blocks, a small bookshelf of communal children's books, and various makebelieve playsets approximating kitchens and workshops. The room as a place and its social

\footnotetext{
${ }^{28}$ There were two occasions on which I mistook this schedule to mean that these staff meetings would always occur on the third Monday of the month and, much to my comfort, both times I was reminded by leaders that even core members make this mistake when they experience a particularly busy month.
} 
meanings overlap physically in a somewhat discombobulating way that materially suggests the symbolic and social work that occurs there: the organizing and integration of overlapping ordinary resources in ways that prevent them from contradicting each other or challenging the principles people use to organize them into messianic marginality.

Even when the tables were not being utilized they used to remain arranged in between meetings, placed end to end in order to form one larger table. More recently every group that uses the room leaves them folded and laid against the wall furthest from the entrance. They also neatly stack the chairs against a different wall. The core members and regulars are exceptionally attentive when it comes time to restore the room to its original condition after a meeting. More than peripheral members, these two types are diligently attentive to disruptions and inconveniences they may cause others through their actions at both meetings and trainings. Rarely will they choose to pursue courses of action that produce these consequences but I have noted only a few instances in which they had not weighed the costs against their goals and prepared to apologize to those they have bothered $^{29}$.

Much like the building itself, the parking lot in front of the building is split into halves which can each be reached from a roundabout at the end of a long driveway connecting the property to the state highway. Militia participants always park in the lot in front of the meeting room. The entry to the building has two sets of doors, leading into what would be a reception area had the space been rented for a physician's office. Only the

\footnotetext{
${ }^{29}$ When training on public lands core members keep an eye out for non-militia people that they may be inconveniencing and will typically reorganize activities to adjust for it. Generally, it is a non-issue because outsiders are seldom encountered. Twice, police were summoned to ask the group what they were doing at Alaine's house and both times the satisfied enough with the answers provided that the $10^{\text {th }}$ was left to conclude their training.
} 
outermost of two sets is kept locked and prior to each meeting a core member of the group has to go get the key from another location that I've heard referred to as a station and an office. Most of the time the core member responsible for this has already accomplished it by the time anybody else shows up but every so often I would arrive to find participants waiting for either a leader to arrive with the key or to arrive, discover the building is locked, and go to fetch the key while the rest of the group makes small talk. It is rare that new recruits will arrive before most of the core members who will be attending the meeting that night but except for the most outgoing cases they generally sit in their vehicles until they see a member that they recognize.

\title{
Premeeting Socialization
}

The first stage of the shift from public space to a more private militia space occurs before the meeting starts. Core members and regulars arrive and catch up with each other while peripheral members, new people, or those who rarely attend navigate the ambiguity of the situation.

\begin{abstract}
I wore my normal attire ${ }^{30}$ and was the first to arrive today, usually leaders and core members are already here by 5:50. Two returning members I did not yet know pulled up shortly after I arrived at 5:40. Not recognizing me, they stayed in their sedan and talked. More people arrived shortly thereafter, including Cypher, Audrey, and another member I'd not seen since several months ago-Arthur. Arthur is 63 years old, with increasing grey in his hair and a slight, fit build resulting from his careful eating habits and enthusiasm for martial arts. He is one of the rare core members with somewhat infrequent attendance; he makes up for it by providing more classes and training resources than others. Cypher's wife,
\end{abstract}

\footnotetext{
${ }^{30}$ Throughout the project I consistently wore black trousers, buttoned shirts, and vests to staff meetings. This was in part because it is how I always dress and in part because I wanted to maintain some distance from the group and preserve my status as a combination of insider and outsider. It also served as a reminder to core members and regulars that I would need an opportunity to explain to peripheral members who I was and what I was doing with the group as the clothing was sufficiently different from others' to invite such explanations.
} 
Gillian, also showed up today. This is exceptionally rare due to her frequent bouts with serious illness.

The people waiting in the car were a couple who I came to know as William and Janet, whose private land we were to train on come Saturday. They are married and have three sons who work on their farm with them during the growing seasons and share many of their interests. William is exceptionally tall compared to everybody else in the group except Charles. He is heavier-set, a little younger than most, if he were any older than his late 40s it would be a surprise. He primarily listens and observes until he sees a chance for a good joke, has a concern or advice to express, or, more commonly, wants to express his agreement with a point that Janet is making. Janet is very talkative, friendly, and engaging, often speaking on behalf of both herself and her much taller partner. She is enthusiastically curious and does a great deal of internet research to pursue her interests. She frequently bringing information about food preps, medical concerns, and threats (which some other group members, but not all, find to be outlandish and conspiratorial) to the attention of the group.

There were a couple of new men present. One with decades of local law enforcement experience was named Brock. Brock is not loquacious in the slightest but rather stern and careful in his speech. He is about six feet tall with a heavy build, close-cropped receding hair, glasses, and neatly trimmed facial hair. The other new man, in his early sixties, bespectacled and talkative, is Theodore. He joked while I was explaining my project to him that I was 'obviously' part of the NSA or some other agency. Later, I had handed out too few consent forms while talking to the whole group about my project and he made the joke again to draw my attention to this.

I greeted Audrey and we made small talk for a little while about how things had been going. He's "well" he said, and followed this up with "I can't complain, and it wouldn't do any good anyway." I told him "I've often found that to be the case too, I tried once but it didn't produce any results." Audrey gave out a little giggle. The rest of the party showed up after they saw me interacting with Audrey; William and Janet who had been watching from their car pulled in to a parking place and greeted him. They talked for a little while about a type of "coffee-type" plant they grow, the fruits of which they have exchanged with Audrey from time to time. The seeds are quite large and come bundled in pods containing four or five. I took the first chance I could find to introduce myself to William and Janet. We shook hands and then they continued their conversation with Audrey.

It is at this point that Cypher and his wife drove up but didn't park, he rolled down his window and told Audrey, Janet, and William that he was supposed to get the key but didn't find out until just then. We all 
acknowledged him and he went off to get the key that lets us into the building.

Arthur and Brock joined the conversation; Arthur introduced me to Brock and we also shook hands. He seemed somewhat skeptical of me and was about as quiet as I was while the conversation continued. Based on an observation of hers about our names that I did not follow Janet brought up Elton John. Arthur described that he used to be a fan of the artist until he found out he "wore his loafers light." Somebody asked him if this meant he didn't like even Elton John's older stuff, and he replied curtly, "not as much." Janet brought up that "regardless of his homosexuality, which is another matter," he was "a good singer, and didn't use any of that... what is it? The computer-sounding...." At this point everybody worked together, tossing out words until they landed on synthesizers. Collectively, they agreed upon the impressive nature of his talents. The group immediately shifted gears and went on to discuss a couple of different home remedies for poison ivy and other irritations; I simply listened. Before too long Cypher and Gillian arrived again with the key to the building and everybody starting moving that way. (Excerpts from field notes Militia Staff Meeting $8 / 10 / 2015)$

Premeeting socialization precedes the transformation of the room and its surroundings into militia space but is a valuable precursor insofar as it encourages participants to draw on the broadest messianic and marginal resources, such as selfsufficiency and notions of decline, in ways that mark them as people who belong there. These conversations set the stage for the transition to the presentational rules of militia messianic marginality. Two genres of narrative work are common throughout staff meetings, and tend to characterize the premeeting phase: Busy Talk, and Decline Talk. They are used in slightly different ways once the meeting proper has started, but they persist as messianic marginality components. In form, Busy Talk encapsulates utterances that detail the speaker's work and personal schedules, efforts at work and play, and the ways in which they navigate their competing obligations. The function of this genre is to present the speaker as a productive, active person whose efforts at work and at their hobbies provide results valuable to their self-sufficiency and social worth. This emphasizes the 
messianic idea that people who work hard and have productive hobbies are better able to support themselves compared to those who are less able or willing to undertake these efforts and have unproductive hobbies. Cypher explains in his interview with me:

Cypher: "ok...I also love to cook..."

Daniel: "me too..."

Cypher: "Indoor cooking, outdoor cooking, fires, stoves, grills, all of it."

Daniel: "That being said, then, do you have any specialties? Favorites or something?"

Cypher: "Big groups. I like cooking for big groups of people, outside, and in strange settings or conditions."

Daniel: "That pretty specific."

Cypher: "(he chuckles) It is. But yeah, I like that. Here's how I think about it: things might get back to normal one day, ok? Hopefully Trump can fix things and we'll be back to normal. But, logically, when I think about it, even then, bad things happen, ok? I know that. Bad things can and do happen and knowing how to cook for a large group of people? That's a helpful skill to have."

Daniel: "I can see that line of thought. I think. So, no matter what happens, that's something that you can do and that's valuable to you and maybe other people too. It's good to have a cook. Is that sort of right?"

Cypher: "Sort of. It's not just that...I saw it with the scouts, in my time with them. It's a good thing to be able to cook food for a large group when you are in unfamiliar settings or things are not going right. That helps everybody."

Marginally, however, such busy people are beset on two fronts: the ever-increasing demands on their time that follow from being a capable person and the decreasing power they have over the products of their efforts. While the latter concern could be interpreted a critique of neoliberal economic policies favoring corporate power and policy influence, which are concerns that several interviewees mentioned. In most Busy Talk, it is more often interpreted in terms favorable to neoliberal ideas about personal responsibility and limited government and reinforce the idea that the poor, often coded as racial and ethnic 
minorities, receive excessive amounts of welfare that the busy people pay for while the wealthy don't pay their share. Consequently, the prevailing view is that the federal government is not only too cozy with moneyed interests but it also takes the results of a productive person's work through taxation and distributes it in unfair, inefficient ways that benefit people who lack those levels of productivity. The belief that fewer and fewer people are willing and able to be so productive and only the wealthy can avoid taxes, means the onus on people such as those in the $10^{\text {th }}$ grows. This links up with Decline Talk in that these two sets of imbalances are often presented as further precipitating the decline of the United States. Remaining committed to productivity is taken as a sign of integrity and social worth, even when it goes unrecognized by those who benefit from it or stand to do so. Explication of this worth can involve contextualizing it in a Scenario (as described in chapter three). Arthur demonstrates this well in my interview with him:

Daniel: "Real issues in society. So, I was wondering what, if any, take you have on what those real problems people face are these days? If there are any that stand out, or that you think are, you know, especially important or noteworthy?"

Arthur: "You mean as, like attitudes? What do you think about things, or?"

Daniel: "Whatever comes to mind."

Arthur: "Well, one of the things involved with the militia is emergency preparedness. There's a lot of people that... they have their nose stuck in their cell phones and their computers and TV and are living outside of reality, of what really could happen. I think it's very important that people take a good, hard look at that. One of the things that I think plays a big part of that, is where their walk is with God. Because if they do not have a close walk with him, they have got a whole lot more problems than just surviving from day to day. It essentially does, will do a reset on the way a person acts with other people in their day to day lives and a peace that comes with understanding where they go when they die; that God is there to help you on a day to day basis. The thing that keeps going on in my mind, over and over again is 'Shut up boy, pay attention.' Okay, you know? But aside from a good, sound religious-type outlook I feel firmly about the idea that people 
need to have... they look to government as their helper but the government can't very well...There's certain things the government can do well, there's other things that it can't. What you need to have is start with your personal life, and be for the lack of a better term, self-sufficient. Now there is no such thing. But you work towards that goal”.

Daniel: "There are degrees of closeness to it?"

Arthur: "Yeah, yeah."

Daniel: "Okay."

Arthur: "It's like, 'oh this broke, well I'm not going to call anybody to fix it, I'm going to fix it myself," sort of thing. There's no point in calling somebody, I'll just fix it myself. If I can't fix it myself, do I really need it? Hmmm? But then the next thing is neighbors, that community that you can depend on to help you out. If nothing else, to give you advice. For instance, I had a truck issue. I run up my neighbors' that works for a car dealership and said, 'Hey, what do you think about this?' Or 'What's this?' He gives me some ideas and I go, 'Okay, gotcha.' Then I take it home and work on $i t$. The next thing out, past your community, is your county. We need to be very active working with our, the folks in our county, in case of problems. No matter what they are. Whether they or you are helping out somebody that's down on their luck and they need some help.

If you've got a neighbor helping a neighbor, you've got some accountability. If you've got some government bureaucrat somewhere saying, 'yeah, you're entitled to this program,' he or she is probably not giving you all the best that you should be getting. A lot of the training that I've had has been off from FEMA. They have a wonderful educational program on the structure of how to solve problems, be leadership. t's just a huge gamut. I don't know if you've ever been on their website to look at some of the stuff, at the FEMA training that's out there. You just do an online course and there's dozens of the things. But one of the things that they emphasize is incident command and control. If you have an incident, good or bad, whatever, you can handle it by yourself, bring in a neighbor, bring in local, county authorities, if that's too much, overwhelmed, you bring in the state. The state's overwhelmed, you bring in the federal.

Federal, you're looking at several days to several weeks of getting help from federal. And when they come in, I always think of it like trying to kill flies with a sledgehammer, it's a little overkill a lot of times. Because if a person was prepared, in their own household, that disaster happens, you go 'Oh bummer, well that changes my plan for the next few days.' You make a hard-left turn, you take care of your problem. Then you look around and see if your neighbor needs some help, get over there. Or you look at your 
neighbor and say, 'He's worse off than I am. I'm going over to help him. I'm going to put my stuff on hold. ',

Busy Talk and Decline Talk can combine with vague and specific Scenarios, as Arthur has shown, and in premeeting they help to reinforce these very sorts of views among members of the $10^{\text {th }}$. These genres allow them to express pride in their collective and individual capacities as productive people by comparing themselves to real or imagined others who lack them. In Arthur's disaster scenarios the relations are quite clear; people who work hard to pursue self-sufficiency will be able to avoid dependency on the government, which is overbearing as a rule, while perhaps well-meaning and occasionally necessary in extreme cases. His view is common among participants: most problems can and should be handled with the least amount of outside help that is feasible, given a critical mass of self-sufficient people. Outside help represents both burdens placed on other people and risks losing agency. Within Arthur's interview one also sees the edges of a harsh critique of those who do not abide by these ideas embedded in these generic combinations. Those who do not strive for self-sufficient are not believed to be attentive, to be religiously pious, and end up increasing the burdens of others, whether directly or indirectly. It is rare for a core member or a regular to explicitly link these constructs to race. Instead, as is the often case in other forms of color-blind discourse, where the aim is to connect these to race, rather than only discussing, these connections are implied through references to urban areas, poverty, one-parent households, dependency, and welfare, which are coded African American and feminine. This leave the speaker the opportunity to say that these issues affect all impoverished people, thus maintaining their own identities as non-racists, which most participants genuinely believe and strive to be based on their understanding of the word. 
The organizations of Busy Talk and Decline Talk changes during official meeting time and the premeeting socialization, unofficial though it may be compared to the intimacy of an interview. For instance, Arthur's more theological understanding of the moral components of self-sufficiency would not be as appropriate for the premeeting arena or the meeting proper as it would challenge the groups commitments to religious neutrality. Furthermore, simply announcing that productive people are maligned and abused by the government and those dependent on it rather than linking all of these components together would come off as a complaint—whining. This would trouble the notion that the militia is a service group, reflecting instead self-interest in the abstract rather than situated within the ability to provide for oneself and others. This is why, for instance, it is common when members of the $10^{\text {th }}$ ask each other how they are they will admit to being busy but usually include a caveat like, “I can't complain, and it wouldn't do any good anyway.” Personal complaints are important indicators that something is wrong in life, the nation, or the world but to present them as such alone risks the presenter coming off as too much like a whiner who does not take responsibility for their own life. Instead, they must be situated in terms of wider problems and decline that they face.

Every formal interviewee situated their answer to my question regarding problems that people face today in terms of decline and loss. Janet and Arthur's exchange about Elton John as well as the one between myself and Arthur are examples of this genre. To summarize my earlier definition, Decline Talk deals with sharing explicit or implicit concerns and complaints regarding the ways in which some aspect of life is no longer what it once was; at its most explicit a speak will include why and how this is the case, and to whom responsibility can be assigned. The more implicit form will only address the 
complaint, leaving the to the audience to fill in who is responsible and why. Implicit presentations rely on shared background in believing that government, progressive politics, progressive social movements, and other, more nefarious forces are at work.

\section{Table 4: Answers to "What is the Biggest Problem that People Face These Days?"}

\begin{tabular}{|c|c|}
\hline Interviewee & Main Themes in Answer \\
\hline Charles & $\begin{array}{l}\text { "Social Decay" resulting from decline of two-parent households and consequent } \\
\text { government dependency. }\end{array}$ \\
\hline Peirce & $\begin{array}{l}\text { Economic insecurity, decline of family stability, political correctness all leading } \\
\text { to increased stress. }\end{array}$ \\
\hline Cypher & $\begin{array}{l}\text { Contemporary welfare sets people up to feel as though they are not capable of } \\
\text { working, rendering them dependent on the government. }\end{array}$ \\
\hline Arthur & $\begin{array}{l}\text { Lack of self-sufficiency fostered by expecting government aid, focus on } \\
\text { entertainment technology, and weakening relationship with God. }\end{array}$ \\
\hline Audrey & $\begin{array}{l}\text { The abandonment of constitutional principles, primarily associated with President } \\
\text { Obama and his orchestration of a decline of American military power, increased } \\
\text { job loss and economic strains. }\end{array}$ \\
\hline Franz & $\begin{array}{l}\text { Government meddling in culture and economy with the aim of promoting } \\
\text { "Socialism", specifically during the last presidency. }\end{array}$ \\
\hline Wade & $\begin{array}{l}\text { Crony Capitalism transforming capitalism into oligarchy and is corrupting the } \\
\text { government. }\end{array}$ \\
\hline $\mathrm{BG}$ & $\begin{array}{l}\text { Uninformed voters who do not examine government actions and the risks to } \\
\text { Christianity and the United States' morality vis a vis the moral shortcomings of } \\
\text { Muslims and liberals. }\end{array}$ \\
\hline Lou & $\begin{array}{l}\text { Lack of morals among younger people, illustrated by bullying and school } \\
\text { shootings. Lack of morality is a consequence of removing God from schools. }\end{array}$ \\
\hline
\end{tabular}

The messianic element here is that the speaker is a person who pays attention to risks and problems and their importance. The marginalizing element arises from the idea that these problems are either unknown to outsiders or treated by the larger society as the illegitimate concerns of the paranoid, racist, sexist, or otherwise intolerant.

In the case of Elton John, Arthur frames his own explicit loss in enjoying Elton 
John's work within the implicit decline represented by the increasingly openness of homosexual men and women who, in his view, represent a related decline in the religious piety of the United States. Janet is devout in her own ways but does not usually explicitly note it. She here affirms implicit decline but draws explicit attention to Elton John's talent and a different aspect of decline represented by what she and others see as a problematic reliance on technology over personal skill. Overreliance on technology is more often discussed in terms of "grid-down" scenarios wherein people who rely on GPS, cellular phones, computers, and the like will find themselves in an increasingly desperate position without the skills to navigate, communicate, and provide for themselves. These concerns are appropriate during the premeeting as they speak to feelings and beliefs that are commonly shared throughout their social worlds and mark them as 'like-minded' but during the meeting proper, depending on who is present, they might face mild censure if carried too far or organized in ways that challenge the preferred techniques.

\section{The Meeting Proper}

Just before six p.m. on a meeting day any attendees still outside move indoors and take a seat around the large table. It seats between fourteen and sixteen comfortably but there are rarely that many. It did happen from time to time, most often during the cooler fall and spring than the summer and winter. Without fail the highest-ranking core member available runs the meeting from the centermost seat on the west side of the table while everybody else sits in their regular seats if attendance is light or wherever they can when there are more people than usual. Officially, meetings run according to Robert's Rules of Order but in practice the degree to which this is true depends on the member running the meeting and how many people are present. Charles was dedicated in his efforts to maintain 
a relative sort of order while Peirce tends to organize things in such a way as to keep people focused on his list of tasks so the meeting ends in a timely matter. In very rare cases that attendance is light and only a few core members show the meeting may not even be called to order, and instead business will be conducted quickly and the rest of the time returns to a state of premeeting socialization followed by an abrupt transition to post-meeting goodbyes.

If asked, leaders will admit that despite the goal that meetings will be called to order at six p.m. they start later as often as not. Typically, this is because those present are waiting for others expected to arrive or they merely get caught up in continued premeeting socialization. Busy talk also occurs during the meeting proper but compared to premeeting socialization it here emphasizes the difficult overlaps between meeting obligations to the militia and those to the other aspects of one's identity. This exchange in May of 2016 between Charles, Cypher, and BG, at the time a relatively new member, is instructive:

$B G$ suggested that he had nearly missed the meeting because he had been relying on updates from the social page for the group to appraise him of meeting dates and it hadn't been updated since the last month. Charles rebutted that Clint was responsible for the group's page and he hadn't checked to see that Clint was taking care of things. Cypher said that he had also nearly forgotten the meeting, adding that we were "lucky" he'd remembered at the last minute. Charles replied in a noticeably pointed tone, "I just figure that we're all big boys who can figure out when the meetings are because it's always the Monday before the third Saturday of the month." Cypher attempted a face-saving retort, "Yeah, but when you have seven or eight things going on every week, you get home one night and you think 'oh yeah, I've got a night off." BG immediately interjected, "nah, there's something....something's always going on." Cypher was attempting to continue his train of thought when Charles cut him off, "You can make a calendar, the same as me." Cypher muttered something unintelligible and then continued, "I can make a calendar, I can make one up for six months out from now. The problem is that I never look at 'em." (Field Notes May $\left.16^{\text {th }}, 2016\right)$ 
Unlike premeeting socialization time Busy Talk during the meeting no longer merely indicates a person's moral worth vis a vis their productivity and time management; the standards are higher, especially for core members and regulars. Achieving membership means Busy Time is held to the additional expectation that the speaker indicates in speech and action they privilege the militia within that framework. A dedicated militia man, I say man here due to both the demographics of the group and the masculinity contest between Charles and Cypher regarding their abilities to organize and control their lives, makes time for his obligations to the militia, knows when they are expected be somewhere, and does not complain. Cypher responds to Charles' admonishment by emphasizing his organizational capacities and contrasting them with the degree to which the excessive number of activities impedes him. BG would not like my interpretation that he sensed the shift in rules and then reoriented his own contribution to the Busy Talk, but it seems more likely than not that this was the case given the change and his efforts to learn to be a part of the group.

Once enough time has passed before the meeting is called to order or it becomes clear that no one else is going to show up the ranking member will announce that the meeting should start officially and invite either Theodore or Arthur to provide a prayer for the meeting ${ }^{31}$. If neither of them is present then it usually falls to Audrey or another similarly ranked core member. Regardless of which member delivered it, the prayer was always a generalized Christian one, meant to be adequate for most attendees and

\footnotetext{
31 The bylaws for the state organization specify under their procedures that "All musters will open with a prayer and the Pledge of Allegiance."
} 
inoffensive despite doctrinal differences ${ }^{32}$. The example earlier in this chapter encapsulates the main body of the prayer. During poor weather, tense political or social events, or when there were widespread concerns among members about a future event, the speaker might add embellishments such as giving thanks that everybody present made is safely or requesting wisdom and safety during upcoming training sessions and potential catastrophes. After the prayer the unit rises, removes any headgear, and recites the Pledge of Allegiance while facing an American flag that either Charles, Audrey, or Peirce has brought with them and affixed to a chair so that it stands upright. The three 3 core members with extensive military experience, Pierce, Audrey and Franz, tend to salute while most others place their hand over their heart. Peripheral members often are unsure which gesture to make. I take these twin rituals to mark the official transition to militia space as the meeting is immediately called to order once the group has completed these observances.

In the event that new people are present, after the meeting is called to order both Charles and Peirce have taken to inviting everybody around the table to introduce themselves and where they live as a sign-in sheet is passed around. This was a practice that Charles added shortly after Cypher raised concerns over low levels of attendance and participation. It is common for people who would show up to a staff meeting, never get introduced to anyone by anybody, and then never come back—many such people are the peripheral members in my data. Officially the practice of having us all introduce ourselves served to make people feel welcome and more likely to interact during meetings as well as to provide more points of communication about militia business. Unofficially, I suspect

\footnotetext{
${ }^{32}$ The specifics of members' religions is seldom a topic they discuss unless there is a point to be made, such as Janet explaining at one staff meeting that she left her previous religion, which she did not specify, because it was intellectually and spiritually stifling. Theodore and Audrey once spent the better part of a half hour discussing their differing views on Christian eschatology at the end of one training day in May of 2016.
} 
that this was also a way to hold current members more accountable for attendance and learn the names of visitors.

New people can be a concern based on the risk that people might besmirch the group's good name through actions and speech. During my entire time with the group there was a mostly subterranean fear of outsider infiltration that became visible when issues of record-keeping, lists of email and physical addresses, and phone numbers were raised. Peripheral members would occasionally express concern that any such lists could be used by an infiltrator to find out who they are. Core members and regulars cared considerably less about this given the public nature of the group but even they are reluctant to make this information available to anybody outside of the core members. This is an example of the boundary work the group does in navigating the public and private dimensions of messianic marginality. On one hand they strive to live up to their presentation as welcoming and accepting but at the same time the feelings of marginality yield suspicion and a sense of risk that can conflict with these aims.

Meetings ideally move from the prayer and pledge and onto "old business' in the form of reading the minutes from the last meeting and reviewing the successes and shortcomings of the most recent training event. As with the start-time, there is greater flexibility here than rigor, and oftentimes the minutes from the last meeting are incomplete or not present and the group works together to fill in the blanks. When this happens, the group will collectively reconstruct the minutes from their own notes and, occasionally, my field notes from the meetings. After this are announcements and new business which revolves primarily around the training for the weekend, where it will be held, who will teach what classes, and subsequent discussion of the details of each of these topics. 
As six o'clock approached most of the group had arrived save for Audrey and Alaine. As people trickled in Charles and Peirce talked about the plans for this meeting and the month's training. One of the early arrivals asked how training last month went, Peirce said that only nine people showed up but that they accomplished a decent amount with the time that they had. It had been a search a rescue training in a wildlife area and they found all but one of the pieces of evidence they needed to track the missing person. The goal had been to find all of the individual pieces of evidence and then tie them together so that they could identify where the person was and rescue them before the elements took them.

$B G$ arrived around 5:50. He took note of the $A A$ and $N A$ banners hanging in one corner of the room, having not noticed them before. His expression of surprise was puzzling to several of us as he has been in the room on several occasions prior to this and the banners have often been there. Charles simply responded that they were not the only group to make use of the room. He then received a phone call which, based on his end of the conversation, was clearly at least a couple of people trying to find the meeting building and assuring Charles that they would be there shortly. It later turned out that this pair had been Bueller and his daughter-in-law who cannot join the militia because she has just joined the active military. They arrived very shortly after the conversation. Bueller is white, no more than 5'10, most likely in his 40s. He is very skinny, and heavily tattooed with a variety of images. None of the images were immediately recognizable to me. His short-cropped hair is receding slightly, a fact he obscured with a black ball cap emblazoned with a military style logo on it for a company that makes equipment they market as special forces gear. He also wore a mesh tactical vest with two different four-to-five-inch knives attached to it. Nobody remarked on them.

Charles introduced Bueller to us and he, in turn, introduced us to his daughter-in-law who was a "new soldier." Immediately both Charles and Peirce simultaneously asked her "What's your MOS?" This is short for military occupational specialty and, for those in the $10^{\text {th }}$ who were in the armed services is among the first questions they want answers to.. She replied that she did not have one yet but was hoping to become a combat medic or combat lifesaver.

Most of the rest of the group for the night had arrived by now, including William and Janet. She greeted me by name and asked how "the paper" "was coming along. I told her, "slowly and with trepidation but it is moving along." She smiled and wished me luck. I tried very hard to hide that I wished they had not arrived given their past flirtation with Sovereign

\footnotetext{
${ }^{33}$ Her name for this dissertation.
} 
Citizen rhetoric earlier in the project. It did not help my mood that William was openly carrying a semi-automatic $1911^{34}$ of some sort on his hip. While she and I had been talking Bueller had been telling the group about some of his post-military training. He runs his own business-training people in handgun techniques and rifle techniques. He passed a few of his cards around. The training he was talking about, to me, seemed like it was meant to indicate that he knew what he was talking about. He presented focused on the intensive set of lessons on the topic of handgun combat techniques that required 1500 rounds of ammunition for the weekend. This is no small expense.

Charles called the meeting to order at this point and asked the group to introduce themselves to everyone. Most people were from a variety of nearby towns and cities including Centerville, Morris, and Middle City. Bueller noted that the training this month was supposed to be in a more rural town and he joked that he would be listening "for banjos....you know, my rule, like that $t$-shirt, 'when I hear banjos I'll be running the other way. " Cypher echoed this sentiment and everybody had a bit of a laugh at it.

The main order of business tonight that was not related to training was to ensure that the group took a vote on whether they wanted to collectively donate to a local charity so it could provide 'buddy packs' for children facing food insecurity. Charles broached the subject of the charity request, "Ok, one of the things that I want us to get done tonight, to talk about, is this letter I got from a local charity. Every Christmas, we donate food to them as a group, which you know. But this came addressed to our group, care of myself. They want us to give a monthly donation for buddy packs - which is like a box of food for a kid for the weekend. This, listen to this, 'one in five children face hunger in this state,' alright? I didn't believe that right away..." Bueller interrupted to point out that was "absolutely correct," if it wasn't worse. Charles picked back up, "yes, I asked around, I asked some people at the schools that I know and they assured me that this was true. I just...That was unbelievable to me. So, I think this is worth our time. It's $\$ 180$ a year for one buddy pack and they want to put out something like 7200 they say. I want us to do this. I try to, I make a point to never ask you guys for money. We have our needs too, but this cause is worth it."

As he was finishing his last sentence a couple of guys gave him some grief about the idea that he 'never' asks them for money. Bueller joked that he knew that Charles donated it all to Obama's campaign. People giggled

\footnotetext{
${ }^{34}$ This is a very popular semi-automatic .45 caliber handgun that was standard issue the various branches of the military for several decades. Today it remains popular for these associations as well as the lethal potential of the ammunition it fires.
} 
a little at this and Charles expressed mock confusion at the idea, as though Bueller had found him out. Bueller continued, "Really though, I was thinking, we could do it differently. You can get something like a six-day supply of camping or survival food from Wal-Mart or outdoors stores for a little bit less than that, last I saw. Then we could give it to people ourselves and cut out the charity or non-governmental whatever. They have overhead and we don't. I would rather the whole amount go to people than lose some of it, most of it, or however much, to the operating costs. " There were some sounds of agreement. Charles commented that Bueller had a point but that donating it through the organization would meet their goals of helping the kids and making a good name for themselves. The group brainstormed for a few moments on other, cheaper ways to provide the food.

Janet expressed that she had a comment to make and everybody turned to her, "Well, I was thinking about this, and it's a good thing, it is, but, well, can we pick which kids get this food? I mean, if I have the choice I would rather the food go to a good, Constitutional kid, you know?" There was silence and some contemplation before Charles said "Well, I hear you, but that's, that's not really the point of this. It's to make a good name and provide something for people in the community." Janet replied, "they just don't teach the Constitution in schools anymore, not like they used to," Peirce, bridging the gap, said, "Janet, I sympathize, they don't teach it like they used to." She continued "When I substitute teach I make sure to teach them. I teach the Constitution." Nobody said anything in response to this. I felt that I was not the only one taken aback and trying to figure out how to respond to this. There was a brief debate over the price of MREs ${ }^{35}$ that people would be able to find in nearby stores. Peirce did not believe the prices that Bueller was quoting and specified that he had personally been to same places recently and the prices were not quite so low. Bueller replied that he had not been recently and this was probably the reason behind the discrepancies in their estimates.

The group began discussing training for this Saturday. It was to be at a house that Alaine now owns. It is adjacent to his home. He purchased the house and surrounding property with the idea that he could tear the domicile down and erect a barn in its place but he lacked the funds and time to finish. Now, the house was simply a series of rooms and stripped walls. He had invited the militia to use it as a training site for room clearing and similar activities. This was the goal for Saturday. Given that Alaine had not yet arrived however, there was concern over whether the training would actually be taking place in such a public arena without having told the

\footnotetext{
${ }^{35}$ This is an acronym for "meals ready to eat." Colloquially the term means prepared foods that include all of the required equipment to cook and eat them, usually styled after the military versions of the food or actual surplus military-issue meals.
} 
neighbors or local authorities. He was supposed to have arrived and confirmed for the group that he made the relevant contacts.

Part of the training was to use balloons taped to man-silhouette targets as feedback for their airsoft guns, which Charles made clear repeatedly were to be the only weapons at the training. Cypher joked that they should use blue balloons so they could be like "blue helmets," and people laughed a little at this idea. Janet suggested that they write "HC" on all of them. People mostly groaned at this idea-she took it too far. The conversation on this part of the training ended shortly after her comment. Charles moved on to discuss a handout he had written. The handout was to be distributed to Alaine's neighbors so that they could have an idea as to what the militia was doing on that property, which is in a town, and why they should not be worried about the group or its activities. His goal in reading it to the group was to solicit some editorial feedback. They suggested a few changes focused on clarification surrounding the fact that they would be utilizing airsoft weapons. Mostly, this reopened the earlier conversation about how publicly visible the group really wanted to be.

Janet specifically expressed concern over two aspects to the risks associated with the fact that they would be training in a town. In the first case she said, "I think that our being there, dressed in uniforms and carrying airsoft, people might get the wrong idea. Right? They might think that we're a threat and come out with a real weapon, while we're there with airsoft. We need to be sure that people either know what we are doing or that we're not appearing threatening. The other thing I was thinking is that it might be a bad thing to train in town anyway because of the trend towards martial law-I mean the way that people are just getting used to armed military-type people being around in their neighborhoods and things. We don't want to reinforce that trend, I don't want to, anyway, because it contributes to making people submissive." This prompted Bueller to mentioned that a SHTF ${ }^{36}$ warning had come out over one of the conservative news websites recently. BG and a couple of the guys said that they had seen it too but nobody had much more than that to say about it and the topic returned to their public appearance.

\footnotetext{
${ }^{36}$ This is a common abbreviation used to avoid impolite language and stands for "Shit Hits The Fan". This too is shorthand for any number of potential catastrophic events likely to result in a total disruption of social life. Whether environmental or human in their origins, SHTF events are one of the reasons that being selfsufficient and capable of defending oneself, one's family, and one's supplies is valuable. The common belief is that most people will panic in such an event, becoming violent, irrational, and very dangerous once they realize their access to resources is no longer a foregone conclusion. Therefore, one must not only have suppled but be prepared to maintain their access to them in the face of urban-dwellers who would kill to have them in their incapability-induced irrational panic.
} 
Charles took this as an opportunity to make the group aware of Homeland Security's suspicious activity reporting guidelines which amount to, "if you see something, say something." There were a few tepid expressions about disliking the Department of Homeland security as an extension of Obama's administration ${ }^{37}$ and because, as Janet said, "We're the original homeland security...the militia. You should see this YouTube documentary, 'Molon Labe,38, which does a history of the Second Amendment and why we're the homeland security...." Janet's comment prompted some agreement, but they switched back to the visibility debate very quickly. She suggested that Alaine should have a block party so that people can meet the group and Cypher replied that the group should just "knock and contact" the neighbors in order to present the handout. Charles challenged this, "you know Cy, people might want to sleep in on the weekends. They would not appreciate us showing up at their doors, knocking and wanting to talk to them about this. That's not something we want to do." Peirce backed this up, "We really should want to avoid negative feedback like that." Janet and he both talked about the prevalence of negative media coverage about militias and the need to avoid giving people anything remotely bad to work with. (Excerpts from field notes on $8 / 15 / 2016)$

The excerpt above contains four narrative genres common to militia social spaces, both at staff meetings and trainings: Scenarios, Normalization Work, Contribution Talk, and Tech Specs. Normalization Work is a subgenre of Who Talk insofar as it deals with negotiating boundaries between the militia and outsiders but it differs insofar as the utterances and stories are for the militia audience rather than the general public. Instead of direct comparisons that rely on presenting their practices, beliefs, and values as a maligned standard that requires action on their part to correct, Normalization Work simply assumes

\footnotetext{
${ }^{37}$ Nobody in the $10^{\text {th }}$ was positive about Obama's presidency. It is difficult to tell how they feel about other administrations but I believe that it is safe to assume that members of the $10^{\text {th }}$ remain skeptical of federal powers but are more inclined to let go of these concerns, temporarily, when a person they accept as conservative, in their terms, is in office.

${ }^{38}$ This is another instance of historical capital referring to the reply of the Spartan Leonidas to invading Persians who demanded that his military group surrender their arms. The Battle of Thermopylae is a useful a point of reference insofar as it represents to many the power of a small, determined force of skilled men fighting an overwhelming oppressor-the historical brutality of Spartan society is not typically addressed in these presentations. Generally, the term is taken to mean "Come and Take Them" and is used in indicate staunch support for civilian firearms as a bulwark against oppression. It is used throughout paramilitary gun culture and the various groups, including the some among the alt-right that draw upon it in different ways.
} 
the normalcy of these standards, rather than defending them. The genres functions to reinforce the groups' internal sense that they are 'normal' when it comes to the issue at hand and how they should take care to avoid living up to what they feel are incorrect public perceptions of militias.

Contribution Talk is usually closely related to Normalization Work, but I consider it a different, complimentary genre that is used in conjunction with others to emphasize messianic elements of militia identities. Contribution Talk refers to explicit statements that a speaker makes regarding how their actions, beliefs, or attributes are or will be beneficial to others; as such it combines readily with most other genres. It functions to illustrate to listeners that the actions, beliefs, or attributes in question are not only self-interested or rational but also meets the needs of others and contributes to a specific population's wellbeing. Charles' points show how Normalization Work and Contribution Talk can combine. The charity project is not only worthwhile given the problem of child hunger, but that it also provides the group a point of interaction with the public that concretely demonstrates, in his view, that the group truly contributes to others rather than "holing up in compounds, hating the government and stuff," as Alaine once put it. He is relying on the shared belief that the group's ability and desire to provide for others is central to their aim of being a public good and normalizes them compared to other militias. Another example can be found in his presentation of the state organization's new training goals to a large meeting in February 2016, 18 people, many of whom were new peripheral members:

"Most of this is military-type training. I've been, I've been with the militia
since 2010 and we've never, never, been deployed to fight anything or
anyone. Yet. Most everything we have been deployed to do is to help in
communities after disasters, organizing, communication, search-and-
rescue type events. I'm not, denigrating or, dismissing this stuff [referring 
to the military-type training] ...it has value. But, we need to focus on the stuff we do. We, each of us, has got to be diamonds in our communities. Right? You'd be surprised what we can get done as leaders who know the sorts of skills this group works on. We have got to be diamonds. You've probably seen that we respond to tornadoes. That's one of the big things we do. We had, like, 40 guys in Joplin shortly after things happened. And there were a lot of other people. Locals, church groups, media, people who wanted to help but didn't have a clear idea what to do and we helped to provide leadership. We made a big splash with them. That's what happens when you're knowledgeable and ready, you make a splash with people. So, I think it's best we focus on these. We want to be prepared to respond to whatever is thrown in our direction. Be it disasters or a fight with whoever or whatever."

Returning then to the previous excerpt, Bueller challenges Charles' presentation on the basis of his distrust of the financial efficiency of charities, thus pushing the boundaries of Contribution Talk and Charles points out that would reduce their chances of achieving connections with outside groups. In effect, this is a debate over whether their emphasis ought to be on contribution or normalization. Charles pushes Normalization and a need to reinforce the nascent positive view indicated by his receipt of a letter addressed to the group that at least their own unit is composed of 'normal' people who contribute in different ways than most but also give to charities and care about hungry children.

Janet's comments that elicited mildly negative responses show the contours of Normalization work and Contribution talk more clearly still. As I stated in my fieldnotes, she and William had started delving into sovereign citizen rhetoric earlier in the project, much to the concern of some core members at the time ${ }^{39}$. This comment is an attempt to

\footnotetext{
${ }^{39}$ At a training event they hosted in September of 2015 on their farm they improvised a short training session that had not been on the agenda. It was ambiguously received and created a number of conversations with me in which members distanced themselves from them in an unsolicited way. The content dealt with the conspiratorial view that at some point the federal government of the United States was surreptitiously replaced with a corporate body whose assets are the nation's citizens under whose names the treasury opens a secret bank account into which their worth as assets on the stock market are deposited. This all operates by a hidden set of laws that maintain citizens in a position of property and/or corporate entities. The idea is that if a person submits the correct types of documents and says the correct words in court they can be legally
} 
engage in Normalization Work for her own beliefs about to whom it is most advantageous to provide such charity and how it relates notions regarding the meaning of the Constitution of the United States. It is clear from her presentation that she had the impression that whatever these views they were sufficiently shared as to require no explanation. When I say this I am not making light or otherwise mocking her. To this day I am not sure that anybody in that room save her and perhaps William was certain of what qualities a Constitutional kid possesses, only that they were a category whose needs she elevated above other children in some capacity. Her comments met with silence because they were drawing on the ordinary resources of Decline Talk, the historical capital of the Constitution, and service in ways that were difficult for others to recognize or understand given the organizational rules at work for militia messianic marginality. Her take did not conform to the expectations for combining Normalization Work and Contribution Talk because it excessively narrowed what was normal and to what communities they should contribute. Charles attempted to bridge the gap by trying to help her save face through vaguely affirming her concerns over the broader Constitutional ignorance and her preference to help those like her before redirecting the group's collective narrative efforts to more familiar Normalization Work. Like all core members and regulars, despite her specific foibles and blind spots Janet is intelligent and quick. She clearly knew what had occurred and, to prevent Charles and the rest of us from dismissing her entirely ${ }^{40}$, sought to clarify

separated by the corporate entity the government controls, thus freeing the person from all debt, legal obligations, or jurisdiction under law enforcement. There are many more details and a summary can be found here: https://www.splcenter.org/fighting-hate/extremist-files/ideology/sovereign-citizens-movement.

${ }^{40} \mathrm{I}$ believe the group would be loath to admit it but it is overwhelming populated by men and a masculine space, as I noted in the introduction. There have been several instances in which Janet's sex has resulted in her being treated differently. The most prominent example occurred when I was first at a training at her home. While the rest of the group were putting up a home-made antenna and testing it she took care of household chores such as laundry, feeding their chickens, and figuring out what their teenaged sons were up to. I cannot 
her position using a more familiar organization of resources in the form of Decline Talk. Hearing Peirce's affirmation, she again went too far by indicating that she might be espousing the earlier, unclear beliefs to public school children in the area. This represented another break from the Normalization Work occurring and a risk to the group's public/private arrangements. This in turn prompted the group to abandon the topic.

The same pattern reoccurred later in the meeting when she suggested that their Airsoft targets be marked in such a way as to represent Hillary Clinton, whom they all dislike intensely. She was expanding on Cypher's comment, recommending that they simulate shooting the "blue helmets." This is a reference to U.N. Peacekeeping Forces who are often implicated in a longstanding conspiracy theory that the U.N. will invade the United States. By and large most members of the group are familiar with this idea and draw on it as an insider's trope more than out of deeply-felt, true concern. It is akin to having something to show others that they are part of the pro-America, small government clique. His comment received a slightly better response from the group due to the nonspecific target: nameless, faceless blue helmets, and the unlikeliness of the Scenario involved. Janet's on the other hand was specific, timely, and represented a breach of meeting protocol insofar as it made light of targeted violence and staked out a position on a specific politician. Seeing again that her comment had caused a change in topic, Janet brought her points back into line with more appropriate Normalization Work and Contribution Talk regarding real risks to their training and social value if they are seen as threatening or unintentionally normalizing martial law. They might get shot by an otherwise well-

attest conclusively that this troubles her because she's not said so but I have no doubt that she is aware of the phenomenon. 
meaning citizen who believes them to be a threat, or even police. This enhances the problem of people becoming accustomed to militarized law enforcement in their neighborhoods. I cannot honestly say whether she or any other members are aware that the latter has already been occurring in minority communities as a result of law-and-order policies or if they would see that as a problem as they draw on many of the same ordinary resources in their own identity work. There is a certain irony here. 'Martial law' is a widely shared concern to varying degrees of seriousness. Since the 1990s militias and others in their orbits have the impression that one of the signs that the government has become tyrannical and is preparing to act against citizens like them is the imposition of martial law. The irony being that they simultaneously support a paramilitarized culture so long as those armed are responsible, law-abiding good guys, and they support militarized policing when it targets groups they view as extremists or prone to criminal behavior. Extremists, in the views of the $10^{\text {th }}$, are also those that outsiders such as myself are more likely to see as advocates for equality across racial, sexual, and class dimensions. As we see, her revised narrative plays much better but not so well as to prevent Charles from further removing the talk from conspiracies and Scenarios via his reference to the Department of Homeland Security and refocusing on their public face. There exists variation here too in terms of the extent to which dislike for people and groups can be expressed and in what ways.

Cypher explained during our interview in the context of a question I asked him about how he develops the opinion that somebody should not be part of the group:

Cypher: "I have...it's not just looks, I have a three-strike policy. With that, the way they dress might be something I notice."

Daniel: "What do you mean?" 
Cypher: "Rude t-shirts, like that. That's...they have a right to their ideas, ok, but it's also rude and that tells me a little about how they might represent us. Another thing is lies or bragging."

Daniel: "Like stories when they say, 'oh I shot a such and such and it was this unbelievable thing' and you know they're full of shit?"

Cypher: "Sometimes. There's lots of guy who say they were military. I never was, so it's different for me than it is for Pierce, or Audrey or someone, they have other information. But if a guy starts talking that he was in the Green Berets or something in Vietnam and I'm looking at him..."

Daniel: "And you look at the guy and he's, I don't know, 40?"

Cypher: "Yeah, I look at them and I [pretends to count on his fingers] say you know friend, you'da been about...12 in 'Nam. What?! Things like that are one for me. Or things like Dave, I think you met him once. He's not around anymore. You'll remember this, he was this ex-military guy, a hero, and that makes this all the worse. We were here [at Arthur's house] maybe, we were all out training, anyway. And he knew who you were and what you were doing out here and was thinking 'here's this liberal city boy' or something. He comes up and asked you 'how's it going? How's your head [racial slur] in Washington working out for you?' And me and some of the guys were looking at that and he'd done...said things like that before, ok? And we realized this was going to be a problem. I don't like Obama, I hate him, but he was the President, ok? And that's not ok anyway. President or not, you don't...you don't talk like that. We'd told him before that that sort of thing wasn't going to fly. We don't associate with Klan types, like some other militias do. We don't do that and he needs to get it together. But then he did that and we told him 'that's it, you can't come around anymore.' That was rough, and it happens. ${ }^{41}$,"

Many members of the $10^{\text {th }}$ have views that I understand as racist insofar as they are negative, stereotyped ideas about the inadequacies of people of color or different religious faith. No member would accept that label and frankly, several would feel betrayed by this portion of the analysis. Instead, the very idea that they could be racist for holding these

\footnotetext{
${ }^{41}$ It would be fair to wonder if Cypher was putting on a show for me here, given the interview setting and that it was a training day. I argue that it is most likely that he was not. By this point in the project, January 2017, he had repeatedly told me that he saw me as much a member of the group as other regulars and had known me for 2 years. I think he would be unlikely to do try to deceive me at this point and, moreover, he started to cry as he relayed the story to me which suggests that the event upset him due to the fact that the unit lost 'a hero' because the man could not keep his racial animus in check sufficiently to belong.
} 
views would be taken as a sign of their marginalization by wider society for their decision to acknowledge what they think of as uncomfortable facts and honest opinions that liberal, politically correct society hides or ignores.

Among members of the $10^{\text {th }}$ specific racial comments are rare overall compared to all other forms of talk. Race Talk occurs throughout the data and in the few cases it is specific it tends to be made in reference to recent events, such as protests or terrorist attacks, and risks presented by people and places. Whether in implicit or explicit forms, the most prevalent racialized remarks are theological in that even core members and regulars are willing to admit to and discuss their concerns about Islam and Muslims. Unlike some other aspects of the talk and narrative in the $10^{\text {th }}$, the variation in talk and narrative about Islam is narrower and orbits a clear theme: Islam and Muslims are categories of dangerous others and largely incompatible with both Christians and United States culture, which most members of the $10^{\text {th }}$ see as fundamentally related. This excerpt from a meeting in September 2015, the same week as September $11^{\text {th }}$, is indicative of the overall pattern:

Charles then very suddenly got serious and brought up "You know the United States has been fighting the War on Terror for a while now... well it's here." He presented a handout he received form some other group which detailed various Islamic extremists who had been arrested in the US. His point was "they are here and that people need to be vigilant." He referred to the "Towers" as a symptom of the risk.

Analytic note [present in original]: This prompted what, for me, was a disappointing show of Islamophobia. I kept quiet and made notes unobtrusively. I would be lying if I didn't admit to myself that I am always disappointed when things like this happen but also grateful for the way it reminds me to keep some distance.

As people passed the handout around one of the new members suggested contaminating the site of a new local mosque with pork or bacon by building it into the foundation. Donald, another new person, brought up a new AR15 with biblical verses printed on it to prevent "Muslims from handling it". 
There was little enthusiasm about either of these, and Wade pointed out that they didn't want to be like the pastor in Florida who went around burning Korans. Sensing the shift in tone, the second man simply ended with the fact that he thought it was great. Charles brought things back to order by gently urging people to come up with "real" ideas for practicing vigilance.

As we see here, there are boundaries at staff meetings for even Islamophobia. Elevated attention in the form of profiling is not off-limits as it relates closely to the defensive, service-based elements of militia messianic marginality from their perspective of Islam as a potential threat. Core members and regulars look at this in terms of the Skittles Analogy ${ }^{42}$ used in the recent presidential campaign. Muslims as a population are generally not a threat but terrorists hide within those populations and scrutinizing them is warranted. This troubles me in and of itself given how it can be put into policy in deeply harmful ways. Whatever empathy might develop out of their own sense of marginalization and unfair alignment does not extend to racial, ethnic, or theological groups and this allows them to support institutional discrimination without seeing it as such. Charles made his point in the context of the September $11^{\text {th }}$ attacks and smaller events in Europe remained within the boundaries of messianic marginality insofar as it spoke to the idea that members of the militia are willing to shoulder the burden of vigilance even if nobody understands. Peripheral members do not yet know these boundaries. The two of them above, neither of whom remained around the group long after, took Charles' concern to suggest that the meeting was a forum for discussing a hate crime dressed as a joke and Bible verses as supernatural deterrents to Muslims. Their talk was much more aggressive and troubled militia messianic marginality by challenging the groups stated acceptance of all religions. While they were not chastised for these comments Charles was deliberate in his shifting

\footnotetext{
${ }^{42}$ Franz clued me into this. He was a peripheral member that moved into the regular group and drew directly on this analogy during our interview.
} 
the conversation back to vigilance, it was a signal that the direction was inappropriate. I know of at least one regular member who holds views more similar to the peripheral members above but he does not discuss them during militia events nor act on them, indicating that during his transition to a regular and then core member he internalized these rules and expectations.

Beyond occasionally overt Islamophobia, among the $10^{\text {th }}$ there is also a pervasive distrust of cities and urban areas based on the risks of street crime, primarily associated with African American men. Unlike their willingness to identify Islam and Muslims specifically, mentions of race and African Americans in particular, are rarer. Race is more often approached indirectly through humor, dependency, and rural/urban comparisons. Cypher made the following illustrative comment during a staff meeting in October 2015, while live-fire training was under discussion:

Charles ended the comment with that pretty much everyone in the group trains with the replica handguns because "most everyone grows up learning how to shoot a rifle." Peirce retorted, "Except in the Bronx [he is from New York]." This received hearty chuckles. Cypher added, "They, though, they can do trick shots!" While he spoke, he engaged in a pantomime, he imitated holding a handgun sideways and firing it from this position. (Field notes 10/12/2015).

At yet another meeting five months later, he challenged a core member's citation of a peripheral member's views on the matter in a discussion on search-and-rescue training:

Arthur interjected: "You know, there's something that we could mention here, it's not PC, but it's something that we should talk about for a second. Again, it's not PC, but Brock told me this. When you're looking for a white person who's gone missing you tend to look away from society, outside of society but if you are looking for a black person you should look at its edges because they won't completely leave it. Blacks tend to stay closer rather than move further out." 
Analytic Note [present in original fieldnotes]: knowing what I know about Brock I suspect that he bases this on his experience in law enforcement in rural Missouri-meaning I suspect he knows few, if any people of color and therefore is susceptible to the stereotype embedded in this reasoning-that people from racial and ethnic minority backgrounds live in urban areas and, like most urban people, are 'dependent' and even if they want to leave society they cannot do so and survive.

Cypher problematized this, "well, Arthur, that might be true of anyone whose living in a city and isn't comfortable with outdoors but I've known some black farmers-even right around here, and I don't think they'd be that way. They're comfortable out and about." That settled that.

Cypher's original comment got more laughs than I am comfortable with. These examples speak to a concept that Blee (2002) draws upon in her work on organized racism. Citing Philomena Essad, she discusses everyday racism "which reflects negative stereotyped views of minority groups," and is "pernicious but unremarkable among whites in racist society." (ibid: 75, Essad 1991). Blee contrasts this with extraordinary racism which is ideological and connects race to a host of other phenomena as a central explanatory factor (Blee 2002: 75). The $10^{\text {th }}$ draws the line at the latter while the former is, indeed, unremarkable to them as they are seldom in the company of people of color. At different points after the Concerned Student 1950 movement had started on the University of Missouri campus Audrey and Charles each confided in me that they felt that the movement was more divisive than beneficial. Audrey believe the disruptions were excessive and suggested that they were leading him to racism while Charles once said that things were not fair but white people had come 'pretty far' and only so much change can come from them. They view themselves as non-racists because as a group they do not tolerate people who emphasize race as a central component of identity and social life, which in their color-blind view of the world is 'real' racism. In effect, they inoculate themselves against charges of racism through their rejections of extraordinary racism and 
race as central to identity. To their view, rather than race itself the idea of minority dependency, whether in terms of welfare or technology, is an issue of the consequences of urban life, government intervention that enhances both, and a liberal, "politically correct" culture $^{43}$ that pretends otherwise. For them, it is not racist make such comments even where they acknowledge that others would consider it to be. They would vehemently disagree with my analysis that their views are largely representative of the racialized dog-whistle politics of the last several decades that have increasingly entered the paramilitary gun culture and politics. Similarly, they would find it upsetting that in their efforts to push further into the mainstream of U.S. politics some white supremacist and white nationalist groups use language similar to their own in their efforts to coopt the language and frames of civil rights and thereby sanitize their racism (Neiwert 2017). Making race visible challenges the hegemony and safety of their olor-blind perspective that preserves the racial invisibility required for their own marginalization to be a point of reference. In my interview with Arthur we ended up discussing the fatal events in Charlottesville. He explained to me that his take:

"You had the protestors and the counter protestors and then the guy. Well I read enough about that and saw some of the video. Well we got stupid combined with stupid out there in the middle of the street and people got killed. As far as what little I saw about it, if I was there on-site I may have come up with a totally different idea on it. But, you know, people are out there and they get in numbers and they can really do stupid things."

In his view there is no distinction between the white supremacists or those who opposed them, everyone involved should have known better than to be in a situation that was likely to turn acrimonious and chaotic. He had earlier explained that he believe the bulk of

\footnotetext{
${ }^{43}$ Mentioning politically correct culture helps marks a statement that even members of the unit might think was racist as a mere observation and simultaneously recalls their sense of marginalization by politically correct culture.
} 
contemporary racial tension is a function of media decisions to emphasize it for advertising money. This combines notions of the dangers associated with urban areas based on the raw number of people in them with the idea that situations, groups, and arguments that center on race are dangerous and divisive. From Arthur's admittedly incomplete take, Heather Heyer's death was not so much the result of a white supremacist striking her and many others with his vehicle but rather that a large number of people who have been roiled by a greedy media and allowed their emotions to get the better of them. In this way he can preserve his messianic identity as a racially neutral, responsible person without having to commit to assigning responsibility to either group of actors thus suggesting an alignment with one or the other and creating marginalizing associations with racists or left-wing protestors. At the same does this makes it difficult for him to see the ways in which his views contribute to those processes.

There is another genre at work in Cypher's comment which he used to sidestep the racial overtones of his comment and keep it in line with the standards of the militia messianic marginality, Tech Specs. Tech Specs appear in all of my data to one extent or another. In terms of form, all instances of Tech Specs follow an overall pattern although the specificity of the details can vary depending on whether the matter at hand is of interest to many or few and the average sophistication of the knowledge shared between participants. Like Contribution Talk Tech Specs can be combined with other genres-most commonly scenarios and Responsibility $\mathrm{Talk}^{44}$-in order to emphasize different dimensions of messianic marginality. There was not a staff meeting at which this genre

\footnotetext{
${ }^{44}$ This is another pervasive topic. It always takes the form of a story of a comment demonstrating that the speaker is careful about their spending and savvy about finding deals. This marks them as responsible and distinguishes them from the wider, wasteful, and frivolous society. I did not foreground it in my analysis here as it is less analytically interesting than other categories.
} 
failed to find use usually during "rabbit chases" 45 . Gun talk is very common, given that ownership and experience with them members take as a given. Contrary to what one might expect, more common than gun talk are discussions of comms equipment, survival supplies, food and water preparation techniques, and information about where and how to find inexpensive gear.

As we see in Cypher's comment, Tech Specs can be used in Race Talk to imply a superior position relative to the amusing incompetence of outsiders. Here he is parlaying a shared technical expertise in the correct techniques for firing handguns into a comment on incompetence and African American criminality. The shared knowledge of correct firing techniques and the work they have done to hone it marks their messianic qualities as responsible, capable gun owners who can proficiently defend themselves and others. Cypher implicates urban areas and African American criminals as causes of gun violence which marginalizes their own positions as gun owners by association, which is taken to be humorous in this case given the degree of incompetence involved. This specific articulation of race through technical proficiency with firearms occurred periodically throughout my fieldwork, albeit rarely, as the group does not often include live-fire in its training events.

Despite the seriousness with which much of $10^{\text {th }}$ treats the work and planned of staff meetings it is also a space of masculine bonding and contest. As such, humor is a component throughout most meetings. Humor is used to defuse tension, engage in status work within the group, and accomplish messianic marginality in less serious yet effective

\footnotetext{
${ }^{45}$ Chasing rabbits is the term that core members have used throughout my time with the group. It refers to instances during staff meetings and trainings wherein discussants become significantly distracted a topic that is not germane to concluding that matters at hand.
} 
ways. Below is a table including the most common themes that jokes contain throughout my data.

\section{Post-Meeting Goodbyes}

Meetings last only an hour or two most of the time. The tendency was for them to run longer when Charles was the leader of the group as he allowed more rabbit chasing that Peirce who prefers for meetings to end in a timely manner. In both cases once the new business of establishing the training plan for the weekend, who will be teaching what, and where it will be held has been concluded people will rabbit chase for a few minutes. Sometimes a regular or core member will point out what time it is and suggest that a vote to conclude the meeting be made. Other times people will simply excuse themselves, announcing that they have something to do. Theodore usually accomplishes this by reminding us that his drive home is more than an hour. This will signal that it is time to conclude the proceedings. A core member will motion to end the meeting and there has never in my experience been a time that another core or regular failed to enthusiastically second it within a few seconds. 
Table 5: Common Themes and Forms of Militia Humor

\begin{tabular}{|cc|l|}
\hline Theme & Description \\
\hline I. $\quad$ Masculinity & $\begin{array}{l}\text { Masculinity jokes are constant. Many are } \\
\text { ribald in nature or deal with frustrations } \\
\text { associated with the women and children. } \\
\text { Age jokes are specific and identify the } \\
\text { declines associated with old age seeking } \\
\text { commiseration over shard indignities. } \\
\text { I.a. Age }\end{array}$ & $\begin{array}{l}\text { Jokes about one's own or preferably others } \\
\text { physical shortcomings are a common jest } \\
\text { designed to provoke a response in a brief } \\
\text { status contest. }\end{array}$ \\
\hline II. $\quad$ "Getting one Over Somebody" Physical Attractiveness & $\begin{array}{l}\text { Humor here depends on relying situations } \\
\text { in which the speak has taken advantage of } \\
\text { or demonstrated a shortcoming of } \\
\text { somebody else. The target can be spouses, } \\
\text { friends, merchants, other members, or } \\
\text { outsiders. }\end{array}$ \\
\hline III. $\quad$ "I'm Not Complaining but..." & $\begin{array}{l}\text { This is a way of complaining about an issue } \\
\text { by bracketing it in a humorous point } \\
\text { suggesting that the aggravation is not } \\
\text { serious. }\end{array}$ \\
\hline IV. $\quad$ Competency & $\begin{array}{l}\text { Jokes about competency can either reduce } \\
\text { the negative evaluation of a speaker's } \\
\text { competency by making it clear that they } \\
\text { too are aware of the deficiency or increase } \\
\text { the groups sense of competency by } \\
\text { downplaying that of outsiders. }\end{array}$ \\
In.b. Incompetence and & $\begin{array}{l}\text { Jokes downplay failures to live up to the } \\
\text { group's expectations for members or the } \\
\text { low-level of expectations. } \\
\text { Poking fun at the failures of others }\end{array}$ \\
\hline
\end{tabular}

Once the call to end the meeting has been made and militia time has ended people filter out very quickly but core member and regulars will sometimes stay, time-permitting, to chat informally in ways closer to premeeting freedom than official militia time. Conspiratorial diversions, more specific complaints about politics and decline, and raising concerns about 
people who have left are allowed here as well as Tech Spec like comms that would be interminable for peripheral members to sit through during the meeting. This time is usually brief and ends quickly.

In this chapter I have demonstrated the ways in which staff meetings change the ordinary resources and messianic marginality in ways that are not evident to peripheral members at first. Tech Specs, Scenarios, Responsibility Talk, Normalization Talk, Legitimacy Talk, Contribution Talk, and historical capital must be organized in ways that still generally live up to the public presentations of the group as presented in chapter three but there is more leeway in terms of people learning to organize them correctly. William and Janet are exceptions to this as they are regular/core members, depending on their availability and while they are not disciplined directly as a result they are still moderating through informal social pressure from other core members. Training days are considerably more private and change these public/private dynamics even further. 


\section{Chapter 5}

“There's a Lot of Loose Talk Going on, Too Much Loose Talk for Me" The Outer Limits of Messianic Marginality at Training Events 
The $10^{\text {th }}$ 's training events are the most private militia setting, given that only core members, regulars and those dedicated to enough to give up a Saturday. As a result of this self-selection the requirements on messianic marginality are less stringent than those at staff meeting and for public documents. It is very much a space of white, rural-centric masculinity. Core members, regulars, and peripheral members all find a more experimental environment at training events; Scenarios can verge on the outlandish, Who Talk can be more detailed and exclusionary, humor can be more explicit, and political positions more pointed. Even within this private, flexible environ there remain limits the degree to which the boundaries of messianic marginality expand and it is most commonly peripheral members who, in the spirit of the "looser" conversations, run up against the boundaries of militia messianic marginality. The types of members present, who is interacting with whom, and what activities are taking place that day inform these limits as well as the degree to which talk diverges from the group's idealized views of itself as not racist, antigovernment, sexist, or otherwise marginalized. This chapter will illustrate these patterns and how the members of the $10^{\text {th }}$ navigate messianic marginality in their most secluded social setting.

As an observer would expect training events are in primarily about putting the group's identity into practice and members discuss it as crucial preparation work that will avail them in performing search-and-rescue operations, moving debris, emergency medicine, surviving in the event of a catastrophe, and armed conflict, whether with the 'bad guys' one runs into from time to time or, perhaps, organized enemies. Training events can be profoundly serious at times, but no matter the topic people will get jokes in as they can. Leaders and core members, compared to regulars and peripheral members are likely to 
infrequently remark on how they activities amount to "playing army" as Peirce, Charles, and Cypher have called it. Core members show others where the lines of serious militia business and recreational militia activities are supposed to be drawn. The differing levels of self-awareness and willingness to seriously acknowledge what the group is or is not capable of, trainings more often serve as an extended forum for exchanging information and ideas refining the boundaries of messianic marginality.

Seriousness is also greater, of course, when live firearms are part of the order of the day, or when a training scenario closely replicates a real situation that the $10^{\text {th }}$ 's long-term members have been deployed to confront. None of these real-life situations have thus far required the use of firearms and leaders are keenly aware of it. Consequently, most trainings do not involve shooting firearms except to satisfy their collective desire to shoot from time to time and thereby energize people. Guns are still omnipresent as accessories to the rest of the uniform, carried as a type of practice. Most shooting takes the form of firing plastic projectiles from $\mathrm{CO} 2$ or spring powered replicas of lethal counterparts. Firearms are therefore an important foundation but they almost disappear, unless used in Tech Specs, Scenarios, or actual shooting, so thoroughly are they integrated into the lives of the $10^{\text {th }}$.

The $10^{\text {th }}$ schedules training events on the third Saturday of every month save a few exceptions. The rarest exception to this is when the leadership cancels a training due to the inability of most core and regular members to attend. Usually they will simply reschedule for a different day. There are also two regular exceptions to this schedule. In November, the "high holy time," as Charles once called deer season, overrides training. Other than Peirce, most of the core group and regulars hunt deer and use their successes to reduce their 
food costs throughout the year; very much like my partner and me. In December there is an annual Christmas party ${ }^{46}$, which takes precedence over training. Last year the Christmas party contained a small comms training exercise but I am given to the impression that while little training events may occur at these gatherings they are far less formally organized than the main training events the rest of the year.

In the remaining ten months of the year trainings are held on a mixture of public and private land. Usually the decisions on where a training will be held rests of the balance of core and regular members at the previous staff meeting and who is able to and willing to offer their own land as a training area. William and Janet, Audrey, or Arthur have enough space that their properties are useful as training areas but when they are not present or unable to host the group then one of two public conservation areas that the core group is familiar with will be selected. Of these two public training sites, only one has facilities for shooting, again, reflecting that while firearms and paramilitary gun culture are significant resources for the narrative practices of the $10^{\text {th }}$ and their physical accoutrements, their actual use of guns is more sporadic.

Organizing trainings in person on the week they are to occur and the mixture of private and public property are significant factors in establishing the private qualities of training sessions. It is not my impression that this represents a deliberate strategy to keep the public away; especially given how frequently the leadership who orchestrates these decisions express their desire for the $10^{\text {th }}$ to be well-known, liked, and respected by

\footnotetext{
${ }^{46}$ I never attended a Christmas party with the group for similar reasons to my avoidance of JTX. I could not be sure who would be present and may not be as comfortable with my presence as the core and regular members who vouch for me at other events. Secondarily, I felt that it allowed me some distance from the group insofar as it was a brief break during which I could review notes and consider their activities in the absence of interacting with them.
} 
outsiders. Instead, the privacy of trainings more a result of the ambivalent nature of the relationship between the $10^{\text {th }}$ and the public, differing perspectives on the value of public attention among membership, as well as the complexities of organizing the unit's activities in only their spare time. It is not a surprise that there is a general inattention regarding how the organization's practices might limit public access to them. The following excerpts from my notes on February and May of 2016, an election year, demonstrate the private nature of training, any incursions from the outside world are noteworthy on training days on

Audrey, Theodore, and I stood a few feet outside of Arthur's shed, where most of the training was taking place today. Theodore opened the conversation by noting yet another plane that was flying by. There had already been several others. This is common given that Arthur's land is near a small airport meant for crop dusters and training. Janet, a few feet away, joked that we should all look down rather than up. Arthur followed this up with the comment, "we should at least check and see if it is black or a helicopter." It was clear that he was making light of the idea that we should worry, in our chats he has made clear to me that he does not take too seriously the idea that anything the $10^{\text {th }}$ does is of much interest to authorities, or anybody else. Theodore looked at me with a big grin and announced, "We should be careful. Someone might have ratted us out, they may have been talking. Did you talk Daniel? Huh? Did you tell people what we were up to?" I did the best I could to appear as though this did not bother me because I honestly doubted he realized how threatening such comments can seem. I managed a chuckle and a, "sure I did," indicating that I was in on the joke, and then ended with a, "no." (Fieldnotes, February 2016)

There was to be short break between formation and the first training session so that people could relieve themselves and prepare whatever they needed. Peirce took his charges aside, bringing them to another portion of Audrey's land to prepare them for their teaching experiences. The rest of us milled about while Charles set up his land navigation lesson. I walked over to the fire pit, which was simply a round slice of a concrete drainage pipe laid on its side, and stood near Franz and Alaine. Alaine joked "Hey Daniel! When did you come snooping around?!' I smiled and told him I'd been here since 8 and figured that he'd seen me. Later once the lesson began, a plane flew overhead and people looked up at it. Franz and Cypher joked that they were being spied on (Fieldnotes, May 2016). 
Despite their desire for recognition the core members of the tenth $10^{\text {th }}$ do not emphasize activities designed to seek it out or secure it beyond their rare deployments, charitable giving and occasional cook outs. Sometimes a member will suggest making pitches to local officials and law enforcement but any such overtures end up delayed by core members and leaders based on a desire to have the unit in a presentable condition. Feelings of marginalization and skepticism towards outsiders make the poverty of outsider attention both a complaint and a comfort. Core members see the group as one deserving of recognition while peripheral members tend to worry much more that recognition risks negative attention. Core members must occasionally grapple with the fact that peripheral and even some regulars fear surveillance and persecution to such a degree that even basic organizational needs such as being able to contact members by email or phone become potential threats in their eyes. Those who do not eventually come around to the core member's interpretations tend to exit the group before long but regulars and core members will periodically contest these boundaries.

A normal training day can be analytically organized into a series of stages: pretraining socialization, muster and announcements, training sessions, lunch, second training sessions, round robin, and dismissal. As in the previous chapter, the analysis here is organized temporally to capture the flow of activity throughout these different stages of the day and allow me to draw upon the entire range of notes from the field training events I attended and demonstrate where fractures and disputes around messianic marginality occur and how participants navigate them. Regardless of the location selected for the month and the activities planned most trainings last the better part of the day, about seven to nine hours. If it is excessively cold or hot, the weather is otherwise terrible, or turn-out is very 
low, they may end after five hours or less. The shortest event I attended lasted only four hours. It was at a location that the $10^{\text {th }}$ had only recently started used, a conservation area other than their normal one. It was difficult to find the correct combination of roads to get there and many of us, including the leader, Peirce, ended up being quite late. Peirce was the latest and when he did arrive, there was a long bull session regarding his failure to arrive at a location he had selected. Most of the remaining time was dedicated to reviewing their recent search and rescue deployment followed by a tutorial on setting up a command center during a deployment ${ }^{47}$.

\section{Pretraining Socialization}

Pretraining socialization is very much like premeeting socialization in that core members and regulars arrive, greet each other, and socialization while peripheral members remain more reserved before the develop a rapport with somebody. The main difference between the premeeting socialization and pretraining socialization is that here everybody is uniform, or the most reasonable approximation thereof that they have yet put together ${ }^{48}$. Rather than create a chaotic flock of interlocutors, people tend to group together into peer groups and engage in Busy Talk, Show and Tell, or other general messianic marginality

\footnotetext{
${ }^{47}$ This is the only deployment that I can confirm occurred during this project. In April 2017 in a nearby town a middle-aged man with severely diminished mental capacities disappeared from the group home in which he lived. Alaine spotted the missing person news on his social media and sent it to Charles who reached out to the family and offered help. They accepted and Charles told Cypher to call everyone. Ultimately Cypher, Franz, Alaine, Franz, and Audrey had responded and aided in the ultimately fruitless search. The man's body was discovered several days later by law enforcement. He had died from injuries resulting from caretakers' forcing him to fight and they had hidden his body in a trashcan filled with concrete.

${ }^{48}$ Core members and regulars reliably have the most complete uniforms and in the correct camouflage pattern. Woodland green is the expected pattern as it matches Missouri foliage quite well and is among the most readily available. A complete uniform includes combat-style boots, pants, a jacket, cover, and name tags. Peripheral members are more likely to have mismatched, nonregulation camouflage, wear $\mathrm{t}$-shirts with camouflage print in lieu of a jacket, and wearing hiking boots or simple work boots. Cypher and Franz are exceptions to this. Franz has never confided in me anything about it but Cypher made it a point that he was only going to be "nickel-and-dimed" by uniform requirements to a point - that of the pins and tags which he found unnecessary.
} 
work. Groups will not move to a person nor invite them into ongoing conversation beyond issuing a wave and greeting to a new arrival, merely greeting them as they show up before returning their attention to those nearest to them. It is incumbent upon new arrivals to initiate further interaction by entering physical proximity of a preexisting group and then engaging with them. The fieldnotes from my first training day in March of 2015 are indicative of these processes:

There were two men there before me and neither of them were members of the group that I had met on Monday. This made me apprehensive about exiting my car and, frankly, was precisely the sort of scenario that had been making me nervous about this event all week. I did not want to show up without the leadership to vouch for my acceptability. I am unsure as to how much of that worry is legitimate and how much of it correctly cautious given how much of my emotional consternation is related to the literature's focus on the dangers that many militia groups represent. Both men were clad in their uniforms: camouflage jackets, tan or olive drab undershirts, and camouflage pants. They waved and smiled as I pulled up, which I later decided is both genuine friendliness and a deliberate effort to change public perception of the militia; they waved at everyone they saw pass the road behind us.

The younger man, Brown, was new and wore mismatched camo. Woodland green and brown on top with tiger stripe bottoms. The articles of clothing clashed noticeably. Brown is white, in his thirties by my estimation, slightly heavy-set, and was very reserved for most of the day. He established his stoicism as soon as I exited the car, which I did after of several minutes of waiting to see if Charles or Wade would show up and explain my presence. I noticed that his pants and mine were the only that remained untucked into boots. I ended up tucking mine in during the step counting exercise as I was both wary of brown recluses that may have been living in the field we were working in and had (finally) noticed that everybody else save Brown had tucked their pants into their boots. Nobody remarked on this or that I had changed my pants to reflect theirs.

Walther is the name of the older man, in his mid-to-late forties at most. His hair is short and quite black save for a stray grey here and there. He makes it a point to make direct eye contact with people to whom he is speaking, which he does often and enthusiastically. He is also a very attentive person prone to notice details and, by his own admission, deeply 
competitive. He notices my wedding band once we've started talking and tell me that he has recently gotten engaged. He's very proud and his excitement over it is contagious. He and his intended, whose name he never mentioned, had planned to have the ceremony or honeymoon in Jamaica but her mother had become gravely ill and they had to delay things to take care of her.

It seemed that Brown and Walther had been milling around for at least a few minutes by the time I pulled in at 7:40 or so. Muster was supposed to be at 7:30 but only they had shown up so they simply started chatting with one another. I think they know each other reasonably well as they paired off for most of the day's activities. After I had spent an awkward few minutes in the car I exited, said hello, and approached them after lighting a cigarette. Both returned my greeting and Walther asked if I was there for the militia activities or just to shoot. I told them that Charles expected me for the militia activities and they both seemed to be content with this explanation. We milled about chatting about the state of the shooting range for a bit-it was very messy, clearly the result of previous users not cleaning up after themselves. This is bad range etiquette. We then moved on to the amusing fact that the leaders, and everyone else, was late at this point. Walther joked that he was usually the late one, which Brown admitted described his punctuality too. This was amusing enough to both of them that they cracked smiles and laughed a little when explaining this to me. I noticed that Walther had a handgun in a plastic holster along with an extra, fully loaded magazine. The pistol was a modern European combat handgun from a high-end company. Brown did not carry his pistol holstered, or at all. Besides myself he was the only one who did not. After a few more minutes an SUV was pulling up the gravel road and they identified that it was Charles; this was after an earlier false alarm where another vehicle had come and gone.

Charles pulled up and parked parallel to the rest of us (I had parked on the far-side, away from Brown and Walther, out of misplaced caution). He got out and I greeted him, he replied that he was pleased to see I had made it and I said that I had been worried that I would be bogged down in teaching work but that had not been the case. Charles asked if I had brought the handgun ${ }^{49}$ I had planned to borrow for the day's shooting and I informed him that I had simply purchased it from the man at the excellent price I had hoped for. We both walked back over to Brown and Walther. Audrey arrived with less fanfare a little bit after. As Walther and Brown joked that they had gotten there at 7:30 Charles started to explain why he

\footnotetext{
${ }^{49} \mathrm{He}$ asked about the specific, $9 \mathrm{~mm}$, semi-automatic handgun that is also the standard issue for most branches of military service. It is popular for its military associations as well as the respect people have for the quality of work for which the manufacturer is known.
} 
was late. The gist of the story was that, as "each you would surely understand", his wife spends much of the time uninterested in sexual activities but, it seemed to him, that as soon as he "had somewhere that I want to be on time she finds me interesting," and so he returned her "amorousness" at the cost of being late. His coy, indirect language made Walther and Brown smile and guffaw before Walther exclaimed that "nobody should pass up such an opportunity."

After Audrey arrived it became clear that it was only going to be the five of us. Charles opened the meeting with a prayer, which was a sort of stop-and-go list, asking the lord to keep everyone safe, their minds clear and aware, and that the day be productive. Charles then told the group that the plan for the day was to practice their shooting for a few hours, then field-strip and clean their weapons (which we never did get around to), eat lunch, and then practice land navigation as well as tracking. After this he explained where each of their missing members were, given that at least double the current number had been expected, not including the character from the J school. Of note to me was that there's a couple in their group Charles intimated were particularly flakey. Another person, Clint, the youngest participant in the group who is no older than me, had come down with some stomach bug acquired from something that he ate. The irony that he ate something that made him sick was tremendously amusing to the other guys as Clint apparently is the cook, which is he job outside the group as well. Wade was in KC for an event related to the Civil War. Cypher and others were at a radio license qualifying class for the day. During the shooting portion of the day I asked Charles if attendance was usually so inconsistent. He said with a sigh that it was, and in disappointed tones he explained that on their best days they can get nearly 20 of their "maybe 70 or 100 members" out at the same time. Usually it is only a few. I asked him if it was mostly a function of busy lives, work, family, and what not. He told me that "It is, but that's the way of things, time is scarce and other responsibilities are important."

After his explanation of the absences Charles once again invited me to introduce my project. I introduced myself as a PhD student from the sociology department and explained that I had been studying guns, gun culture, and had become interested in learning about how militiamen "go about doing militia stuff" and, furthermore, "how they daily do identity work." The two new guys took this in stride, nonplussed by my description. I asked if I should go get the consent forms and they, as well as Charles, said sure and so I fetched them. I walked them through the privacy information, including the data protection, and emphasized again that I am interested in how they go about their militia stuff, my interest in identity as a daily performance, and the ways it relates to masculinity and history. They 
had no questions about this information. Instead, there was a rather serious moment when Walther said, "I only want to know what you pledge allegiance to." Temporarily flummoxed I asserted, "the flag." He then immediately followed up, "which one?" I answered, "the American Flag." Evidently satisfied, he concluded, "Then I'm ok with you being around."

Originally, they had intended to open the day's activities with a pledge of allegiance as is their custom but there were no flags at the range. Audrey quickly said that he had a solution to that in his SUV. He wandered off to his car and from its rear produced a small flag that clips onto the door frame of vehicles. He attached it to his car and the rest of the group came over. Charles announced that they were going to do this "in formation" and both he and Walther invited me to participate - if I was so inclined. I felt that saying no would be in bad taste while saying yes would be good rapport building and unproblematic. I think this was also Walther's way of adjudicating my honesty in response to his earlier question as well as my character. They explained to me how they set themselves up for the pledge. Each adopted a position in front of the flag and once the person furthest to the left had situated himself the next would outstretch his left arm and approach the leftmost man until his own arm touched the should of the leftmost. Charles took it upon himself to position me next to Brown. The pledge recitation was pretty similar to others I had participated in throughout my life, including the removal of hats the placing of hands over hearts, and the nearly traditional slight delay between when whomever is leading the pledge begins and the rest of a crowd joins on a number of different words. Charles started us off and by "of America" everybody had joined in.

My own anxiety about the meeting seems to be a common experience. Although the $10^{\text {th }}$ emphasizes their openness once one manages to arrive at an event the difficulties in getting the time, date, and location of a meeting, largely due to organizational shortcomings, does little to dispel the image of militias as secretive and dangerous. New people respond to this, I think, with similar anxiety which may be further enhanced by any extraneous concerns they have with being persecuted by the government or other outsiders. Those who already know a core member or a regular seem less anxious. As people grow more familiar with the specific standards for identity presentation, such as the importance of the American flag and the pledge, this anxiety passes. 
Busy talk in this setting often involves family matters and work as they relate to masculinity and, indirectly, race and geography, catching people up on recent events or caretaking that they have been engaged with. Other than Janet, women are typically not present at trainings and they become a space of accomplishing masculinity, whiteness, and competence as well as broader militia work. There is a mixture of beliefs regarding how sex and militia messianic marginality interact, some members, like Cypher and Janet, do not see masculinity as having much to do with the militia, preferring instead to emphasize duty and citizenship as explanatory factors. Others, like Arthur believe that it is a biological reality that men are the best prepared to fight and protect their families. I do not think that any member would recognize that the different variations in their beliefs are permutations of broader patriarchal resources that have been used to build the paramilitary gun culture, security-society, and are also used by overt misogynists and racist groups in more detailed and explicit arrangements to justify subordinating women.

Among the men of the $10^{\text {th }}$, women are presented in turns as sources of frustration and confusion, crucial partners who mitigate male foolishness, "the boss" of households and capable fighters, and objects of appropriate male sexual attention. I call this genre Man Talk, a subgenre of Who Talk. It takes the form of masculinist complaints or observations about frustrations, difficulties, or humor that relies on presumed heterosexual male experience. Its function is to allow speakers to confirm their masculinity with the audience and position their experience and identities relative to women and other men. Charles' story is a clear example here. in response to the mocking attack on his punctuality and leadership, which was never intended to be serious, he explained it in terms of the inconveniences of his wife's sexuality which he expected the rest of us to understand as heterosexual men. 
Taken by itself, of course, complaining about the tryst would challenge his masculinity insofar as men are expected to seek and achieve heterosexual activity. The inconvenient nature of the activity had to be framed as a decision that any man would make, which Walther made explicit ${ }^{50}$. Interestingly, Charles' coyness about sex in this admission suggests to me that either he knows his wife would be unlikely to appreciate in its framing or detail or that the admission itself is at the boarder of appropriate sharing.

Sexual virility is not a rare topic when it comes to status contests and jesting among men, although I was somewhat surprised that participants made comments linking firearms and male genitalia. Given how sensitive they seem to marginalize aspects of their identities as men and gun enthusiasts I had assumed that the link between the two that outsiders sometimes posit as an open secret of the gun culture would make them less willing to make such comparisons. I found I was incorrect on the first training day I attended when Walther made a joke about "accidental discharges." These are not jokes and stories that often occur when Janet or other women are around or at staff meetings.

Masculine responsibility in the militia training setting is primarily established through talk and stories that position it against the irresponsibility or incompetence of others who benefit from it. Take a complaint the Cypher made while he set up equipment for a training after I had discussed with him some recent expenses associated with our dog's health:

Cypher asserted that he understood that all too well and then told me that his wife had been terribly sick all year. At this point he was "fairly sure we owe over \$200,000 or \$300,000 dollars," he added sotto voce that

\footnotetext{
${ }^{50} \mathrm{I}$ am not proud of it but I tested this excuse against "getting lost" in explaining my own tardiness on two occasions. The former resulted in congratulations while the latter resulted in advice on how to navigate in Missouri and appreciating the countryside.
} 
she "had not been taking good care of herself anyway." I balked and asked him I heard correctly. He said that he did and I expressed my sympathy. He shrugged and said that was why he "understood and how things go." He turned back to his gear. I asked him if I could help and he told me that there was nothing, everything was already mostly in order.

His wife and her lack of personal responsibility are both presented in terms of financial and emotional costs that he pays rather than her experiences. He deals with these responsibilities and dismisses his complaint because that's "how things go." Age, decline, responsibility, and difficulty are used for humorous effects wherever possible within the group but these are also serious concerns that frustrate them. Based on Cypher's other comments about his wife over the time I have known him I do not think he intended to compare his wife to my dog directly, given that I have heard him make jokes about such a comparison and make clear that his wife is by his estimation better than most. His point was his feelings about what he sees as her irresponsibility in making sufficient efforts in returning to health, this shifts the weight of the situation onto him. As far as masculinity work in the militia setting goes this demonstrates how masculinity, self-sufficiency, and responsibility are tied together in ways that reliably situate men in superordinate positions to others around them. That the position is presented as burdensome disguises it in messianic terms without addressing the wider consequences for subordinated people. His complaint that she does not take care of herself despite his efforts on her behalf captures this dynamic. Because there are rarely women or children present at trainings, these subordinated positions are seldom challenged and this preserves the messianic claims as well as the pervasive sense of marginality. Rather than agents in the world, women and children serve as resources in performing masculinity. 
At one training he hosted in October of 2016 Alaine and I spoke at length on his efforts to prepare his eldest daughter for college and how her skills in softball might offset the tuition costs.

Theodore and I stood there silently for a few moments. Fleetingly, we discussed the pleasant weather and our hopes that it would not rain on us today, and then we parted ways to engage others in conversation. Alaine walked by me on his way to deliver something to the leadership, who were inside the shooting house, and then stopped next to me on his way back to his garage. He asked how I was and I replied that I was busy but fine before returning the question to him. He said he was incredibly busy too as his eldest daughter was trying to get into college and this was, "exciting but way busier than you'd think, there's a lot to it." I inquired as to what was the most time consuming and he explained, "she's taking the ACT a couple more times so that she can increase her scholarship chances and that's taking some effort from her and everybody." He continued, asking whether or not I had taken prep courses for the entrance tests. I replied that I had not but I did purchase and work my way through a couple of practice books that those programs sometimes use. Alaine wondered if it had helped I admitted to him that I thought that it had, given that I took the test five times and got the same aggregate score each time. He laughed loudly before incredulously repeating "five times!?" I smiled and nodded, affirming that he heard the correct number. He went on to tell me about the two schools that his daughter had already gotten into. One was in the southern part of the state. It was far cheaper than the other and they were willing to offer her a softball scholarship so he was "inclined to have her chose to start there and then move to another school afterwards." The other school was a private school, offering her a small amount of aid. The tuition there was over \$30,000 dollars and this was why he wanted her to get more aid than was presently available, if she was going to select that school. I expressed surprise at the cost and he quickly assured me, "it is a very good school from what I've heard. Don't get me wrong, I'm willing to get her there if she wants, but I would prefer that all the years of carting kids and stuff around for softball pays off. You know? I liked it but at the same time I was thinking about the longer-term possibilities, not just the fun." I told him that I understood.

Alaine's Busy Talk with me foregrounds a masculinity in which the family-oriented work he does is enjoyable in some ways, but was also attached to long term financial planning which, as a responsible man, he did. New grandchildren, or the achievements of children 
are badges of successful heterosexual family work and important to both masculinity and its appearance in messianic marginality work. Hence, his daughter's efforts are framed in terms of his own efforts to enable them. Her choice of school is not only a matter of her preferences but what actions he needs to perform to enable her. Alaine is an interesting case compared to other members who seldom go into detail about their families and associated obligations other than to state they exist when they interfere with militia activity. Since his introduction to the group Alaine has repeatedly made it clear that his girls' sports events and needs would remain a key obligation in his life, privileged over anything the $10^{\text {th }}$ was doing. Even in cases that he did not quite live up to his ideal, like the time he attended a leadership training on a day his eldest daughter had a game, he was constantly receiving texts about its progress. When she hit an important play he exclaimed "YES!" and immediately interrupted proceedings to proudly show me the picture of her he had just been sent by his wife, who had attended the game. This calls into question the degree to which his claim to privilege the work associated with his children's sporting events relies on his wife's efforts but is in line with messianic marginality uses of masculinity.

Similar to many outsiders who draw on the same sort of ordinary resources, members of the $10^{\text {th }}$ tend to believe that men are increasingly maligned by an overly feminized society for the very tendencies that make them capable providers and guardians. These expectations in Who Talk and other genres set members of the $10^{\text {th }}$ against the foil of liberals, progressives, and affirmative action programs which are to blame for both their feelings of marginalization and sense of a lack of recognition for their labors. The $10^{\text {th }}$ would be dismissive of the idea that in other settings among the alt-right, like the men's rights movement, incels, men going their own way, and pickup artists communities, these 
resources are organized to justify explicit misogyny. Among my participants they are used in a capacity that upholds essentialist views on sex and gender that are naturalized among members of the $10^{\text {th }}$ and justify the sex-linked hierarchies they are familiar with but allow them to retain a distance from sexism and racism as they understand it. It is why Peirce can in the course on one interview: celebrate strong women he has met in the military, such as a driver he saw changing the massive tires on her vehicle and who categorically explained to him that she not only did not want his help because it would slow her down; and say that women should not participate in elite training if any standards have to change to accommodate them. Members generally believe that women should receive "equal pay for equal work," but should only seek equal work in capacities they are biologically capable of doing so. For instance, during my interviews with Franz and Pierce, both of whom have military experience, both explained that women should not be in combat situations given the stress, the additional risks they face from enemy troops, and the difficulties they might face should their menses ${ }^{51}$ begin during deployment. This helps to maintain the broader ordinary resources used to position women as uniquely at risk compared to men and therefore dependent on them, or at least a personal firearm, for what independence they can achieve beyond their personal qualities.

\footnotetext{
${ }^{51}$ There is a pervasive avoidance of menstruation as a topic save for two specific types of talk. It can be brought up in the contexts of a disabling malady suffered by women and thus indicative of both the biological reality of sexual difference and a limit to women's abilities to seek equality. It more commonly comes up in reference to the utilities of cotton menstrual products for emergency medicine that involves hemorrhaging wounds. In this latter case the speaker can be expected to preface their mention of the product with a variation of "Not to be gross, but..."
} 
Because the narrative environment at trainings is more fluid it provides

opportunities for mistakes in presentation as much as success. Take these excerpts from

my field notes at a training event in August 2015 for example:

Gradually, and at the urging of both Janet and William whose land we were training on, we all wandered over to one of their two corrugated metal buildings that served as garage/barns. The one we spent most of the day in was the furthest from the main gate to their land. The building's other occupants were various farm vehicles and attachments although there was plenty of room in the front area of the building for us to set up a wide semicircle of chairs and remain in the shade. This lattermost objective was crucial as the weather was very hot and humid.

There was some tech talk in the shade for a few minutes, very little of which I can follow. Mostly it had to do with the antenna we were going to set up today for William and Janet. Janet walked us through where we could find water and the restroom. We transitioned to a discussion bug protection and Janet asked if I came prepared. I mentioned that I had taken the advice of the group and purchased something with a significant amount of DEET in it, to which she said was a good decision and several other echoed her in this. Cypher began to explain to everyone, as he frequently does, that you could "purchase various mixtures with differing concentrations of DEET. Looking for a good one can take time."

I took the opportunity to show him mine and, taking it, he exclaimed "You've got here, you've got...98.11\%! Wow, that's the highest I've even seen." I joked I was, "new to these things so I just picked the most concentrated one I could find based on bad they said the bugs would be. I read the warnings and saw that this was some serious stuff. Do Not Eat, For external use only... all that happy stuff." This was not very amusing to anybody. He asked, quite seriously, if I knew I shouldn't use it with sunscreen. I replied that I had read that and he informed me that "the mechanism for this stuff was that it should evaporate off of your body and if you did anything that prevent it from doing that it would instead soak into you, through the skin, and poison you."

He and Arthur asked me if I knew what the symptoms of DEET poisoning were. I admitted that I did not. Cypher relayed to me that the "chief symptoms are fever and diarrhea." Trying to salvage my mistake, I told him that those seemed like they'd be pretty noticeable and he pointed out that on a hot day this may very well not be the case as you would feel warm anyway and heat sometimes caused otherwise perfectly healthy 
people to get diarrhea anyway. I affirmed that I would be careful and aware. Charles entered the conversation at this point and told me that for the future I should consider getting another product, which was a treatment for clothing that would provide repel bugs for up to six washings. He asked who was familiar with it and several people, including Brock, affirmed what it was called, that it was available at most stores in the camping aisle, and that it worked.

With that settled we all went over to the closer of the two American flags Janet and William keep; one is at the beginning of their driveway at the bottom of the hill they live on and the other in the yard in front of their house. They went inside for a moment while the rest of us got into formation for the pledge of allegiance and a prayer. Charles stood at the head of the formation and from left to right were Arthur, Audrey, Cypher, and Brock in the front row, I was behind Brock, and headed back to the left were Janet and William. We went through the pledge and then Charles asked Arthur to lead us in a prayer for the day. He thanked God for the nice day we had and that all of us could meet together before asking for good judgement and good luck for the day.

Charles said there were a lot of announcements but really there were just a few. First, he reminded us all that Shmita is coming up and this was a brief topic of conversation-he also gave the order to relax once he noticed that most people had already relaxed. Evidently, we should all be ready for whatever is going to happen. The consensus was that it was likely to be another financial collapse ${ }^{52}$. When he brought it up, Cypher and Arthur jumped in and said that they had covered it during the meeting on Monday, as he had instructed them to do. Charles asked if they had been reading up on it, as there was a lot of information about it on the internet if you went to "alternative news sites." Once again, Audrey had nothing to contribute to this. I do not know if he's just reached a point in his life that all of this seems rather useless or if he would rather to keep to himself when it comes to conspiracy matters. Charles continued by saying that it was not clear what, if anything, was going to happen in September and so, "people should simply keep doing their normal prep work on food, water, ammunition and keep their heads about them."

\footnotetext{
${ }^{52}$ This is a period of religious observance associated with Judaism that has become central to a number of conspiratorial numerological theories whose central point is that every seven years the world is changed by dramatic events. It is not unlike other conspiracy theories that link Jewish people, convenient readings of religious documents, and then use them in deliberately or incidentally racist ways that explain troubling world events.
} 
This led Janet to bring up Jade Helm ${ }^{53}$. She and William followed up on rumor that Jade Helm soldiers had been found in Missouri. Their own investigation had found this to be false. They had together gone to the location where a great white tent and various mysterious persons were said to have been and saw nothing out of the ordinary. Cypher challenged this and said the tent and people had been there and, moreover, they had been spotted in all kinds of places. At each place, they set up a tent and buses and after a few days they vanish just as quickly. The group treated his claim with skepticism. Janet returned his challenge, and emphasized that they didn't find anything. This segued into a conversation about buses that everybody had seen. What was noteworthy about these busses were that they were all white and had bars installed in the windows. Everybody involved agreed that the vehicles were otherwise unmarked. In their shared concern over what they could be, Cypher offered that, "In all of my years working in a capacity that affords me regular sights of school buses that this seemed odd." Janet pointed out that they could belong to the Department of Corrections but Cypher and Brock shut her down on the basis that such buses are clearly marked. Nobody offered any other nonthreatening explanations such as that that buses could be old and in transition to a bus graveyard. Charles jumped in and changed the subject back to the day's training.

My failure to understand the significance of the detailed information that Cypher and others expect regrading insect repellant shows both that Tech Specs are infused with moral importance and that core members will help repair failures to appropriately use narrative genres if the speaker appears willing to learn. That I purchased a potentially dangerous chemical product and intended to use it without a sufficiently full understanding of its dangers became evident to Cypher through my inappropriate use of humor to dismiss the concerns. Despite the importance of humor, it cannot override the expectation that responsible, self-sufficient people should be conscientious about risk in ways that I did not demonstrate despite my efforts. In response both Cypher and Arthur took it upon

\footnotetext{
${ }^{53}$ Jade Helm 15 was a series of announced military training events in the summer of 2015 that took place through the American Southwest from California to Texas. Members of the $10^{\text {th }}$ were among many rightleaning people that feared the training was a prelude to one of many different scenarios ranging from Obama's administration instituting martial law to a Federally-supported Chinese invasion via Mexico.
} 
themselves to aid me in identifying the level of sophistication that was expected of me in this setting. As I continued to flounder, falling back again on my established identity as a humorous person, Charles and Brock joined into the group use of Tech Specs to correct me.

In including the conspiratorial Scenarios above my point is not to indicate that these beliefs are common ones or that everyone in the $10^{\text {th }}$ is equally committed to conspiratorial explanations for the decline they feel in the United States. Indeed, most core members are closer to Audrey and Arthur who either do not comment on them at all or take the approach that they will focus on issues they can do something about, a category which does not include world-ending, multigenerational conspiracies of the global elite. Instead, my point is two-fold: demonstrating that despite the routine of the pledge and prayer indicating that militia time had officially started the privacy of the setting meant that there was still room for this talk insofar as it connected to militia work. Secondly, these topics have proven rarer and more fraught than I would have believed, in fact, and this makes them analytically valuable examples of the boundary work in militia messianic marginality. That the $10^{\text {th }}$ draws limits to conspiratorial talk while a large number of their fellow citizens do not appear to do so suggests to me that the problem of disintegrating epistemology in the public sphere is more complex than the growth of conspiracy-oriented news sites.

Charles' suggestion that they seek out alternative news sites is perfectly germane to their shared, typically inchoate distrust of the federal government and the now-familiar 'Mainstream Media. ${ }^{54}$ Charles' concern with the vaguely threatening contours of the

\footnotetext{
${ }^{54}$ Upon questioning, few members will specify outlets they prefer and usually offer very vague responses suggesting they view a variety of outlets and critically compare their coverage. Some, like Franz and BG were more forthright and told me that they primarily listen to talk radio. I believe the vagueness of their
} 
Shmita are in some ways a simple permutation on anti-Semitic conspiracy theories that the $10^{\text {th }}$ does not view as such. It also serves as a spring board for emphasizing that members' preps will leave them situated well in the face of whatever problems arise. He hedges very overtly in specifying that it is not clear that anything will happen at all; this makes his point that they should continue the prep work that bylaws make clear the group expects of them. Jade Helm is much more specific Scenario and the considerable number of resources that must be integrated in order accomplish messianic marginality with it opens Janet up to challenges. Even though she is following Charles' lead, the Jade Helm conspiracy directly involves the government as an active aggressor and implicates politicians in a global scheme to dominate the United States. During a staff meeting this would be likely to provoke a more immediate response from core members and regulars who deliberately bracket their own political comments as unrelated to the $10^{\text {th }}$ and its business. Distrusting the government is expected, especially when liberals head it; suggesting that it could one day be involved in direct, targeted oppression of patriots is acceptable too so long as the talk or narrative is future oriented. The standard bracketing techniques use to render such narrative work acceptable is 'if the government becomes tyrannical' or a variation there of. Temporal vagueness leaves a distance between participants and 'anti-government' extremists. The secondary and often unintentional escape hatch it provides is that evidence indicating tyranny exists is undefined, leaving it a valuable resource for the messianic marginalization of other groups who believe taxation, land-use laws, climate change action, or efforts to alter institutional inequalities are tyrannical actions.

answers is a function of their awareness of my position as a researcher and academic, their broader awareness that their sources are viewed by others as disreputable, and their desire to present themselves as critical thinkers, which most of them believe themselves to be. 
In Janet's talk about Jade Helm, the temporal bracketing conditions were not met and the talk could only carry on for only a couple of minutes of conflicted elaboration until it collapsed under the weight of the narrative work required to persist with it. Later in the day Janet and William started down this road again during a lull in the training day but with sovereign citizen materials. The pair is reliably the most enthusiastic consumers and presenters of these resources within the group and, more than other core members, they push the boundaries of militia messianic marginality by trying to integrate these views into the group's identity work. Over the course of the next few trainings, other core members and regulars distanced themselves from the pair. In interviews with Charles and Peirce I asked how they approached this and both explained that they did not want to "call people out" during a training so they politely wait to redirect unless something under discussion represents a serious threat to the group's integrity.

\section{Training Sessions}

Training sessions are little less flexible than pretraining socialization because of the focused, organized nature of lessons during official militia time. Training sessions last between a half hour to a couple of hours depending on the topic and the level of detail that the person teaching has put into their preparation. It is common for people to excuse themselves from part of training due to other obligations in their lives or health concerns. Over the course of the project it has been reliably surprising to people insider and outside of the $10^{\text {th }}$ that most trainings are based on presentations of slides or handouts rather than action and shooting. Alaine and a few others have occasionally pointed this out to the core over the course of my involvement with the $10^{\text {th }}$ and there was a push for more active training. This culminated in the room breeching exercises that took place at Alaine's spare 
house for two consecutive months in the fall of 2016. Firearms remain present despite their lack of use, and some trainings are based in cultivating skills that will be useful to shooting at some later date. Most training days have a morning set of sessions and an afternoon set of activities. If there will be a live-fire segment the leaders orchestrate it so the maximum number of people will be able to attend. The table below contains a summary listing of the entire militia training curriculum.

\section{TABLE 6: Militia Training Curriculum}

\begin{tabular}{|l|l|}
\hline Curriculum Category & Description \\
\hline Firearms & $\begin{array}{l}\text { Firearms training rarely include live-fire exercises but it does occur at least a few } \\
\text { times a year. It is minimally organized and primarily for fun and contest. Airsoft } \\
\text { pistols are more common, along with physical training regimens designed to } \\
\text { improve shooting abilities. }\end{array}$ \\
\hline Comms & $\begin{array}{l}\text { Communication training revolves around three pillars: readying the members of } \\
\text { the 10 } \\
\text { the to acquire and maintain personal radios for militia activity, explaining } \\
\text { radios, operational security and social aspects of amateur radio. }\end{array}$ \\
\hline Food and Water Prep & $\begin{array}{l}\text { Germane to the group's expectations of self-sufficiency in the face of difficulty } \\
\text { there are frequent lessons on how to store food and water as well as strategies to } \\
\text { acquire them cheaply. }\end{array}$ \\
\hline Land Navigation & $\begin{array}{l}\text { Land navigation revolves around using compasses and maps to locate oneself and } \\
\text { others. This involve military scenarios and search and rescue scenarios. }\end{array}$ \\
\hline Physical Training & $\begin{array}{l}\text { Medical training typically focuses on emergency medical scenarios such as } \\
\text { natural disasters and armed conflicts. Rarely this will also involve alternative } \\
\text { medicine practices. It also involves show and tell of gear and experimentation. }\end{array}$ \\
\hline Search and Rescue & $\begin{array}{l}\text { Physical training is fairly rare and given the ages of most participants is it usually } \\
\text { light. Stretching and light cardio are the most common. Occasionally there is } \\
\text { hand-to-hand combat training but this is also light and low-impact. }\end{array}$ \\
\hline $\begin{array}{l}\text { Trainings in this vein focus on integrating Land Nav, Medical Training, Comms, } \\
\text { and Generalized Outdoors information with specific search and rescue } \\
\text { procedures. }\end{array}$ \\
\hline Outdoors & $\begin{array}{l}\text { This includes trapping, hunting, foraging, and other survival topics. These are } \\
\text { less the topic of formal training sessions but integrated into others where time } \\
\text { and energy permits. }\end{array}$ \\
\hline
\end{tabular}

Messianic marginality work during training sessions tends to focus on the topics at hand despite the occasional rabbit chase. The interactions below took place after we had been shooting. The shooting activities were nominally training but primarily revolved around 
Show and Tell around different firearms, firing them intermittently, evaluating the results, and informal competition centered on accuracy.

Walther told us a story that took place in his kitchen. He had decided to clean his guns and wanted to do so in the kitchen. He paused to stress that this was an activity with which his fiancée had taken umbrage in the past. Rather than emptying the magazine of the handgun by removing it from the gun and then pushing the shells out one by one he had decided to rack ${ }^{55}$ them out onto the counter. He made it a point to explain that his fiancée hates this and questioned what he was doing as soon as she heard the live rounds hitting the counter. Walther confessed that she has a point about it being inappropriate but rolled his eyes at the same time. Going back to his story, while he had been doing this he had not been counting the number of rounds that he had racked out and, upon being distracted by the critique his fiancé had leveled at him, believed that he had finished. "Now," he said, "I'm not the type of guy who dry fires when I think the gun is empty, I...," he mimics pulling the slide back to visually inspect the chamber, "...check. I check. And when I did this time, guess what was there?" Everyone muttered, "a live round" just as Walther admitted it.

Charles, suddenly very serious, asked if he had had an accidental discharge in the house. Walther, now terse and defensive, replied "no, not that time, the whole point had been that I didn't." Charles, satisfied with the answer, asked yet again, but with a grin this time, "so you haven't had any accidental discharges?" Walther returned the grin and replied snappily, "Not with any weapons, no." Everybody laughed at this although I felt guilty for thinking to myself that the belief there is a relationship between guns and male genitals is more accurate than I think most gun guys would be happy to admit. Simultaneously, I was surprised that he, or anyone there for that matter, would be willing to make a joke about premature ejaculation at their own expense.

Walther then told us that he'd once been trekking out into the woods for a deer hunt with several friends. He was hoping to try out an $\$ 80$ rifle he'd purchased but he'd accidently bumped some portion of the gun and it had fired. He explained this result as a defect and added the dismissal that, "I got what I paid for." A key part of the story was that the round had dug a deep trench across the ground that it had impacted and, aside from scaring everyone in the party as well as any deer they had hoped to see, a

\footnotetext{
55 The procedure of pulling back the slide on a semi-automatic pistol in order to cycle a round into the chamber or eject one that is already present. Here he was ejecting the rounds by repeating this process until the magazine was empty.
} 
potentially fatal tragedy had only been avoided by virtue of the fact that he'd been carrying the rifle in such a way that it was "pointed in a safe direction". He pantomimed a couple of the ways he could have been holding it that would have produced a fatal or injurious outcome. The lesson as Charles put it was that "Everybody, if you shoot long enough, will have an accidental discharge."

Walther's last story was short, and basically revolved around his 'better to check' theme. While cleaning guns, in the kitchen again, and his fiancé wanted him to switch the laundry out for her. While he had accomplished this, he left his weapons on the table and his kids had or, at least might have, come by and toyed with the guns. The problem, according to him, was that he had left the guns unloaded and the children may have loaded them while he was otherwise occupied. It struck me that the problem was that the gun had been left accessible in the first place but I remained silent.

In most firearms-related trainings Tech Specs is used in detailing information about ammunition firearms performance that serves to mark people as cultural insiders as well as responsible gun owners. Having a mastery over firearms demonstrates the messianic element of the time and energy required to achieve mastery over the tools required to deal with the world. Speakers do not always directly pair Tech Specs with marginalization but it readily combines with Who Talk, Man Talk, and Decline, so it is a constant undercurrent. Walther explained to me on the first day:

Walther asked if I had ever shot an AR. I told him I hadn't. I felt bad for lying, and still do, but gun guys often like to teach new people so although I have done so a couple of times I figured that it was worth the small deception to hear how he would talk about them. I added that I was somewhat familiar with them. Immediately he inquired, "how familiar? You mean like video game familiar?" This the second challenge that I accidentally passed through responding that I knew a couple of things about technical details and functioning but that was it. "This will be great, then," Walther exclaimed as he reached for his AR. He spoke at some length and quite sarcastically that this was the "most offensive weapon we could handle today," and it had "a large number of offensive parts like the fore grip." He walked me though the various internal components and explained that AKs were a bigger problem as far as real danger went because they could be made to fire in full auto with little more than a strategically placed 
toothpick. This was very much illegal he said, but to do so was easy. "You cannot," he assured me, "do the same thing with an AR-15 because disrupting the mechanism in that way would just make it fire the entire clip at once; unsafe and a giant, illegal waste.." I added that it seemed like, "a stupid thing to do." He joked that I must think he's, "a crazy man, I can just see your notes, 'now, this one guy, he was a real gun nut, like, way out there." I laughed and said I would not likely write anything like that because, frankly, technical knowledge like that hardly constitutes gun nuttiness.

While this conversation had been going on a family had shown up at the shooting range. A man, woman, child, and another older man. It looked like the day was about having the oldest man teach the child about shooting. We had been paying them little mind but very suddenly there was a rapid series of reports and this drew everyone's attention. In part, this was because several of us did not have ear plugs in at this point because there had been no warning that they were to begin shooting. Taken aback as we were by the discourtesy there was more curiosity than anger. The child, decked out in a cowboy costume, was apparently firing a fully automatic tommy gun. The members of the $10^{\text {th }}$ and I agreed it must have been re-chambered in 22 but even so, that it was fully automatic was very odd. The oddity was more than a little scary to me, but simply interesting to the others. The older man brought out some milk jugs for the boy to shoot at and placed them downrange. He hit one and it exploded quite loudly-it turns out it had been full of some kind explosive gas. None of the others exploded. Walther asked the man if it was a certain chemical and the man told him it was a different one. Walther then explained to him that the other two must have leaked. The old man didn't respond and simply crushed them before disposing of them in a large plastic drum.

Inspired, Walther started into quite a long list of concerns and complaints during which I couldn't help but wonder if he forgot who I was. He tersely asked me, "what do most kids learn to shoot with?" I responded with, ".22s". He then asked me, "what ammunition was being made more and more scarce?" The answer to this was also ".22". He then walked me through his thought processes: this scarcity was a deliberate effort on the part of various people "to prevent kids from learning about guns;", they wouldn't want to learn with larger rounds as that "would not be comfortable or fun." After this, he continued, "then they go to the colleges that teach them that guns are bad and a whole lot of other liberal stuff." While he was reiterating this last comment, Brown nodded towards me and Walther seemed to recall that I was very likely one of those liberal college professor types and he scaled back his complaints, adding "Not all of them 
are like that, you know, I'm not so closed-minded to think that they are all like that. But a lot of them are."

His points about how knowledge of guns is marginalized by outsiders is situated in a broader sense that those who do not like them simply do not understand them. Liberal is often used a shorthand for people whose combinations of political preferences, education, religious preferences, and non-rural living arrangements mark them as marginalizers of people like those in the $10^{\text {th }}$. In this combination of Decline, Who Talk, and Tech Specs such people are positioned as ignorant of firearms, fearful, and then using or corrupting institutions to prevent others from understanding firearms to satisfy their own emotional needs. Race is also articulated through Tech Specs although, as I've noted above, it is seldom announced as such. When firearms training takes place even core members are tempted to indicate a belief that racial minorities, particularly African Americans, cannot or choose not to use firearms correctly. To indicate this to others they will hold a handgun sideways and either draw everybody's attention to it or simply jest that they are going to shoot "ghetto style." In these ways humor and Tech Specs are used indicate their own messianic knowledge as law-abiding gun owners by virtue of comparison to stereotypes of urban, African American criminals while avoiding demographic terminology. It is a fascinating contradiction between holding in contempt politically correct culture and those they feel support while censoring their own language in their own spaces to avoid imagined critique of their opinions and beliefs, thereby maintaining the imagine of the militia as racially neutral, at least by their own standards.

Walther's decision to exclude me from other marginalizers once Brown called his attention to the risk he was creating for this messianic marginality work was prefaced on my status as a fellow gun owner and an outsider who came to them to ask what they did, 
believe, and felt. While my status as a white, heterosexual man has undoubtedly proven advantageous for my access to the group, I believe that it is my status as a knowledgeable, if self-taught, gun owner that has provided the greatest point of connection between myself and my participants. Whether the speaker specifies that the decline of firearms as status symbols is intentional or not they invariably conclude it has the effect of killing off a gun culture that the $10^{\text {th }}$ personally identifies with and associates with their own agency, citizenship, and the nation's history. The ways in which the rights of firearm ownership have also been used to maintain racial and sexual hierarchies throughout the nation's history are invisible here.

Evidence linking firearms to public health hazards, like mass shootings or suicide, is dismissed as ignoring the mental and moral health of the perpetrators in service to unfairly lumping law-abiding gun owners and criminals together. The sometimes too narrow gap between the two categories are narratively erased as objects of discussion because these are issues that their organizations of ordinary resources are not geared to address. Each of these problems challenges the value of firearms for militia messianic marginality; consequently, narrative and talk is focused on what criminal or ignorant others do or might do to them. This is evident in Walther's stories later that day, characterized by his framing of his fiancé and children are impediments to his firearms-related behaviors that create risks beyond those he admits to creating with his own choices. Instead of acknowledging any irresponsibility in detail he only admits to his partner's point before placing the potentially lethal accidental discharge on her distracting him. Reinforcing the standard position of women as well-meaning but demanding and ignorant regarding firearms allows him to simultaneously emphasize his responsibility in preventing the 
accidental discharge. Similarly, the cheap, malfunctioning firearm harmed no one due to his efforts despite that he admits indirectly he should not have purchased it. Charles' comment about the inevitability of accidents is taken to indicate the perpetual need for responsibility while treating firearms and their risks as mundane ones.

On other topics like food and water preps Tech Specs become a type of group work wherein different members will riff with one another regarding different Scenarios in which new approaches to the topic itself or altering the strategies under discussion might prove useful. This helps to reinforce the value of the information itself as well as its utility in messianic identity work. From September 2015:

Cypher had produced handouts. There were two pages of bullet points about the importance of water in a survival situation and the pros and cons of various purification methods. He also presented a map of the various parts of the state, separated into directional groupings. He told us that these were useful because they were the areas referred to by weather people and emergency personnel. The $10^{\text {th }}$, too, could use them as references when listening to reports about emergencies. Cypher, who often reads his handouts in full, began by reading off his "rules of threes." Each rule involves some multiple of 3: seconds, minutes, weeks, so on and a connection of the time periods to the survival risks one faces at each. Below, another rule read "One is none, two is one..." He asked the group what this meant. Nobody answered for a moment and then Walther explained "it means that if you have one thing, whatever it is, and no back up you may as well think of yourself as having none. If it breaks, that's it." Cypher said this was correct and elaborated on it briefly using examples of knives and equipment.

Cypher moved to various methods of water purification and storage concerns. He spent a great deal of time elaborating on his own storage system for fifty-five-gallon drums of water-which involves stacking them top to bottom using a long plastic counter and wood supports. This led to another group discussion about ways to acquire such barrels and the risks associated with acquiring them from certain sources. This quickly developed into a shared interest in a group purchase of barrels. The idea that everybody present would thereby gain access to affordable barrels generated great deal of talk about the ways that bleach can leech out of 
plastic. Janet contributed to this group work and asked about the risks or issues associated with distilled water. Apparently, this is mostly an issue of lacking crucial minerals which can be mitigated when one has adequate food. She apologized for having cut into his presentation after he pointed out that her question was his very next topic. Walther, who did not apologize for interrupting, brought up a tactic for getting water that he thought of. "Rural pipelines are often large bore and if you found where your meter was you could dig down and access that pipe and any water left in it for a while." Cypher regaled us with a tale in which he had cut a grape vine which had proceeded to leak water and, growing curious, he cut it at a higher point only to find that there was a great deal of water that it had been storing. This group narrative work served as evidence that there are myriad ways that a resourceful person, such as those of us who were present, could acquire drinking water should the need arise.

Cypher responded again to Janet's earlier curiosity and shifted back to the subject of distilling water using homemade contraptions to collect, boil, and then recollect the water. This initiated another group improvisation discussion. Several members of the unit tossed around ideas for how a person could build such devices cheaply and effectively. Cypher also warned them that some designs, particularly when dealing with dirty water, would need to be watched carefully. "Think about rotgut whiskey. Right? There first stuff that comes out of a still is waste, it's poison. Same thing could happen here." William joked that they should keep talking about whiskey and this got some laughs. Much to what I imagined as William's disappointment, the conversation turned to chemicals and plastic bottles. Janet and William expressed concern over storing water in plastic bottles as temperature changes cause chemicals used in the plastic to leak out. Cypher said that there were numbers on the bottoms of plastic bottles which indicated the manufacturing procedures behind them. Harold jumped in on this topic after being silent for a while. He is very into organic food and knowing exactly what is in his food and water, I'm not surprised he knows a great deal about this subject. He specified for the group that bottles or containers that have two, four, or five on the bottom are safe and free of the most dangerous chemicals while bottles with a one, three, six, or seven are not safe. There was some confused discussion over whether everybody heard that seven was safe or unsafe. This happens occasionally when there is crosstalk.

Cypher's initial points link Tech Specs to a popular Scenario in which militia members can aid officials in an emergency situation. This is prefaced on the expectation that members of the $10^{\text {th }}$ will pay attention to weather risks and take the time to keep up with that 
information so as to pass it along to authorities who will take them seriously. In this context the questions and scenario play indicate close attention and critical thought rather than ignorance or inadequacy. Walther's elaboration tied together his knowledge of water infrastructure and rural life and linked them to their shared belief in the buffer that rural lives provides compared to urban areas in the event of serious catastrophes. Cypher built on this foundation with his tale, emphasizing nature as a resource he is capable of drawing upon. The following conversation about the risks associated with certain plastic bottles is further indicative of the tension between valuing the benefits that human technologies provide and the risks that members associate with them which we see earlier in the rule regarding redundant equipment. Utilizing technology to augment one's knowledge and skills is a praiseworthy effort, like a man enhancing his abilities to protect himself and others with a firearm, but becoming dependent on them represents moral failing as a selfsufficient person. In this way the group can turn the hyper-individualist consumerism of neoliberalism into avatars of capability and independence rather than dependents at the mercy of corporate power and government oversight.

Training sessions do not always focus on survival, self-sufficiency, and firearms. At Alaine's land in September 2016 William and Janet once again pushed the boundaries of messianic marginality too far for some of the core members.

Everybody came back to the garage to continue the neighborhood charting lesson. One of Will and Janet's kids muttered a joke to her while Audrey was explaining why this training was important. Audrey, as well as everybody else, looked over to them and she told us that "He said that we shouldn't come to trainings anymore, because you give us homework." People laughed for a moment and then Audrey began explaining why having a chart of the neighborhood could help in organizing emergency responses. Will and Janet's group went back to their own conversation. 
After a few minutes Audrey stopped to look at his notes again and Bueller ${ }^{56}$ interjected, evidently upset at the chatter, "You know, it's fun and games now, but if the shit hits the fan soon-and the way things are going it looks like it might-you'll want to have been paying attention. You know? In my town, we've been hit six times. There were six robberies recently, and with things like Black Lives Matter and the protests, and the election, and ISIS, you know? We've been hit six times and I know that I'm going to be paying attention. Just recently I saw on the news two stories about car jackings. In one, I don't remember where, they took this lady right out of her car and shot her. In another one, both were unfortunately committed by black men, in this other one some lady in a parking lot was getting to her car and two people came up and they were going to kill her and take her car and the only reason she made it out was another citizen was armed and saw what happened. He got one of them and the other ran away. The point is, and this is especially for you young kids, this is serious stuff."

This abrupt outburst shook everybody up a little. There were thirteen people in the room, including five peripheral members, most of whom fell silent now. Noticing that I was the only one taking notes at this point, I repositioned myself at the back of the room, nearer the door leading outside. Audrey, who had recently walk into to this from the kill-house he and the leaders had been setting up and not realizing what he was about to contribute to, said that we should pay attention because if something serious happens there may be a lot of confusion. Janet jumped off this, "Chaos, they want chaos. They'll use that." Nobody asked who 'they' are or what they will use the chaos to accomplish. I think everybody understood that Janet meant the New World Order or some other equally nefarious group. Audrey and Bueller coauthored a Scenario in which the militia is tasked by a local sheriff or the national guard with protecting a neighborhood. In such an event, they would want to be able to quickly make or read a map of the area so they would not have to further bother anybody who lived there and would not let anyone in that should not be there. Alaine pointed out that to his mind it was crucial that they know what they are doing and be on good terms with their local law enforcement. He added that he has been trying to get to know each of the local authorities in his area so they would trust him if they needed him. Janet and Will piped in that they were trying to do the same thing.

Audrey who by now was trying to bring people back to the lesson pointed out that making the charts for their own area in advance of some event would provide much needed information because, "there's going to

\footnotetext{
${ }^{56}$ Bueller was a peripheral member who was asked to stop attending by the leadership after this event as well as their discovery that he had lied about his military background.
} 
be looting if something comes down, and if you know what people have then you can help them find out what happened to it." This really sent things off the rails. Bueller went off, "Hey, you young kids, you're thinking this is some silly stuff? Listen, you may not be old enough to remember how things have been in the past but here's the thing: trust people who have lived through some things to tell you that what we're seeing now. These are serious things, ok? This may not seem like a big deal to you all but things are happening." Theodore got up and excused himself to, "get my coffee". Bueller continued, "Think about this, the new Missouri driver's licenses. They have a little RFID chip in them. Right towards the top corner. It's really small but with that any highway patrol or police, as you drive by they can run a scanner and now they've got everything that's on that license. Everything there is on you. Think about that while you kids are bebopping ${ }^{57}$ along in your car headed some place."

Janet followed up with an email that she had received which, "said that RFID chips will be implanted in people's forearms soon. They want to put them in our arms. The email said that it was a provision of Obamacare that is set to go into effect in 2017." William added, "it's part of the cashless economy idea. Everything about you is right there on that chip." Bueller said that he recommends that everybody buy an anti-RFID wallet from Walmart to prevent this from affecting them. Janet elaborated that this strategy to control people was an obvious one and intimated that it was predicted by the Bible before she asked if there was some way that they would be able to break the chips. Bueller admitted that he did not know and this narrative changed into a group problem solving exercise to figure out how one might do this. He suggested that a magnet might work but they should ask the "computer guru." Bueller then gestured to who I assumed was Alaine, who was behind me by now. It turned out that he was pointing to me, "Hey guru, could a magnet break the RFID chips? Daniel?" I was surprised at this as nobody in the group, or in my life for that matter had ever called me guru. I quickly replied that I didn't know how RFID works but if the devices relied on any sort of standard computer memory then a sufficiently powerful magnet-such as those used in hard drives or rare earth magnets - might be able to damage or disrupt them. I neglected to add that all that would do is draw further attention to you should somebody scan it and expect a response. I left the garage immediately after.

Theo and I were standing together outside of the garage where this discussion was continuing behind us and he looked at me with a knowing stare. I looked back, smirked, and shrugged. He slowly approached me and

\footnotetext{
${ }^{57}$ As I was formatting these notes for this chapter I felt to need to add that I joined William and Janet's progeny in laughing at the fact he had accused us of 'bebopping.' To this day I scarcely believe he said it. I suspect he meant it ironically, to emphasize our subordinate positions due to age.
} 
gently motioned that we should step further away from the door. Theodore turned to me, moved in closer, and whispered, "There's a lot of loose talk going on, too much loose talk for me. And you hear how Bueller keeps calling the young men kids? That needs to stop, it's disrespectful to them and not what we should do. They're out here too, they care." I nodded and told him that I tended to just remove myself from these moments. He told me that he was going to tell Charles about it. Conveniently, this was moments before Charles came out of the training house. Theo immediately walked to intercept him before he could approach the rest of the group. I positioned myself a little closer so I could hear. Theodore was true to his word, "Charles, I wanted to let you know that there's been a lot of loose talk going on in there and that new guy you brought in, Bueller? He keeps calling the younger members 'young kids' and I don't think that's the way we should be approaching it. I think you should have a talk with him about it." Charles stoically listened and then responded that he would talk to him about it. Charles then walked into the garage and loudly asked the group if they had any questions about their training so far today. They immediately fell silent about the conspiracies and responded that they did not.

As I noted, Bueller was relatively new and while Janet and William are core members others sometimes keep them at arm's length. Thinking that he was doing Audrey a favor Bueller attempted to rein in William, Janet, and their kids but did so by making explicit the notion that they should fear Black Lives Matter, ISIS, and African American men. Each of these groups is linked in his speech to Scenarios and danger that people like him feel marginalized for mentioning, ergo his self-distancing with the use of "unfortunately," when mentioning race specifically. While ISIS is treated as an unproblematic threat by most of the $10^{\text {th }}$, BLM and African Americans are typically only permissible resources to use in threatening Scenarios and Who Talk if left veiled in colorblind language of extremism and urban dangers. Without that linguistic buffer the distance between 'real racism' and the feelings of the members of the $10^{\text {th }}$ uncomfortably collapses. His characterization of all of them as threats waiting to "hit" the homes and towns in which members of the $10^{\text {th }}$ live matches the form of common Good Guy v. Bad guy and Civil 
Unrest Scenarios but his presentation bordered on overtly racist by the group's standards as he specifically linked race and threat.

Audrey attempting to regain some control is something Charles and Peirce do but Bueller's attempts to be everything to everyone thwarted Audrey's effort. By building off of the initial effort to redirect the group towards more acceptable Scenarios, like responding to natural disasters, helping authorities, Audrey used looting as his last fallback in trying to redirect the conversation. Janet's references to a 'they' and 'chaos' were vague enough to be not be especially concerning to others, such as Theodore, until she and Bueller linked it to the specific RFID, Tyranny Scenario. Theodore excusing himself was very likely not an intentional signal to them but indicates that only so far that these visions of aggressive persecution be carried before longer-term members will respond to the "loose talk" by leaving or directly challenging it. Leaders can be more direct in shutting this sort of talk down. In line with his later explanations to me, Charles simply interrupted the proceedings and redirected it with his authority are the unit's leader. Even so, there's a peculiar social gravity to these events.

If one is present during these events then most of the interlocutors simply assume that everybody present holds the same concerns and is game for elaborating on them. Just as Audrey found himself unintentionally included in this narrative work, I had too. Because I remained in the room I was a participant in the narrative work regardless of my own silence, indicated by Bueller's willingness to draw upon me as both a resource and new coauthor of their developing story. That Theodore and I knew to leave and that he confided in me outside are not accidents of the training location. Based on his prior admissions to me about such concerns we had rapport and this was not the first time that people who did 
not want to participate in this type of talk and narrative work simply walked away from it. One notices that he does not specify that he thought it was racist or too paranoid but does identify insulting the younger men for their ages is problematic given their efforts to be active in the 10th. Dismissing them as young diminishes their masculinity and messianic marginality. Charles' willingness to firmly shut down the talk was indicative of the limits to which Scenarios, Decline Talk, Race Talk, and Who Talk can be pushed. Once people begin damaging the abilities of the $10^{\text {th }}$ to be taken seriously by core members, regulars, and important outsiders they have to be brought back into line. If they persist, as Bueller did throughout the project then they will be ejected from the group, as we saw in an earlier chapter. Janet and William push the boundaries too, but they also reliably understand when Charles or Peirce subtly tell them to realign their presentations and respect their authority to make this demand.

As social spaces of messianic marginality production trainings can get off track but it is usually fairly easy for a leader to pull things back together and reestablish which rules are at work. Given that training days can go on for 7 or more hours, people need breaks from this sort of discipline in their talk and presentation. Members of the $10^{\text {th }}$ cannot be 'on' all of the time and lunch time serves as a less demanding presentational space where standards can be relaxed again, allowing participants to engage in more free play with arranging training material and other ordinary resources into less formal militia identity work.

\section{Lunch}

Lunch almost always took place at eleven or noon and would last an hour or slightly more. Unless it was one of the rare occasions that Cypher had arranged a group meal this 
usually meant the breakup of the unit into smaller social groups to consume food they had brought themselves. Arthur almost always brought a military MRE while the rest of the $10^{\text {th }}$ usually brought combinations of both homemade and store-bought sandwiches, canned food, chips, and soda ${ }^{58}$. Charles was a reliable exception to this as he usually brought a small package of nuts, a small can of tuna, and a few crackers to compliment his water. When training on private land, the owners typically ate inside with their families while the rest of us stayed outside. During exceptionally cold months it most people retreat to the heated interiors of their individual vehicles. Compared to premeeting socialization, people float between groups less often during lunch and resume drawing on Who Talk and humor but sometimes Tech Specs and Scenarios continue to be used if the training material was especially exciting for specific people. While it is still technically militia time, lunch is freeform and less scripted. For me, lunch represented a time that I could take a break from face work, catch up on notes, and jot down additional points of interest. Usually my notes are sparse for these times unless I was noticing something out of the ordinary. This example from January 2016 demonstrates:

When I got back from my car I realized that they had been saying a prayer over the food prior to eating — which should not have been a surprise to me at this point-and quickly bowed my head. After the prayer somebody-I wasn't sure who-made a joke that we would benefit from the prayer based on Cypher's food and they were seriously but gently rebuked by Charles, Audrey and Arthur. Each of them simultaneously said something slightly different to the effect that Cypher's food was certain to be delicious. I had a brief conversation with Harold, who noted that I appeared to have brought a container of butter for lunch, "You're the only guy here, I think ever, that showed up for a group meal prepared with his own butter." His comment was meant to play off our rapport, largely based in a shared affinity for observations masked in snarky comments. I took it

\footnotetext{
${ }^{58}$ My own lunches usually involved some homemade deer jerky, water, vegetable crackers, or a nut-based protein bar. Alaine once pointed out my choices and playfully mocked me for "eating like a college student."
} 
as such, explaining, that I had intended to use it as a bowl although it ended up being unnecessary; I added that "yes, I also bring butter everywhere with me. You know, to be prepared. Butter has many uses beyond its capacity to improve bread." Harold chuckled a little bit at this and went to get food.

I made it a point to wait until everybody else had been served before I gathered a bowl and proceeded to the food. Cypher served me, as he had everybody else, insisting that, "a chef should always eat last because that way everybody who the food is going to kill will be dead or dying by the chef's turn to eat. Then I'd know I made a mistake somewhere and shouldn't eat it too." One theme that came up this time-as well as during deer season last year-were stories of hunting success and failure. I wouldn't have predicted the latter but there are occasions during which admitting failure is both acceptable and important to demonstrate that one had learned something. There was also basic food talk, discussing how good the food was, their own ideas for it, and so on. I didn't make note of anything in particular here. While we ate there was some general political talk in which I heard mixed ideas about Trump as a candidate-ranging from intense skepticism based on his social class and background as a democrat to tentative support, hoping he could change things.

I had a conversation with Peirce while we were waiting for seconds. The conversation was largely about our experiences with the east coast. He's originally from New York City and seldom lets people forget it. I mentioned that I spent every summer throughout my childhood in Massachusetts and Connecticut. He suggested that he didn't miss the large size or noise of cities but he, like me, missed the seafood. We each named a couple of seafood places that the other had not heard of but mutually agreed that they sounded great. Later, he and Harold were talking about the difficulties involved in long distance moves. This was cross-country in Peirce's case and international for Harold. I didn't catch much while I was eating but they seemed to agree that the difficulties did not outweigh the benefits of a preferred living situation.

Core members disagree from time to time but they will almost always defend one another from peripheral members or even regulars when it comes to competency and status.

This dynamic is vital to maintaining the group's standards for messianic marginality and intragroup status to a degree that I am not sure they would admit, even if they are as aware 
of the latter process as I believe they are. Neither Charles not Peirce attempts to command, but they do rely on their positions of authority to push the group and conversation in directions that they feel are productive for the group. Challenging Cypher's cooking was over the line because he takes immense pride in it and he was responsible for giving everybody something to eat at the cost of missing training and standing next to the fire for hours. To make light of his efforts and skills diminishes his capabilities and marginalizes his competency. Were he not present, as was the case much earlier with Clint and his food poisoning, the presentational circumstances may have been more forgiving. The political talk was a surprise at first given the earlier experiences I had with the group and the way they bracket political conversation but it clued me into the fact that lunch is not as regimented as other militia time. Trump was not a candidate that any member was willing to enthusiastically endorse at any point in my data and only rarely came up, usually in the context of Decline Talk and Who Talk. Arthur, for example, expressed a dismissal attitude about the efficacy of building a wall during a later training, derisively mocking the idea as an example of ridiculous solutions to complex problems. Pierce, during the same training as Arthur said that he "really don't like him," but given the other choices he felt forced into the vote. Cypher too hoped Trump could "fix things" after the election, but doubted it. His status as an urban dweller, wealth, and connections to democrats were concerns that marked him as a risk.

Lunch can is influenced by which members are present, very much like training sessions. My notes from the September 2016 meeting at which Bueller demonstrate this:

For lunch, I joined Audrey, Theodore, Bueller, and BG in the shed. My lunch was deer jerky, baked vegetable crisps shaped like snap peas, and flax pita bread. I mostly kept to myself as usual but Bueller quickly broke 
my self-imposed conversational isolation. He noticed my veggie crisps and looked at them sideways until I made eye contact with him. He raised his chin in a half nod, a highly contextual action which in this case implored me to explain my odd-looking food. I told him they were like potato chips but made of vegetables, baked and then seasoned with onion and black pepper. He sighed dramatically, indicating his disappointment in either the world or me, cut off another piece of the summer sausage that was his lunch. A moment later he confessed the crisps were probably good but he was "much more of a meat and cheese person. Yeah, I don't...I know I should eat more green stuff, I know that, but I'm much happier to eat meat, cheese, orbread, like this meal here. That's just how I've always been." I nodded and offered him a crisp. He declined.

The topic then changed to politics, again mostly Bueller talking. He was talking to nobody in particular at first but then he focused on Theodore. He was not aware that Theodore had not appreciated his earlier hypermasculine, militaristic performances. Bueller remarked, "I should...well, you know what? I shouldn't talk about what I think about the election, should I? As a religious person, a pastor, [asking Theodore] I should not think negative things about people or candidates, right? Theo? Padre? I shouldn't say bad things about people that I don't like? Isn't that right?" Theodore sighed quietly and continued to munch on his food, choosing to ignore Bueller's goading. After but a few more moments of pressure and "Padre" Theodore curtly addressed the probing, "No. No, you shouldn't. As a Christian you should forgive and you should not even think terrible things about people, let alone say them." Bueller was taken aback and sullenly acknowledged, "so that's the case then."

After a few more bites of food, Bueller said that he had a fact that he wanted to talk to me about. I looked at him and he began speaking, "So, Daniel, do you know much about the flag?" Like Theodore, I had also grown tired of this and simply said, "I know a few things." He continued, matter-of-factly, "Well, most flags, especially on military bases and what not, they have a number of things that are always there. One is the big ball at the top of the pole, sometimes I hear it called a truck...doesn't matter. Do you know what's in those? A match, a razor blade, and a single .45 bullet and a service pistol. Why do you think those items are there?" Deciding to engage in this contest rather than remain a passive subject in his masculine/military work I pleasantly rattled off, "Well, based on only those items, I expect they are there so that the last person defending the flag can take it down and dispose of both it and themselves so as to prevent their capture by enemies. Something along those lines." He curtly corrected me, "Nope. The razor is there so that the last soldier can cut out the stars and stripes of the flag. The match is there so that they can burn them to prevent 
the enemy from capturing the colors and the bullet is there so they can shoot themselves to avoid being captured." I chose to ignore both the fact that the .45 caliber pistols he was referring, the 1911, was seldom issued anymore and the fact that he had been so intent on teaching me this that he completely ignored that his explanation was precisely what I had guessed.

Unlike Alaine's playful jests, which most people in the $10^{\text {th }}$ became accustomed to as a function of his energetic personality, Bueller was engaged in a more serious masculinity work meant to elevate his status, diminish mine, or both. As we saw with Cypher, messianic marginality in the militia has little room for direct, serious challenges to others within the group. Elevating qualities believed to indicate masculinity has limits too. Eating primarily meat and cheese over vegetables is fine to discuss in general Man Talk as masculinity performances are important. The marginalizing foil in a presentation should be people outside of the group or at least those who are not present at that time. My original passive response may have encouraged him to move on to Theodore who might be a more satisfying target. Theodore is deeply religious, soft-spoken, older than most other members, and frequently serves as the group's all-purpose pastor. He believes that world might end soon and spends some of his free time engaged in publishing biblical prophecy but he also upholds the militia's expectation that political and religious conversation remains rare and civil. He surprised Bueller in his aggressive critique of the way he was trying to deploy religion, politics, and humor in his messianic marginality work. To recover his status after the dressing down Bueller elected to 'teach' me and thereby reduce my status by emphasizing his military credentials, as he had done since he first approached the group earlier in the month.

I later learned that these instances drew attention from the leadership. Peirce's military experience clued him into the fact that Bueller had exaggerated his military 
service. Instead of a combat medic, as Bueller claimed he had been, he had actually been a truck driver and not trained in most of the specialized knowledge he boasted of. Bueller's belief that the militia was a space for high levels of militarism, competitive machismo, and conspiracies led him to stretch the boundaries of messianic marginality to such a degree that he quickly alienated both leaders and several core members could not tolerate him. Even the flexibility of messianic marginality in the least restrictive militia spaces was not enough. He was quietly and privately asked by Peirce not to return between these events and the following month.

\section{Second Training Sessions, Round Robin, and Day's End}

The second round of training sessions follows the same patterns I outlined above. The primary differences are two-fold. First, these second sessions are favored for the more active training for the day, shooting, tactical movement, patrol, and so forth. It is something to look forward to and leaders use this to motivate members to stay through the earlier, less active training sessions. The second difference is that it is much more flexible than the first session. People grow tired, bored, and concerned with the other tasks they still need to accomplish that day. For example, during the few room breeching and room clearing trainings that took place at Alaine's house, which were supposed to be focused, professional, and exciting there were several hours of considerable effort. Midway through the second session of the day, the front door of Alaine's unoccupied spare house has become so damaged from members kicking it in that the leaders and I had buttressed it with a two-by-four to maintain sufficiently realistic structural integrity. they quickly became more of a game of experimentation and sharing Scenarios. This transition took place when Alaine, who had been the point man for the breaching team, grew too tired to 
kick the door in. After a few failed attempts Cypher used his greater weight the crash through using his bottom. As he fell down the breeching team fell apart in laughter and even Peirce cracked up and could be heard from the rafters of the house where he was operating the recording equipment they were using to improve their coordination. Indicators like this are a sign that people are 'done' with the day. Training will continue for another hour or two but it becomes more of a freeform, group work dominated by humor, Who Talk, and Busy Talk. Before too much longer, the primary NCO for the day will call a round robin where group members form a circle and share their concerns and praise regarding the day's efforts. After this ends the leading NCO will ask for a motion and a second to conclude the day. It is rare that this takes more than a few seconds and rarer still that anybody other than myself, a leader, and the person who owns the property will stay long after. People quickly gather their things, help leaders store the shared equipment, and then part ways until the next month.

In concluding this chapter on the boundaries of messianic marginality in the $10^{\text {th }} \mathrm{s}$ most private settings my notes dealing with Bueller indicate that even I had ended up irritated with his boisterousness and felt pulled into his challenges. I did not anticipate this or that he was so keen on 'teaching' me that he would talk at me rather than to me. I felt slighted. My own brooding indignance with his challenging my knowledge and then ignoring what I had to say in response in service to status game I had not agreed and whose standards I did not care for viscerally indicated to me how the larger group's perceived marginalization might feel. It is not constant but more like a nerve. A myelin sheath that keeps it operating has been built up through the decades of socialization into regional and local cultural groups in which whiteness, traditional gender roles, Christian beliefs, rural 
lifestyles, and firearms are positioned in relation to each other in unquestioned, naturalized ways. So long as the sheathe is there the nerve fires as expected and nothing seems wrong. For the $10^{\text {th }}$, and the broader populations from which they draw their membership, this protective layer gets gradually shaved off by challenges to their world and identitieschallenges that need not be direct or real. They may come from news outlets, whether consuming unfriendly media that directly challenges it or friendly media that emphasizes that the challenges that exist, members of the group, or outsiders who challenge the rules. Each of these reminds the person of the moment they started to feel forgotten, less than, or left behind by the outside world, even as politics and social arrangements are still largely organized to their favor. After a while the insulation provided by the myelin is thin enough that the nerve begins to misfire and things no longer make sense. When that protective sheathe of invisibility is gone one must either continually rebuild a wall out of its ruins or find another way to organize the remains that makes sense and provides some comfort. In large part, the leaders of the $10^{\text {th }}$ socialize people to do the latter and then defend it. This does not excuse the casual racism, Islamophobia, or sexism the group displays in their efforts to collectively and individually organize the ordinary resources they are familiar with in ways that allow them to valorize their qualities and beliefs.

I am confident that many members of the $10^{\text {th }}$ would disagree with me and the forthcoming conclusion. I acknowledge the work they do to distance themselves from organized hate groups and pursue their limited visions of equality. However, the ordinary resources they deploy and the ways in which they arrange them leave them less willing and able to see the ways in which they remain institutionally supported and powerful, often at the expense of the outsiders and others that serve as their reference points. The same 
resources are used by in similar ways by modern hate groups and others far more extreme than the $10^{\text {th }}$. As such, the messianic marginality of the paramilitary gun culture, and the $10^{\text {th }}$, can be made to serve as attractive stepping stones for other people with raw nerves to cultivate a different messianic marginality that moves beyond ordinary racism and angst into organized, extraordinary violence directed towards marginalized groups they believe are marginalizing them. 
Conclusion

"Playing Army": The $10^{\text {th }}$ as a Space of Live-Fire Roleplay with Real-World Consequences 
In this brief concluding chapter, I will summarize what my data demonstrate regarding the initial questions this project sought to answer: First, what strategies and resources do members of a local militia unit use to maintain their belief in themselves and the group as morally and socially valuable in a highly polarized cultural environment? And secondly, how do members accomplish their identity work in their own social environments, what resources do they draw upon in doing so, and what rules exist for accomplishing this work? Everybody does identity work in their everyday lives and the most privileged members of society at any given time reliably expect that the ways in which they organize ordinary resources will be taken as normal or untroubled. This was the case for people like the members of the $10^{\text {th }}$ throughout most of their lives to hear them tell it. This can give the illusion that individual people create and project identities. As previous sociological scholarship demonstrates, the work of 'being' in society is profoundly social and often political; overtly in the case of marked people and covertly institutionalized in the case of the unmarked. Over the last several decades people whose race, sex, religion and other status characteristics were not unmarked began directly and successfully challenging the social arrangements that many of my participants grew up protected by; they were increasingly able to influence many of the social institutions that afforded this protection. People who had remained largely unmarked hither to that point began to experience in small part what it felt like to be marked, for their identities and everyday lives to be visible as potential problems, and to be subject to institutions whose rules and regulations did not align with their own views and experiences of the world.

The efforts undertaken by members of the $10^{\text {th }}$ to control what aspects of themselves are visible and relevant to their fellows as well as potentially unfriendly 
outsiders and how their identity work should be interpreted occupy a great deal of the time the $10^{\text {th }}$ spends together. While my data show some of the ways that the militia members and others integrate guns with the other elements of their identities like whiteness, masculinity, and self-sufficiency the $10^{\text {th }}$ also demonstrated firearms-related activity was only a portion of the identity work that went on. Firearms are largely taken-for-granted even when they are linked with race, sex, class, responsibility, and geography in ways that allow members of the paramilitary gun culture, and the $10^{\text {th }}$ more specifically, to valorize their own qualities and thereby create positive identities for themselves during their activities together.

As I argued in chapter two, firearms are a foundation for their identity work throughout the paramilitary gun culture and for the $10^{\text {th }}$. The economic, political, and social challenges to relatively untroubled masculinities and whiteness throughout the 1960s and 1970s produced a counterreaction that continues to this day among members of the $10^{\text {th }}$ and their parent organization. It continues among the myriad other militias with more aggressive outlooks as well as the increasingly active members of the alt-right who have endeavored to seize public attention and from which the $10^{\text {th }}$ distances itself. The growth of resentment and distrust for institutions, particularly at the federal level, grew as they slowly became more amenable to the demands of women, racial and ethnic minoritiesparticularly African Americans and people who are not Christian, LGBTQ people, economically disadvantaged people, and their allies. The feelings of marginalization this produced among many conservative white men with ordinary resources and identities based in the social orders prior to these points combined with neoliberal hyperindividualism and the continued shifts of power and resources to urban centers and 
financialization of the economy, efforts to level the playing field remaining for people who did not sit at the levers of power. Together, these conditions helped to produce a deep story of decline among a variety of groups on the American right including the first wave and now second waves of militia groups. With this, came a cooptation of the language and ordinary resources of people who suffered more pervasive and institutionalized marginalization throughout the history of this country which is now used to challenge their positions. The application of civil rights language to firearms ownership and its use by white nationalists is no accident.

As I noted in the introduction, my own interest in firearms as a proto-enthusiast was likely the single most valuable resource to me as a field researcher ${ }^{59}$. The growth of paramilitary culture can be tied to both time periods as policing grew more militarized and approximations of the armaments and accessories of soldiers and police, the next generation of men's men, became more widely available. Many men, largely, but not exclusively, white, took cues from the ways in which the NRA and others organized the ordinary resources of patriotism, whiteness, masculinity, and self-sufficiency and began to reestablish a privileged position for themselves as armed-citizens who could and should be trusted to defend themselves and others from threats when the state could no longer be relied upon to do so, at least from their perspectives. Having the technical knowledge, practice, and interest in how to discuss firearms in ways considered legitimate by insiders

\footnotetext{
${ }^{59}$ Being able to confidently identify firearms in terms of their caliber, manufacturer, and developmental history, and country of origin marked me as sufficiently knowledgeable to be taken seriously as enough of an insider to be trusted. Beyond this, my obvious lack of capabilities when actually shooting provided an opportunity for militia members to teach me. Teaching new people how to appreciate firearms is an opportunity to play up the messianic interpretations of those resources and being a responsible gun owner. This changes once enough rapport has been built in an individual shooting session and competitions emerge or people gradually slack a little more than an ideal presentation would allow.
} 
marks one as a responsible person aware of the risky nature of the world. To fail in these, or lack interest in them risks being marked as a person for whom others must care. Therein lays the root of messianic marginality in paramilitary gun culture and the $10^{\text {th }}$ as well. In their view, people owe it to themselves and others to be prepared to respond effectively to any threats they encounter in the world. This limits the demands that one places on others that if made and met, place the recipient in a position of dependency and lessened their power relative to the provider.

The ordinary resources of messianic marginality among members of the paramilitary gun culture are distinctly neoliberal, individualist, and filled with risk and uncertainty. The militia directly challenges the broader strategies for organizing them though, through their dedication to the idea of collective effort as a more effective response to problems larger than a single armed bad guy. In both cases, however, the identity of the armed good guy is most easily performed and defended from combination of more secure financial, social, and status positions relative to the people subject to their critiques. That the distance between law-abiding and criminal behavior is narrow is difficult to address using only these ordinary resources unless drawing upon race or another proximate resource for personal responsibility like criminal behavior. Members of the $10^{\text {th }}$ can unite the two depending on the crime and the person a person may be unfairly targeted by a government and its agents that fear an armed populace unjustly, made a mistake but are still generally a 'good guy', or were only playing at being responsible only to be discovered and therefore deserve whatever punishment is meted out. This is why those involved in the standoff in Oregon considered LeVoy Finicum's death as he fled authorities a tragedy perpetrated by the Federal Bureau of Investigation against a 'patriot.' More generally 
speaking, it is also why African American people who are shot by local police officers are assumed to have done something to warrant the action.

As the $10^{\text {th }}$ and others use these resources, they are most viable from a position of seldom being in dangerous situations and insulated from people who have that might challenge the dualistic notions upon which their constructions of messianic marginality rely. Aside from the concerns that the $10^{\text {th }}$ expresses about the risks to the group and their own personal livelihoods from people with criminal records entering the group, their uses of these ordinary resources preserve a largely racist illusion of a criminal/law-abiding dichotomy and image of cities as plagued by dangerous crime committed by people of color. The lack of sympathy and sense of threat that members of the $10^{\text {th }}$ associated with Black Lives Matter and Antifa is an extension of this logic. Rather than being interpreted as responses to the sorts of persecution that members of the $10^{\text {th }}$ worry will be applied to them both groups instead suggest the decline of law-and-order and increasing danger throughout society.

Throughout the empirical chapters I have cataloged the ways in the talk and narratives through which the $10^{\text {th }}$ accomplishes messianic marginality also maintain hierarchies and stereotypes associated with race, sex, and religion that make sense within their own experiences and beliefs about the world. These very same status characteristics they feel are increasingly marked and out of their control, inspiring the $10^{\text {th }}$ to valorize them according to local cultural equipment and expectations. The limited audience for these narratives and talk help to reinforce the sense of normalcy this process generates and helps participants emphasize the messianic aspects of their characteristics. Members of the $10^{\text {th }}$ distance themselves from those they hold responsible for making more visible the 
negativity the fear is surrounding their whiteness, firearms enthusiasm, Christian beliefs, ideas about sex roles, rural lifestyle, and politics. The responsible parties reliably include: liberals, urban dwelling people, the federal government, feminists, non-Christians, groups that foreground racial and ethnic statuses, LBGTQ individuals, and gun control proponents in addition to various groups who use the same resources as the $10^{\text {th }}$ in more extreme, damaging way. Losing some of the control over how people perceive their qualities is distressing and the people in these groups, especially the former ones, may be believed to mean well or they may be considered part of a grand plot to destroy the country, or some combination of the two, depending on who asks and where the talk takes place. In any case they remain associated with the decline of American. While William and Janet may present these marginalizing trends in terms of conspiracy, often to the chagrin of other core members, most simply look at the as eroding the self-interest that motivates people to work hard, maintain marriages, look after themselves and thereby build communities that do not depend on outsider help.

Where the militia distinguishes itself from other groups that draw on these resources most clearly in chapter three, pertaining to their public documents. It is evident that their most public messianic marginality work is also work to distance themselves from others they also believe morally wrong and whose actions further decrease the control they have over their own identities: aggressive and racist militias, organized hate groups, people who are excessively pro-gun, criminals, people with criminal backgrounds including mass shooters, and the overtly hypermasculine. The buffers they create in these presentations leave them the opportunity to downplay the connections between their own resources and characteristics and the those listed above in addition to the standard groups the hold 
responsible for their sense of marginalization. By communicating these standards and beliefs in their advertisements the core members and leaders hope to appeal to like-minded people within the paramilitary gun culture who are ready to organize their efforts. The $10^{\text {th }}$ integrates the largely illusory value of armed citizens with the efforts of the group's broader interests in order to provide real service to others in the event that they are invited to do so. This requires a substantial investment of time, effort, and resources beyond those required to acquire a concealed carry license and conflicts with the hyper-individualized masculine image of the lone, armed good-guy. It may be these disconnects more than any other that limit the degree to which people seek the group out as much as the stereotypes of militias that members of the $10^{\text {th }}$ concern themselves with.

In chapters four and five the data show that members of the $10^{\text {th }}$ emphasize their own experiences and integrate them with the broader resources to produce a distinct messianic marginality. This also means they can leverage the same notions to challenge others' uses of them, especially if those others are lower in these status hierarchies than the ones challenging them. The leaders, core members, and regulars of the $10^{\text {th }}$ work hard to present themselves to each other in ways that match up with their personal identities as responsible, conscientious, community-oriented, patriotic family men. They see themselves as heirs to Mayberry but have few incentives to consider that during the heyday of their own younger years was not experienced that way by the marked people in society. Based on my experience the core members do strive live up to these expectations as they see them and genuinely believe in equality and justice within the boundaries to which they 
are accustomed. Theirs is a contrast to other militias ${ }^{60}$, urban people, feminized men and racial minorities who cannot fend for themselves, and a government that they feel does not understand their needs and wants.

In the U.S. these ordinary resources and identities have historically been primarily accessible to white, heterosexual, land-owning, men of differing Christian denominations who served as the unmarked standard against which others and their uses of these resources were measured. Now that whiteness, class, and sex are more visible to people who hold those status positions it is not a surprise that they utilize discomfort and resentment in combination with the stories and talk surrounding firearms, over which they feel a sense of personal ownership, to strike back at their perceived enemies. The public messianic marginality work of white supremacists, Neo-Nazis, militias of varying stripes, and much of the alt-right draw on paramilitary gun culture, just as the $10^{\text {th }}$ does. The difference is that the former groups emphasize the marked quality of whiteness in an attempt to drown out competing, marginalizing interpretations of it and place it at the center of their messianic understanding while the $10^{\text {th }}$ is much more reserved and pushes for whiteness to return to as much of an unmarked state as it has been in their past experience.

It is also clear to me as an analyst that even the 10ths presentations of messianic marginality obscures the ways in which their work to create, present, and maintain those identities is often reliant on exclusions based on stereotypes that they may acknowledge as

\footnotetext{
60 The first Bundy standoff occurred just as I was accessing the group and the occupation of the Malheur Refuge one midway through my time in the field. Many of comments of those involved drew on these resources as well and yet members of the $10^{\text {th }}$ had little to say about either but the unit started emphasizing professionalism and discipline more than they had in the previous months. I realized that they were preemptively responding to the possibility that their organization and unit were going to become more visible as a result.
} 
such, if pushed by experience with people who challenge them in their behavior and actions. To find that I am a liberal academic gun owner was a challenge for some, like Bueller, who chose not to see common ground. The core members and regulars are more likely to see commonalities when given the chance and strive to protect the group from the most egregiously exclusionary forms of messianic marginality. Nevertheless, in the most private militia spaces even core members and regulars deploy a foundational set of ordinary resources contributes to the institutional marginalization of the others they fear in ways worse than the marginalization they feel from their own visibility.

\section{Shortcomings}

For the levels of access to the $10^{\text {th }}$ and its activities that this project was able to secure and the data that resulting from it there are several serious shortcomings that require address. Given the variation even within the $10^{\text {th }}$ and the learning curve required of peripheral members means that the findings in this document cannot necessarily be applied to them except insofar as their own organization of ordinary resources was inadequately matched to the group thus limiting their participation in the group, whether this was voluntary or involuntary. The data to make any broader claims about the messianic marginalization of peripheral members simply is not there except in the occasions that they were present, spoke, and participated. The risk this lack presents to the project is limited, however, by the fact that its aim was always to focus on the intricacies of how the people regularly participating in the $10^{\text {th }}$ organize their personal and collective identities together. The data also provide evidence for the claim that peripheral members possess strategies for organizing messianic marginality that must be either be closely aligned to the group to begin with or be altered through socialization if they will persist in it. Franz, Peirce, and 
BG are examples of members who joined during the course of the project and eventually ended up as a leader and two core members respectively. Finally, peripheral members do not participate the same degree as core members or regulars and I argue that the data ultimately reflect their significance to the group and its activities given this reality.

The small number of full interviews is another shortcoming that I mentioned in the first chapter so I will not belabor it. Simply put, the data from the interviews reinforces the analytic points I have made because they indicate the views of the core members and leaders. While Franz and Lou were still relatively new members and their interviews provide some diverging uses of shared ordinary resources the extent to which peripheral members and even infrequent regulars differ is not indicated in my data. Being unsure of how far I could push members, even core members who knew me, I was less assertive in pushing for interviews than might have been possible. It was difficult to gain access to the group and there were a number of moments through the project that peripheral members let me know they did not trust me but would tolerate me until then. Given the degree to which all the members of the $10^{\text {th }}$ are sensitive to the risks that outsiders present, this further discouraged me from more than reminding those who expressed an interest in interviews, asking for their phone numbers and giving them mine, and checking in from time to time to see if our schedules aligned.

My learning curve in fieldwork aside, another difficulty in gathering a greater number of interviews were the busy schedules of most participants and the variations in attendance common to peripheral members and some regulars. Core members were around me much more often than others and presented more opportunities to connect, develop rapport, and plan interviews. This subpopulation of the $10^{\text {th }}$ also tended to be more secure 
with the public nature of the group and this likely allowed them to feel greater comfort in talking with me. I argue the length and detail of the majority of the interviews helps to offset this weakness somewhat but the narrow breadth of the members who shared that time ultimately means to some extent the weakness stands as a fact of this project.

\section{Future Research}

Throughout the project I have oscillated between excitement, frustration, and despair that many of the people that my participants blame for their plights experience marginalization with greater danger, pervasiveness, and institutional power behind it, particularly at present. Members of the $10^{\text {th }}$ contribute to these issues despite their own views of themselves and, in most cases, genuine feelings that they strive to be reasonable, equitable people. The increasing number of groups drawing on these resources increase the difficulty with which members of the $10^{\text {th }}$ can condemn them, especially if those using them are cynical or savvy in their use. To do so requires marginalizing people whose ordinary resources and organization strategies resemble their own too closely for comfort. This often means that even the most well-meaning members can support policies that produce harmful effects for those they feel they have very little in common with. Future research with such groups should continue to explore the boundary work these resources are deployed to accomplish and the rules for doing so in particular social spaces. In this way better strategies for presenting and advocating for policies in line with increasing equality in society can be developed.

Despite the ways that I have enjoyed the company and experiences I have shared with the group I see that they are susceptible to cooptation by other aggressively violent, race-oriented groups. The efforts of the core and regular members have been enough thus 
far to prevent such an event, but a collection of people who are less sensitive to these risks, who feel significantly greater marginalization, or are more susceptible to alarmist conspiracies could be accessed and influenced more easily, especially by a person skilled in using these resources to radicalize people sensitive to them. This was one of the ways racist groups began interconnecting with the militia in the 1990s and remains an outreach strategy today. This is dynamic played out in a larger, broader scale during the most recent election and, using their newfound legitimacy those who used to be the most marginal elements on the far-right are continuing to organize and act publicly, often violently. This dynamic therefore presents on ongoing risk. Additional research comparing the ways in which members of the alt-right and its various subgroups draw upon and organize these resources will be important for making future distinctions between groups that are likely to be dangerous to the public and the they blame for their marginalization and groups like the $10^{\text {th }}$, who, harmful though their identity work can be in its support for institutionalized inequalities, are mostly talk. 


\section{Bibliography}

Abanes, Richard. 1996. American Militias: Rebellion, Racism, and Religion. Downers Grove: InterVaristy Press.

Aho, James. 1990. The Politics of Righteousness: Idaho Christian Patriots. Seattle: University of Washington Press.

Alexander, Michelle. 2012, The New Jim Crow: Mass Incarceration in the Age of Colorblindness, Revised Edition. New York: The New Press.

Anderson, Benedict. 2006. Imagined Communities: Reflections on the Origin and Spread of Nationalism, Revised Edition. London: Verso.

Andrea, Peter and Richard Price. 2003. "From War Fighting the Crime Fighting: Transforming the American National Security State." International Studies Review 3(3):31-52.

Atikinson, Paul and Sara Delamont. 2006. "Rescuing narrative from qualitative work." Narrative Inquiry 16(1): 164-172

Azrael, Deborah, Lisa Hepburn, David Hemenway, and Matthew Miller. 2017. "The Stock and Flow of U.S. Firearms: Results from the 2015 National Firearms Survey." Russell Sage Foundation Journal of the Social Sciences 3(5): 38-57

Balko, Radley. 2014. Rise of the Warrior Cop: The Militarization of America's Police Forces. New York: Public Affairs.

Bankston, William, B., Carol Y. Thompson, Quentin A. L. Jenkins, and Craig J. Forsyth. 1990. "The Influence of Crime, Gender, and Southern Culture on Carrying Firearms for Protection." The Sociological Quarterly 32(2):287-305.

Baum, Dan. 2013.Gun Guys: A Road Trip. New York: Vintage Departures.

Bell, David. 2000. "Farm Boys and Wild Men: Rurality, Masculinity, and Homosexuality.” Rural Sociology65(4): 547-561

Bell, Shannon, E., Alicia Hullinger, and Lilian Brislen. 2015. "Manipulated Masculinities: Agribusiness, Deskilling, and the Rise of the Businessman-Farmer in the United States." Rural Sociology 80(3):285-313.

Berger, Peter L., and Thomas Luckmann. 1967. The Social Construction of Reality: A Treatise in the Sociology of Knowledge. New York, NY: Anchor Books. 
Blee, Kathleen. 2002. Inside Organized Racism: Women in the Hate Movement. Berkeley: University of California Press.

.2007. "Ethnographies of the Far-Right." Journal of Contemporary Ethnography, 36(2): 119-128.

Blee, Kathleen and Kimberly Creasap. 2010. “Conservative and Right-Wing Social Movements" in Annual Review of Sociology 36: 269-286.

Boggs, Carl. 2005. Imperial Delusions: American Militarism and Blowback in the Age of American Empire. Lanham: Rowman and Littlefield.

Bonilla-Silva, Eduardo. 2001. White Supremacy and Racism in the Post-Civil Rights Era. Boulder: Lynne Rienner.

Brandth, Berit and Marit S. Haugen. 2005. "Doing Rural Masculintiy-From Logging to Outfield Tourism.” Journal of Gender Studies 14(1): 13-22.

Brekhus, Wayne, H. 2003. Peacocks, Chameleons, and Centaurs: Gay Suburbia and the Grammar of Social Identity. Chicago: The University of Chicago Press.

Bruner, Jerome. 1991. “The Narrative Construction of Reality.” Critical Inquiry 18(1): 121.

Bucholtz, Mary. 1999. "You da man: Narrating the racial other in the production of white masculinity." Journal of Sociolinguistics 3(4): 443-460.

Campbell, Hugh and Michael Mayerfeld Bell. 2000. "The Question of Rural Masculinities.” Rural Sociology 65(4): 532-536

Carlson, Jennifer. 2014. "States, subjects and sovereign power: Lessons from global gun cultures.” Theoretical Criminology 18(3): 335-353.

. 2015a. Citizen-Protectors: The Everyday Politics of Guns in an Age of Decline. Oxford, NY: Oxford University Press.

. 2015b. "Mourning Mayberry: Guns, Masculinity, and Socioeconomic Decline" in Gender \& Society, 29(3): 386-409.

Cerwonka Allaine, and Liisa H. Malkkii. 2007. Improvising Theory: Process and Temporality in Ethnographic Fieldwork. Chicago, IL: The University of Chicago Press. 
Chambliss, William, J. 1994. "Policing the Ghetto Underclass: The Politics of Law and Law Enforcement.” Social Problems 41(2): 177-194.

Chermak, Steven. 2002. Searching for a Demon: The Media Construction of the Militia Movement. Boston: Northeastern University Press.

Christie, Nils. 2000. Crime Control as Industry: Towards GULAGS, Western Style. New York: Routledge.

Churchill, Robert. 2009. To Shake Their Guns in the Tyrant's Face: Libertarian Political Violence and the Origins of the Militia Movement. Ann Arbor: The University of Michigan Press.

Connell, R.W. 2005. Masculinities, $2^{\text {nd }}$ Edition. Berkeley: University of California Press.

Connell, R. W., And James W. Messerschmidt. 2005. "Hegemonic Masculinity: Rethinking the Concept." Gender and Society 19(6): 829-859.

Cook, Philip, J., Jens Ludwig. 1997. "Guns in America: National Survey on Private Ownership and Use of Firearms." National Institute of Justice, Research in Brief, Washington DC: U.S. Department of Justice. Last accessed May $5^{\text {th }}, 2018$ (https://www.ncjrs.gov/pdffiles/165476.pdf.)

Cook, Philip, J., and Kristin A. Goss. 2014. The Gun Debate: What Everyone Needs to Know. New York: Oxford University Press.

Costanza, Stephen, E., John C. Kilburn, Jr. 2004. "Circling the Welcome Wagons: Area, Income, Race, and Legal Handgun Concealment." Criminal Justice Review 29(2): 289-302.

Cowen, Deborah and Amy Siciliano. 2011. "Surplus Masculinities and Security." Antipode 43(9): 1516-1541.

Crothers, Lane. 2002. "The Cultural Foundations of the Modern Militia Movement." New Political Science, 24(2): 224-234. 2003. Rage on the Right: The American Militia Movement from Ruby Ridge to Homeland Security. Lanham: Rowman \& Littlefield Publishers, INC

Dees, M. 1996. Gathering Storm: America's Militia Threat. New York: Harper Collins Publishers. 
Dyer, Joel. 1997. Harvest of Rage: Why Oklahoma City is Only the Beginning. Boulder: Westview Press

Emerson, Robert, M., Rachel I. Fretz, and Linda L. Shaw. Writing Ethnographic Fieldnotes, Second Edition. Chicago, IL: The University of Chicago Press.

Eichstedt, Jennifer and Stephen Small. 2002. Representations of Slavery: Race and Ideology in Southern Plantation Museums. Washington D.C.: Smithsonian Books

Essad, Philomena. 1991. Understanding Everyday Racism: An Interdisciplinary Theory. Newbury Park: Sage.

Faludi, Susan. 1999. Stiffed: The Betrayal of the American Man. New York: William Morrow.

Filteu, Matthew, R. 2015. “A Localized Masculine Crises: Local Men's Subordination within the Marcellus Shale Region's Masculine Structure." Rural Sociology 80(4): 431-455.

Formisano, Ronald P. 2012. The Tea Party: A Brief History. Baltimore: The Johns Hopkins University Press.

Freilich, Joshua, J. Pienik, and G. Howard. 2001. "Towards Comparative Studies of the U.S. Militia Movement." International Journal of Comparative Sociology, 42(12): $163-210$.

Freilich, Joshua. 2003. American Militias: State-Level Variations in Militia Activities. New York, NY: LFB Scholarly Publishing LLC.

Freilich, Joshua, and William Pridemore. 2005. "A reassessment of State-level Covariates of Militia Groups." Behavioral Sciences and the Law, 23(1): 527-246.

Freilich, Joshua and William Pridemore. 2006. "Mismeasuring Militias: Limitation of Advocacy GroupData and of the State-Level Studies of Paramilitary Groups" Justice Quarterly, 23(1): 147-162

Gallaher, Carolyn. 2002. "On the Fault Line: Race, Class and the US Patriot Movement." Cultural Studies 16(5): 673-703

Garland, David. 1996. "The Limits of the Sovereign State." British Journal of Criminology 36(4):445-471. 
George, John and Laird Wilcox. 1996. American Extremists: Militias, Supremacists, Klansmen, Communists, and Others. Amherst: Prometheus Books.

Gibson, James. 1994. Warrior Dreams: Paramilitary Culture in Post-Vietnam America. New York: Hill and Wang

Glaser, Barney, G., and Anslem Strauss. 2017[1967]. The Discovery of Grounded Theory. New York: Routledge.

Goffman, Erving. 1959. The Presentation of Self in Everyday Life. New York, NY: Anchor Books.

Gordon, Avery. Gordon, Avery. 2008. Ghostly Matters: Haunting and the Sociological Imagination. Minneapolis: University of Minnesota Press

Green, John, C. 1999. "The Spirit Willing: Collective Identity and the Development of the Christian Right." Pp. 153-167 in Waves of Protest: Social Movements Since the Sixties, edited by Jo Freeman and Victoria Johnson. Lanham: Rowman and Littlefield Publishers.

Gubrium, Jaber and James Holstein. 2000. "The Self in a World of Going Concerns." Symbolic Interactionism 23(2):95-115.

Haider-Markel, Donald P, and Sean P. O'Brien. 1997. "Creating a "Well Regulated Militia": Policy Responses to Paramilitary Groups in the American States." Political Research Quarterly 50(3):551-565

Hall, John, Mary Jo Neitz, and Marchall Battani. 2003. Sociology on Culture. New York, NY: Routledge p. 38.

Harvey, David. 2005. A Brief History of Neoliberalism. New York: Oxford University Press.

Hill, Stephen and Randall Beger. 2009. “A Paramilitary Policing Juggernaut.” Social Justice 36(1): 25-40

Hepburn, Lisa., Matthew Miller, Deborah Azrael, and David Hemenway. 2007. "The US gun stock: results from the 2004 national firearms survey." Injury Prevention 13:15-19.

Hochschild, Arlie, R. 2016.Strangers in Their Own Land: Anger and Mourning on the American Right. New York: The New Press. 
Holstein, James, Jaber Gubrium. 2000. The Self We Live By: Narrative Identity in a Postmodern World. New York, NY: Oxford University Press.

Sage Publications. 2009. Analyzing Narrative Reality: Los Angeles, CA:

Howard, Jenna. 2006. "Expecting and Accepting: The Temporal Ambiguity of Recovery Identities." Social Psychology Quarterly 69(4): 307-324

Jones, Robert, P. 2016. The End of White Christian America. New York: Simon and Schuster.

Katriel, Tamar. 2012. "12: Analyzing the Social Life of Personal Experience Stories." Pp. 273-291 in Varieties of Narrative Analysis edited by James Holstein and Jaber Gubrium. Los Angeles, CA: Sage Publication.

Kleck, Gary. 1988. "Crime Control through the Private Use of Armed Force." Social Problems 35:1-21.

Kellner, Douglas. 2008. Guys and Guns Amok: Domestic Terrorism and School Shootings from the Oklahoma City Bombing to the Virginia Tech Massacre.

Kelly, M., Villaire, K. 2002. “The Michigan Militia and Emerson's Ideal of SelfReliance.” Journal of Social Philosophy 33(2): 282-296

Kimmel, Michael, and Abby Ferber. 2000 “'White Men are this Nation:' Right-Wing Militias and The Restoration of Rural American Masculinity." Rural Sociology 65(4): 582-604.

Kimmel, Michael. 2012. Manhood In America: A Cultural History, Third Edition. New York, NY: Oxford University Press.

2013. Angry White Men: American Masculinity at the End of an Era. New York, NY: Nation Books.

Kleck, Gary and Marc Gertz. 1995. "Armed Resistance to Crime: The Prevalence and Nature of Self-Defense with a Gun." Journal of Criminal Law and Criminology 86: $150-187$

Kraska, Peter, B. 1996. "Enjoying Militarism: Political/ Personal Dilemmas in Studying U.S. Police Paramilitary Units.” in Justice Quarterly,13(3): 405-429. .2007. "Militarization and Policing: Its Relevance to $21^{\text {st }}$ Century Police." Policing 1(4): 501-513. 
Kraska, Peter, B. and Louis J. Cubellis. 1997. "Militarizing Mayberry and Beyond: Making Sense of America Paramilitary Policing." Justice Quarterly 14(4):607629.

Kraska, Peter and Victor Kappler. 1997. "Militarizing American Police: The Rise and Normalization of Paramilitary Units.” in Social Problems, 44(1): 1-18.

Lamont, Michele. 2009. The Dignity of Working Men: Morality and the Boundaries of Race, Class, and Immigration. New York: Russel Sage Foundation.

Lemieux, Frederic. 2014. "Effec tof Gun Culture and Firearms laws on Gun Violence and Mass Shootings in the United States: A Multi-Level Quantitative Analysis." International Journal of Criminal Justice Studies 9(1):74-93

Lepore, Jill. 2010. The Whites of Their Eyes: The Tea Party's Revolution and the Battle over American History. Princeton, NJ: Princeton University Press.

Light, Caroline E. 2017. Stand Your Ground: A History of America's Love Affair with Lethal Self-Defense. Boston, MA: Beacon Press.

Lillrank, Annika. 2003. "Back pain and the resolution of diagnostic uncertainty in illness narratives." Social Science and Medicine 57:1046-1054.

Lizotte, Alan, J., David J. Bordua. 1980. "Firearms Ownership for Sport and Protection: Two Divergent Models.” American Sociological Review 45:229-244.

Lott, John, R., Jr. 1998. More Guns, Less Crime: Understanding Crime and Gun Control Laws. Chicago, IL: University of Chicago Press.

Mariani, Mack. 1998. The Michigan militia: Political engagement or Political alienation? Terrorism and Political Violence, 10(4): 122-148.

Mayes, Mary Jo, Jenner L. Pierce, and Barbara Laslett. Telling Stories: The use of Personal Narratives in the Social Sciences and History. Ithaca, NY: Cornell University Press.

McAdam, Doug, and Karina Kloos. 2014. Deeply Divided: Racial Politics and Social Movements in Postwar America. New York: Oxford University Press.

McDowell, David. 1995. "Firearms and Self-Defense." The Annals of the American Academy of Political and Social Science 539: 130-140. . 2005. "Review: John R. Lott, Jr.'s Defensive Gun Brandishing Estimates." The Public Opinion Quarterly 69(2): 246-263. 
Mead, George Herbert. [1934] 1967. Works of George Herbert Mead Volume I: Mind, Self, \& Society from the Standpoint of a Social Behaviorist. Edited by Charles Morris. Chicago, IL: The University of Chicago Press.

Melzer, Scott. 2009. Gun Crusaders: The NRA's Culture War. New York, NY: New York University Press.

Mulloy, Darren. 2004a. American Extremism: History, Politics and The Militia Movement. New York, NY: Routledge . 2004b. "Conversing with the Dead': The Militia Movement and American History" in Journal of American Studies 38: 439-456. . 2008. "“Liberty or Death': Violence and the Rhetoric of Revolution in the American Militia Movement." in Canadian Review of American Studies 38(1): 119-145.

Neiwert, D. 1999. In God's Country: The Patriot Movement and the Pacific Northwest. Pullman,: Washington State University Press.

2017. Alt-America: The Rise of the Radical Eight in the Age of Trump. London: Verso.

O’Brian, Sean and Donald Haider- Markel. 1998. "Fueling the Fire: Social and Political Correlates of Citizen Militia Activity." Social Science Quarterly, 79(2): 456-465.

Olick and Robbins 1998. "Social Memory Studies: From 'Collective Memory' to the Historical Sociology of Mnemonic Practices.” Annual Review of Sociology 24: 105-140.

Omi, Michael and Howard Winant. 2013. Racial Formation in the United State, Third Edition. New York: Routledge.

O’Neill, Kevin, L. 2007. “Armed Citizens and the Stories they Tell: The National Rifle Association's Achievement or Terror and Masculinity." Men and Masculinities 9(4): 457-475.

Murphy, Sherry L., Jianquan Xu, Kenneth D. Kochanek, Sally C. Curin, Elizabeth Arias. 2017. National Vital Statistics Reports, Deaths: Final Data for 2015, 66(6), 12. $<$ https://www.cdc.gov/nchs/data/nvsr/nvsr66/nvsr66_06.pdf > Last accessed June 19, 2018. 
Newton, George D., and Franklin E. Zimring. 1969. Firearms and Violence in American Life: A Staff Report Submitted to the National Commission on the Causes and Prevention of Violence. Washington, DC: National Commission on the Causes and Prevention of Violence.

Quadagno, Jill. 1994. The Color of Welfare: How Racism Undermined the War on Poverty. New York: Oxford University Press.

Reissman, Catherine K. 2008. Narrative Methods for the Human Sciences. Thousand Oaks, CA: Sage Publications.

Rios, Victor, M. 2011. Punished: Policing the Lives of Black and Latino Boys. New York: New York University Press.

Roulston, Kathryn. 2010. Reflexive Interviewing: A Guide to Theory and Practice. Thousand Oaks, CA: Sage Publications.

Rubin, Herbert, J., Irene S. Rubin. 2005. Qualitative Interviewing: The Art of Hearing Data. Thousand Oaks, CA: Sage Publications.

Russel-Brown, Katherine. 2009. The Color of Crime. $2^{\text {nd }}$ Edition. New York: New York University Press.

Salander, Pär. 2002. "Bad new from the patient's perspective: an analysis of the written narratives of newly diagnosed cancer patients." Social Science \& Medicine 55: 721-732.

Salter, Michael. 2014."Toys for the Boys? Drones, Pleasure, and Popular Culture in the Militarisation of Policing." Critical Criminology 22(2): 163-177.

Scott, Marvin and Stanford Lyman. 1968. "Accounts" in American Sociological Review 33(1): 46-62.

Skocpol, Theda and Vanessa Williamson. 2013. The Tea Party and the Remaking of Republican Conservatism. New York: Oxford University Press.

Smith, Douglas, A., Craig D. Uchida. 1988. "The Social Organization of Self-Help: A Study of Defensive Weapon Ownership.” American Sociological Review 53(1): 94-102.

Smith, Tom W., and Jaesok Son. 2015. General Social Survey Final Report: Trends in Gun Ownership in the United States, 1972-2014. Chicago, IL: University of Chicago 
Stern, Kenneth. 1996. A Force Upon the Plain. New York: Simon and Schuster.

Stroud, Angela. 2012. "Good Guys with Gun: Hegemonic Masculinity and Concealed Handgun" in Gender and Society 26(2):216-238. .2015. Good Guys with Guns: The Appeal and Consequences of Concealed Carry. Chapel Hill, NC: University of North Carolina Press.

Stryker, Sheldon and Peter J. Burke. 2000. "The Past, Present, and Future of an Identity Theory.” Social Psychological Quarterly 63(4): 284-297.

Swidler, Ann. 1986. "Culture in Action: Symbols and Strategies." American Sociological Review, 51(2): 273-286

Van Dyke, N., Soule, S. 2002. "Structural Social change and the Mobilizing Effect of Threat: Explaining Level of Patriot and Militia Organizing in the United States" Social Problems, 49 (4): 497-520.

Van Maanen John. 2011. Tales from the Field: On Writing Ethnography. Chicago, IL: The University of Chicago Press.

Vertigans, Stephen. 2007. "Beyond the Fringe? Radicalization within the American FarRight” Totalitarian Movements and Political Religions, 8 (3-4): 641-659.

Vizzard, William. 2000. Shots in the Dark: The Policy, Politics, and Symbolism of Gun Control. Lanham: Maryland: Rowman and Littlefield Publishers, INC.

Weiss, Robert, S. 1994. Learning from Strangers: The Art and Method of Qualitative Interview Studies. New York, NY: The Free Press.

Weeber, S., Rodeheaver, D. 2003. "Militias at the Millennium: A Test of Smelser's Theory of Collective Behavior" The Sociological Quarterly, 44 (2): 181-204.

Weeber, S., Rodeheaver, D. 2004. Militias in the New Millennium: A Test of Smelser's theory of Collective Behavior. Dallas, TX: University Press of America, INC.

West, Candance, and Don Zimmerman. 1987. "Doing Gender." Gender and Society 1(2): $125-151$.

Wolcott, Harry, F. 1994. Transforming Qualitative Data: Description, Analysis, and Interpretation. Thousand Oaks, CA: Sage Publications.

Woodward, Rachel. 2000. "Warrior Heroes and Little Green Men: Soldiers, Military Training, and the Construction of Rural Masculinities." Rural Sociology 65(4): 640-657. 
Wooley, Owen. 2006. "The political work of narratives: a dialogic analysis of two slave narratives." Narrative Inquiry 16(2):295-318.

Wright, James D., Peter H Rossi, and Kathleen Daly. 1986. Under the Gun: Weapons, Crime, and violence in America. Hawthorne, NY: Aldine de Gruyter.

Yamane, David. 2017. “The sociology of U.S gun culture.” Sociology Compass 11(7). https://doi.org/10.1111/soc4.12497

Young, Marion, I. 2001. "The Logic of Masculinist Protection: Reflections on the Current Security State." Signs, 29(1): 1-25 
Daniel Petrin was born in Stillwater Oklahoma. After graduating from Stillwater High School, he was admitted to Oklahoma State University where he graduated Cum Laude, majoring in psychology and minoring in philosophy. Daniel was admitted to the sociology master's program at OSU and graduated after defending his master's thesis detailing how militia members managed their identities on public internet forums. In the hopes of continuing this line of research Daniel applied to and was accepted into the doctoral program of the sociology department at the University of Missouri. Shortly after he began conducting fieldwork designed to study gun culture and militia behavior. Upon nearing the end of the doctoral program, he accepted a tenure-track faculty position at the Community College of Rhode Island and completed his dissertation on militia identity and interaction in the summer of 2018. 